\title{
Avaliação da biodisponibilidade de uma nova formulação de micofenolato mofetil e de um método para sua monitorização terapêutica
}

Dissertação apresentada à Faculdade de Medicina da Universidade de São Paulo para a obtenção do título de Mestre em Ciências

Área de concentração: Fisiopatologia Experimental

Orientador: Prof. Dr. Elias David-Neto

São Paulo 
Dados Internacionais de Catalogação na Publicação (CIP)

Preparada pela Biblioteca da

Faculdade de Medicina da Universidade de São Paulo

Creprodução autorizada pelo autor

\section{Romano, Paschoalina}

Avaliação da biodisponibilidade de uma nova formulacão de micofenolato mofetil e de um método para sua monitorização terapêutica / Paschoalina Romano.-- São Paulo, 2007.

Dissertação(mestrado)--Faculdade de Medicina da Universidade de São Paulo para obtenção do título de Mestre em Ciências.

Área de concentração: Fisiopatologia Experimental.

Orientador: Elias David-Neto.

Descritores: 1.Ácido micofenólico/farmacocinética 2.Monitoramento de medicamentos 3.Disponibilidade biológica 4.Equivalência terapêutica 5.Transplante de rim 6.Técnicas imunoenzimáticas

USP/FM/SBD-050/07 
À minha família, de todo o coração, por me acompanharem e apoiarem durante as decisões importantes da minha vida. 


\section{AgradeCimentos}

À minha família amada e sempre unida, Filomena e Lisanto (in memorian) meus pais, que sempre incentivaram, protegeram e ensinaram a importância da verdade, da honestidade e da amizade para uma vida feliz.

Aos meus irmãos Nicola, Paolo, Giuseppina e cunhadas Regiane e Ana Claúdia pelo apoio e amizade.

À minha sobrinha Mariana, a grande alegria de todos nós e uma benção pela inteligência e bom humor.

Ao meu orientador, Prof. Dr. Elias David-Neto, pelo apoio durante todo o desenvolvimento desta dissertação, que com dedicação e inteligência valoriza tudo que faz.

Aos amigos Prof. Dr. Nairo Massakazu Sumita e Dra. Maria Elizabete Mendes, Diretor e Chefe do Laboratório de Bioquímica Clínica da Divisão de Laboratório Central (LIM 03) da Faculdade de Medicina da Universidade de São Paulo, pelo incentivo em toda a minha carreira e apoio integral neste estudo.

Ao Prof. Dr. Marcelo Burattini, Diretor da Divisão de Laboratório Central-LIM 03 da Faculdade de Medicina da Universidade de São Paulo com admiração pelo seu trabalho administrativo e incentivo.

Aos meus amigos Prof. Dra. Atecla Nunciatta Lopes Alves, Pérsio de Almeida R. Ebner, Dr. Alexandre Fortini, Vânia da Rocha Morsoleto, Letícia Néri Guimarães, Guiomar Leite de Assis e Roberto Carlos Dionísio Novaes pelo carinho e pelos ótimos momentos de convívio. A ajuda de vocês fez com que este trabalho ficasse melhor. 
Aos médicos da Unidade de Transplante Renal, principalmente, Dra.Lílian $M$. Pereira, Dra. Maria Cristina R. de Castro, Francine B. C .Lemos, Dra. Elisângela S. Prado e Dra. Flávia S. R. Medeiros, pela competência profissional e por estarem sempre prontos para ouvir, tirar dúvidas e ajudar.

Ao Grupo de Pesquisa Clínica da Unidade de Transplante Renal, que tem seriedade e amor na condução de estudos de grande relevância científica. Meu agradecimento sincero ao Prof. Dr. Elias (chefe), às farmacêuticas, Melissa e Luciana, à enfermeira, Fabiana, ao auxiliar administrativo, Rafael e a auxiliar de enfermagem Margarete, pessoas maravilhosas, fizeram com que eu me sentisse como parte deste grupo. Esta experiência multiprofissional, que sempre foi um sonho, foi de muito orgulho para mim. Para Érica Kakehashi, uma das primeiras pessoas com quem tive contato neste grupo, com todo o meu carinho.

Aos amigos Dr. Joaquim M. Santi, Dr. Archimedes Ângelo Martinez e farmacêutica Liza Maria Midori, meus primeiros mestres na vida profissional, com vocês aprendi a importância do método, dos registros e da dedicação.

Aos amigos do antigo Setor de Urgência da Divisão de Laboratório Central, onde começou meu interesse por pesquisa. Meus agradecimentos pela profunda alegria que foi o convívio com vocês.

Às enfermeiras da Unidade de Transplante Renal do Hospital das Clínicas da FMUSP, pela competência com que executam as tarefas e pelo cuidado com que cuidam dos pacientes.

Aos funcionários da Bioquímica Clínica da Divisão de Laboratório Central do Hospital das Clínicas da FMUSP, pela dedicação, competência e motivação a cada novo desafio. 
Às amigas Francisca e Phâmela do Disk-Lab da Divisão de Laboratório Central do Hospital das Clínicas da FMUSP, sempre prontas a ajudar nas horas mais complicadas. Francisca é uma pessoa com coração enorme, sempre pronto a acolher a todos.

Às funcionárias do setor de Pós-graduação da Fisiologia Experimental do Hospital das Clínicas da FMUSP por sua dedicação, atenção e gentileza. Deixo aqui minha admiração.

Aos funcionários da Biblioteca Central da Faculdade de Medicina da USP, pelo carinho e dedicação com que realizam suas funções, obrigado pelo apoio e gentileza.

À Rosely e Sueli pela revisão desta tese, tornando-a mais compreensível.

Ao Serviço de Documentação Científica da FMUSP e ao Sr. Josué Moreira de Souza pela diagramação, edição e impressão dos exemplares desta tese e ajuda constante.

Aos pacientes que participaram deste estudo pelo desprendimento, confiança e senso humanitário para ajudar o próximo.

Aos amigos sempre presentes na minha vida, nas horas alegres e tristes: Dânia, Sueli, Fumiko, Meire, Acram, Regina, Clarinha, Isabel, Angela, Lídia, Leila Borracha, Tatiana, Patrícia, César, Dr. Marcos, Márcio, Neide Abe, Virgínia, Maria do Carmo, Cida, Glória e tantos outros que completam meu ciclo de amizades sinceras.

Ao Rogério e Cicília pela ajuda estatística.

À Maristella e funcionários da Cromoanalysis Ltda, por disponibilizarem amostras dosadas por LC-MS/MS e pela ajuda e amizade. 
"Cada palavra é segundo a sua essência um poema"

João Guimarães Rosa 


\section{Normalização adotada}

Esta tese está de acordo com:

Referências: adaptado de International Committee of Medical Journals Editors (Vancouver)

Universidade de São Paulo. Faculdade de Medicina. Serviço de Biblioteca e Documentação. Guia de apresentação de dissertações, teses e monografias. Elaborado por Anneliese Carneiro da Cunha, Maria Julia de A. L. Freddi, Maria F. Crestana, Marinalva de Souza Aragão, Suely Campos Cardoso, Valéria Vilhena. São Paulo: Serviço de Biblioteca e Documentação; 2005.

Abreviaturas dos títulos dos periódicos de acordo com List of Journals Indexed in Index Medicus. 


\section{SUMÁRIO}

Lista de Abreviaturas

Lista de Figuras

Lista de Tabelas

Resumo

Summary

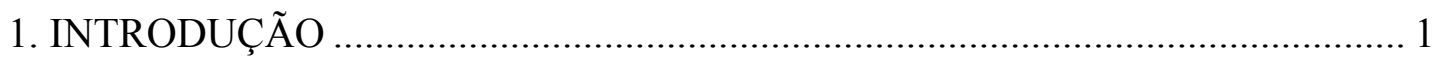

1.1 Validação da metodologia de imunoensaio enzimático (EMIT) .................... 12

1.2 Estudo da biodisponibilidade de duas formulações de MMF......................... 17

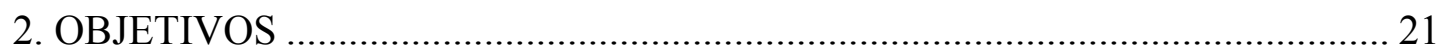

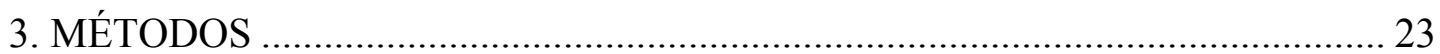

3.1 Metodologia da validação do imunoensaio enzimático ............................... 24

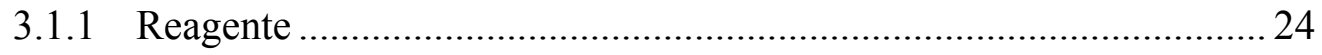

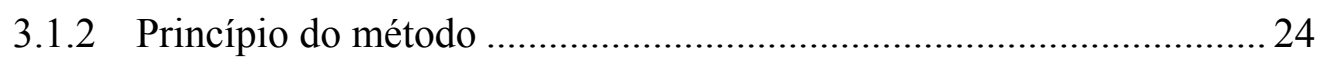

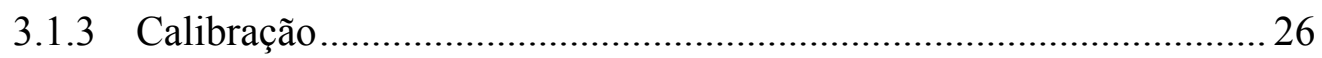

3.1.4 Validação do Ensaio EMIT ${ }^{\circledR}$ 2000-Mycophenolic Acid Test ............ 26

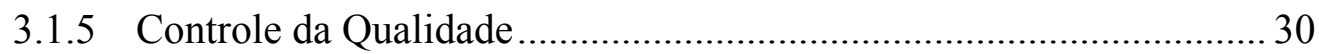

3.2 Metodologia do estudo de bioequivalência entre duas formulações de MMF ... 31

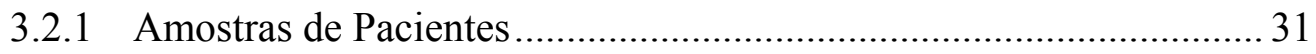

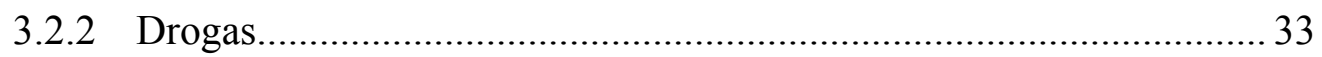

3.2.3 Análise de amostras de pacientes transplantados renais estáveis ....... 33

3.2.4 Comparação de Bioequivalência entre duas formulações de MMF ... 34

3.2.5 Análise dos resultados Farmacocinéticos....................................... 35

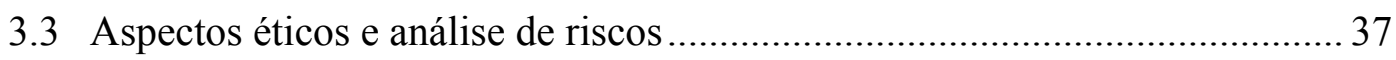

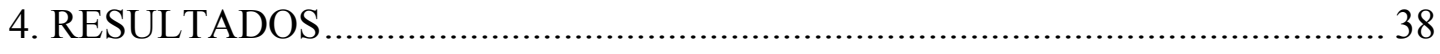

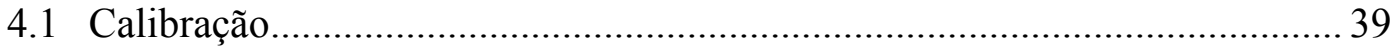

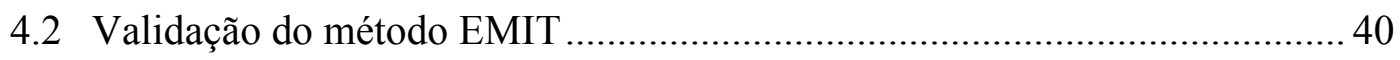

4.2.1 Precisão intraensaio e interensaio.................................................... 40

4.2.2 Linearidade, Limite de detecção e Sensibilidade analítica................. 41

4.2.3 Estabilidade do analito MPA na amostra matriz ............................. 41

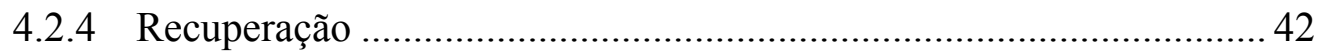

4.2.5 Comparação de metodologia EMIT com LC-MS/MS ..................... 43

4.2.6 Controle da Qualidade............................................................. 45 
4.3 Análise da Biodisponibilidade de duas formulações diferentes de MMF .46

4.3.1 Dados Demográficos 46

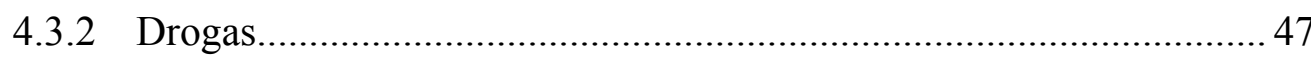

4.3.3 Análise farmacocinética das duas formulações ................................ 48

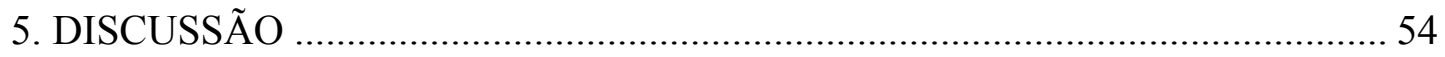

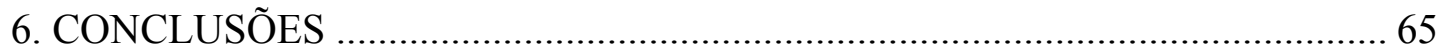

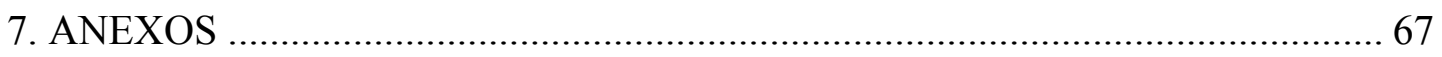

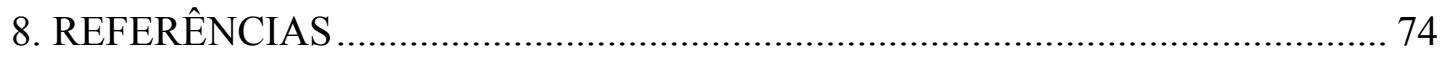

APÊNDICE

Artigo publicado como suplemento do IFCC - AACC/ 2005 …............................. 86 


\section{LISTA DE ABREVIATURAS}

MMF Micofenolato Mofetil (Micofenolato de Mofetila)

MPA Ácido Micofenólico

CNI Inibidor de calcineurina

EMIT Teste de imunoensaio enzimático

LC-MS/MS Cromatografia líquida de alta resolução acoplada a espectrometria de massa

RA Rejeição Aguda

CyA Ciclosporina

TAC Tacrolimus (Tacrolimo)

MPAG Metabólito glucoronídeo fenólico de MPA

AcMPAG Acil glucoronídeo de MPA

PK Farmacocinética

CAN Nefropatia crônica do enxerto

IMPDH Enzima inosina monofosfato desidrogenase

AUC Área sob a curva concentração-tempo pós-dose

C0 Concentração pré-dose

C2 Concentração plasmática na segunda hora após a dose

C3 Concentração plasmática na terceira hora após a dose

C4 Concentração plasmática na quarta hora após a dose

C6 Concentração plasmática na sexta hora após a dose

C8 Concentração plasmática na oitava hora após a dose

C10 Concentração plasmática na décima hora após a dose

C12 Concentração plasmática na décima segunda hora após a dose

UGT Enzima uridina difosfato glucuronosil transferase 


\section{LISTA DE FIGURAS}

Figura 1 - Representação Gráfica da curva de calibração.

Figura 2. Correlação entre dosagens de MPA pelo método EMIT e LC-MS/MS.... 44

Figura 3. Erro de concordância estimado por Bland-Altman ..... 44

Figuras 4a, 4b e 4c. Representação gráfica da dispersão dos valores do Controle de Qualidade.

Figura 5- Médias \pm SE de todos os pacientes que participaram do estudo obtidas para as duas formulações em estudo de MMF

Figura 6 - Representação gráfica do perfil farmacocinético CellCept ${ }^{\circledR}$ 51

Figura 7 - Representação gráfica do perfil farmacocinético de MMF-SA 


\section{LISTA DE TABELAS}

Tabela 1. Resultados obtidos para precisão intraensaio e interensaio

Tabela 2. Limite de detecção, sensibilidade analítica e linearidade.

Tabela 3. Estabilidade da amostra (porcentagem de perda ao longo do tempo)

Tabela 4. Teste de recuperação por adição de concentração conhecida de padrão em amostra de plasma sem MPA

Tabela 5. Comparação entre as variâncias obtidas nos testes de interensaio realizados na DLC, quando comparados aos do fabricante.

Tabela 6. Dados de controle de qualidade obtidos durante o período das dosagens

Tabela 7. Erro total, em porcentagem, para o teste EMIT durante o período das dosagens

Tabela 8. Dados demográficos e clínicos dos pacientes que se submeteram ao estudo farmacocinético com as duas formulações de MMF

Tabela 9. Média, erro padrão e razão das concentrações plasmáticas e parâmetros farmacocinéticos para as duas formulações em estudo

Tabela 10. Resultado da análise de variâncias com medidas repetidas para a concentração máxima (Cmax) e $\mathrm{AUC}_{0-12 \mathrm{~h}}$ e tempo máximo para atingir Cmax (Tmax).

Tabela 11. Análise de bioequivalência: IC $(90 \%)$ da razão entre as médias geométricas entre as duas formulações MMF-SA e CellCept ${ }^{\circledR}$ com resultados transformados em logaritmos para Cmax e $\mathrm{AUC}_{0-12 \mathrm{~h}}$ 


\section{RESUMO}

Romano P. Avaliação da biodisponibilidade de uma nova formulação de micofenolato mofetil e de um método para sua monitorização terapêutica [dissertação]. São Paulo: Faculdade de Medicina, Universidade de São Paulo; 2007. 84p.

O Micofenolato Mofetil (MMF) é amplamente utilizado em transplantes de órgãos sólidos e tem como seu metabólito ativo o ácido micofenólico (MPA). A alta variabilidade intra e interindividual dos níveis plasmáticos de MPA em pacientes transplantados renais que recebem a mesma dose de MMF, a combinação com diferentes imunossupressores que afetam seu metabolismo e a oscilação destes níveis com o tempo decorrido após o transplante justificam a sua monitorização. Pequenas mudanças na dose de MMF podem comprometer a eficácia terapêutica. O objetivo deste trabalho foi avaliar a farmacocinética de duas formulações de MMF. Estudouse um ensaio para a dosagem de ácido micofenólico (MPA) plasmático (EMIT ${ }^{\circledR}$ 2000, Dade Behring) e a seguir, a biodisponibilidade da nova formulação de MMF disponibilizada por Strides Arcolab (MMF-SA), comparativamente ao CellCept ${ }^{\mathbb{R}} \mathrm{em}$ pacientes transplantados renais estáveis. A metodologia de imunoensaio enzimático (EMIT) apresenta resultados relativamente mais elevados em relação à cromatografia líquida de alta resolução, devido à reação cruzada do metabólito acil glucoronídeo de MPA (AcMPAG) com o anticorpo presente no reagente. O método é capaz de detectar não só o MPA, mas também o seu metabólito ativo AcMPAG, o que pode representar uma vantagem. Comparamos o método EMIT com cromatografia líquida de alta resolução acoplada à espectrometria de massas (LC-MS/MS) e obtivemos $\mathrm{r}^{2}=$ 0,9612 . O método apresentou: sensibilidade analítica de $0,02 \pm 0,0016 \mu \mathrm{g} / \mathrm{mL}$; limite de detecção de $0,01 \pm 0,0015 \mu \mathrm{g} / \mathrm{mL}$; linearidade de $14,58 \pm 0,3300 \mu \mathrm{g} / \mathrm{mL}$; coeficientes de variação, intraensaio de $2,14 \%$ - 5,09\% e interensaio de $4,18 \%$ $5,02 \%$. A estabilidade da amostra foi de 90 dias em temperatura de $-20^{\circ} \mathrm{C}$. Concluiuse que a metodologia EMIT para dosagem de MPA é de fácil execução e apresenta boa precisão analítica. Participaram do estudo de biodisponibilidade, vinte e quatro pacientes adultos, transplantados renais, que já recebiam o CellCept ${ }^{\circledR}$ em combinação com Tacrolimus $(n=14)$, ciclosporina $(n=7)$ ou sem inibidores de calcineurina $(\mathrm{n}=3)$. Todos recebiam prednisona. As duas drogas foram administradas em esquema cruzado, com intervalo de uma semana entre as farmacocinéticas. Neste intervalo, os pacientes continuaram recebendo CellCept ${ }^{\circledR}$. Foram analisadas as curvas farmacocinéticas de 12 horas para cada uma das duas formulações, nas mesmas doses equimolares. As médias $\pm \mathrm{SE}$ das medidas de concentração máxima (Cmax) e da área sob a curva (AUC), para CellCept ${ }^{\circledR}$, não foram estatisticamente diferentes das médias \pm SE para MMF-SA $(11,29 \pm 1,35 \mu \mathrm{g} / \mathrm{mL}$ versus $11,05 \pm 1,08 \mu \mathrm{g} / \mathrm{mL}$ e $49,11 \pm 5,15 \mu \mathrm{g} . \mathrm{h} / \mathrm{mL}$ versus $47,59 \pm 3,99 \mu \mathrm{g} . \mathrm{h} / \mathrm{mL}$ ), respectivamente. Da mesma forma, o intervalo de confiança 90\% de MMF-SA / CellCept ${ }^{\circledR}$ para Cmax $(93,57 \%$ $121,73 \%)$ e para AUC $0-12 \mathrm{~h}(93,75 \%$ - 108,90\%) ficaram dentro do intervalo de bioequivalência $(80 \%-125 \%)$. Concluímos que CellCept ${ }^{\circledR}$ pode ser substituído com segurança pela formulação MMF-SA genérica em pacientes transplantados renais estáveis.

Descritores: ácido micofenólico, farmacocinética, monitoramento de medicamentos, disponibilidade biológica, equivalência terapêutica, transplante de rim e técnicas imunoenzimáticas. 


\section{SUMMARY}

Romano P. Assessment of the bioavailability of a new micophenolate mofetil formulation and a method for therapeutic monitoring [dissertation]. São Paulo: "Faculdade de Medicina, Universidade de São Paulo"; 2007. 84p.

Mycophenolate mofetil (MMF) is largely used in solid organ transplantation. Mycophenolic Acid (MPA) is the active metabolite of MMF. The high intra and interpatient's variability of the MPA plasma levels in transplant recipients under the same dose of MMF, the association with immunosuppressant drugs that change the MPA metabolism and pharmacokinetic parameters over time may cause impact in the optimal dose of MMF. The therapeutic monitoring of MPA may improve the efficacy and safety. The aim of this study was to: 1 - to validate the EMIT assay for MPA monitoring and 2: to assess the bioavailability of two MMF formulations. The performance of the EMIT $^{\circledR} 2000$ Dade Behring Mycophenolic acid enzimatic immunoassay was evaluated. There was a high correlation between the LC-MS/MS and EMIT $\left(\mathrm{r}^{2}=0.9612\right)$. Because of the cross-reactivity of the antibody used in the EMIT assay with the active acyl glucuronide metabolite (AcMPAG), the EMIT concentrations are higher than those from high performance liquid chromatography (HPLC).The analytic sensitivity was $0.02 \pm 0.0016 \mu \mathrm{g} / \mathrm{mL}$; detection limit $0.01 \pm 0.0015 \mu \mathrm{g} / \mathrm{mL}$; linearity $14.58 \pm 0.3300 \mu \mathrm{g} / \mathrm{mL}$. The $\mathrm{CV}$ of within-day precision was $2.14 \%-5.09 \%$ and the $\mathrm{CV}$ of between-days precision was $4.18 \%-$ $5.02 \%$. The sample stability was 90 days at $-20^{\circ} \mathrm{C}$. The EMIT assay is easily performed and fulfills all the requirements for an assay. We studied the MMF formulation from Strides Arcolab (MMF-SA) and CellCept ${ }^{\circledR}$ in twenty-four adult, renal transplanted patients, receiving $\mathrm{MMF}\left(\mathrm{CellCept}^{\circledR}\right)$, before the bioavailability study, combined with tacrolimus $(n=14)$, cyclosporine $(n=7)$ or without CNI $(n=3)$. All patients received prednisone. They had a 12 hours pharmacokinetics (PK) of total MPA measured after the same equimolar doses for the two formulations. The PK analysis revealed two mean PK curves that overlaid over each other. Mean \pm SE of maximum concentration (Cmax) and area under the time-concentration curve (AUC) of CellCept ${ }^{\circledR}$ were not statistically different from the generic MMF-SA $(11.29 \pm 1.35$ $\mu \mathrm{g} / \mathrm{mL}$ vs $11.05 \pm 1.05 \mu \mathrm{g} / \mathrm{mL}$ and $49.11 \pm 5.15 \mu \mathrm{g} . \mathrm{h} / \mathrm{mL}$ vs $47.59 \pm 3.99 \mu \mathrm{g} . \mathrm{h} / \mathrm{mL}$, respectively). In the same way the MMF-SA/CellCept ${ }^{\circledR} 90 \%$ confidence interval for both: Cmax (93.57\%-121.73\%) and $\mathrm{AUC}_{0-12 \mathrm{~h}}(93.75 \%-108.90 \%)$ was within the bioequivalence interval $(80 \%-125 \%)$. In renal transplanted patients, CellCept ${ }^{\mathbb{R}}$ can be switched by the generic MMF formulation.

Keywords: mycophenolic acid, pharmacokinetics, drug monitoring, biological availability, therapeutic equivalence, kidney transplantation, immunoenzyme techniques. 
1. INTRODUÇÃO 
As drogas imunossupressoras são indispensáveis para o sucesso na prevenção de rejeição em pacientes transplantados renais.

A comunidade científica tem concentrado esforços, no sentido de aumentar as taxas de sobrevida do órgão transplantado e do paciente, tentando evitar-se a rejeição aguda e a nefrotoxicidade relacionada aos inibidores de calcineurina (CNI): ciclosporina (CyA) e tacrolimus (TAC), a infecção por vírus e a incidência de tumores, associados a altas doses de imunossupressores. Ciclosporina e tacrolimus representam as bases da imunossupressão em transplantes de órgãos sólidos.

A imunossupressão nestes transplantes usualmente se faz com o uso de múltiplas drogas imunossupressoras. A possibilidade de estas drogas atuarem em sítios diferentes, faz com que a associação de várias drogas resulte em efeitos sinérgicos $^{(1)}$. O sinergismo entre as drogas possibilita a utilização de doses menores de cada uma delas, contribuindo para a diminuição dos efeitos adversos e amplificação de seus efeitos benéficos.

A introdução da ciclosporina, no início dos anos 1980, aumentou a sobrevida do órgão transplantado no primeiro ano em $80 \%$, devido a sua eficácia em evitar episódios de rejeição aguda ${ }^{(2)}$.

Embora estruturalmente diferente da CyA, o TAC também impede a produção de interleucina-2 (IL-2) pelos linfócitos T por inibição da calcineurina. Estudos recentes têm demonstrado a superioridade clínica do $\mathrm{TAC}^{(3)}$ sobre CyA, com menor incidência de rejeição aguda (RA) e melhora da função renal no longo 
prazo $^{(4)}$. Nos primeiros meses pós-transplante, quando o risco de rejeição é alto, a necessidade de uso dos inibidores de calcineurina parece, ainda, ser imprescendível.

O ácido micofenólico (MPA), um produto do fungo Penicilium, isolado em 1896, purificado em 1913 tem efeito imunossupressor conhecido desde 1969, e uso clínico possível após a síntese de um éster denominado micofenolato mofetil (MMF), que foi introduzido entre as drogas imunossupressoras, no início dos anos 90 . O MMF é uma pró-droga semi-sintética que libera MPA na circulação ${ }^{(1)}$.

O MMF é produzido pelo Laboratório Hoffman La Roche, com o nome comercial de CellCept ${ }^{\circledR}$. A pró-droga micofenolato mofetil confere aumento da biodisponibilidade oral de $\mathrm{MPA}^{(5)}$.

O MMF é rapidamente absorvido e desesterificado, após ingestão de dose oral. Após a absorção o MMF é rapidamente hidrolisado no fígado para MPA, que após conjugação resulta em seu metabólito inativo o glucoronídeo fenólico de MPA (MPAG) e o acil glucoronídeo de MPA (AcMPAG) que apresenta atividade imunossupressora $^{(5,6)}$.

O pico de absorção de MPA ocorre entre 1 a 2 horas após, e um segundo pico ocorre entre 6 e 12 horas após ingestão da droga. O segundo pico resulta da recirculação entero-hepática de MPAG que, após hidrólise, é novamente convertido em MPA no trato gastrointestinal. Em humanos, a interferência no ciclo enterohepático pode reduzir a área sob a curva concentração-tempo (AUC) de MPA em 35 a 40\%. O MPAG é excretado pelos rins e a AUC de MPA aumenta nos casos de insuficiência renal ${ }^{(7,8)}$.

A variabilidade da pré-dose $(\mathrm{C} 0)$ pode ser causada pela flutuação diária da recirculação entero-hepática, com base nas alterações fisiológicas de excreção 
biliar, drogas co-administradas, doenças ou variáveis genéticas, podendo resultar na redução ou indução da atividade de transportadores e enzimas metabolizadoras $^{(9)}$. Porém, estes mecanismos ainda não estão bem descritos, sendo necessários novos estudos.

A redução da recirculação entero-hepática diminui a MPA-AUC total, por redução da reciclagem de MPAG para MPA no intestino, com conseqüente diminuição do segundo pico em pacientes com atividade de alanina aminotransaminases (ALT) elevadas. Em pacientes que utilizam antibióticos orais, ou naqueles com diarréia causada por bactérias, pode ocorrer uma redução da recirculação entero-hepática. Por outro lado, altos níveis de MPA-AUC total causam diarréia como efeito adverso, devido à enterotoxicidade de metabólitos do MPA, como o $\operatorname{AcMPAG}^{(8,10)}$.

O MPA e o AcMPAG têm diferentes perfis farmacocinéticos, sendo que o AcMPAG atinge a concentração máxima entre 4-8 horas, tendo baixo impacto na concentração de MPA pelo método de imunoensaio enzimático (EMIT), na primeira hora após administração de MMF. Porém, este impacto aumenta, consideravelmente, de 4-8 horas após a dose, o que deve ser levado em consideração ao se interpretar os resultados clínicos ${ }^{(11)}$.

A eliminação média do MPA marcado radioativamente em voluntários normais lhe confere uma meia vida de aproximadamente dezessete horas ${ }^{(5)}$.

O MPA é ligado à albumina humana sérica, e somente $1,25 \%$ da concentração de MPA no plasma encontra-se sob a forma livre. Acredita-se que a sua forma livre é a fração farmacologicamente ativa da droga, e que esta promove a inibição da enzima inosina monofosfato desidrogenase (IMPDH), encontrando-se em equilíbrio com a concentração total, na vigência de níveis estáveis de albumina sérica ${ }^{(12)}$. 
O MPA in vitro diminui a proliferação dos linfócitos $\mathrm{T}$ e $\mathrm{B}$ por inibir a IMPDH, importante para a síntese de DNA destas células ${ }^{(1,13,14)}$. Além disso, o MPA parece diminuir, também, a glicosilação de moléculas de adesão em linfócitos, impedindo o afluxo destes para os tecidos e sua ligação às células endoteliais, fator que pode contribuir em seu efeito imunossupressor ${ }^{(15)}$.

O MPA é o princípio ativo que tem efeito inibidor seletivo, não competitivo sobre a IMPDH enzima essencial na biossíntese de purinas na via denominada de novo, presente nas células dos mamíferos. Os linfócitos são particularmente susceptíveis à inibição pela IMPDH, quando comparados às outras células, devido à ausência da via salvage pathway para a produção de nucleotídeos guanosina nos linfócitos ${ }^{(16-18)}$.

Existem duas vias, mais importantes na biossíntese de purinas: de novo e salvage. Na de novo, a 5-fosforibosil 1-pirofosfatase catalisa uma reação entre ribose-5-fosfato e ATP para formar 5-fosforibosil 1-pirofosfato (PRPP). PRPP é um precursor de inosina monofosfato, a qual, na presença de inosina monofosfato dehidrogenase (IMPDH), forma guanosina monofosfato. Guanosina monofosfato é um precursor de guanosina difosfato (GDP), de guanosina trifosfato (GTP), e de desoxi-guanina difosfato (dGTP). O MPA impede a conversão de inosina monofosfato para guanosina difosfato, esssencial na síntese de nucleotídeos para a síntese de RNA ${ }^{(17)}$.

A inibição da atividade da IMPDH entre 60 e 87\% ocorre, aproximadamente, ao mesmo tempo em que ocorre o pico de absorção de MPA no plasma. Essa inibição é mantida durante quatro horas após a dose, então, gradualmente a atividade da enzima retorna aos níveis pré-dose. Em pacientes com níveis mais elevados de Cmax, a completa inibição da atividade da IMPDH ocorre ao mesmo tempo em que 
ocorre o pico de máxima absorção de MPA no plasma, mas é rapidamente revertida, retornando em cerca de duas horas, após a dose, ao nível pré-dose ${ }^{(19)}$.

O MMF não deveria ter ação sobre os precursores de glóbulos vermelhos e de plaquetas, uma vez que estas células têm a via salvage para a síntese de purinas. No entanto, as evidências mostraram que o MMF deprime, também, as séries vermelha e plaquetária $^{(20)}$.

Em 1995, Sollinger et al. ${ }^{(21)}$ conduziram os primeiros ensaios clínicos com micofenolato mofetil (MMF) em pacientes transplantados renais, após os resultados obtidos em modelos animais ${ }^{(22)}$.

A eficácia e a aprovação de MMF para a prevenção de rejeição aguda no transplante renal, bem como a sua aceitação como um potente imunossupressor devido sua baixa toxicidade, foi comprovada através de três grandes estudos clínicos randomizados, multicêntricos, em pacientes transplantados adultos ${ }^{(21,23,24)}$.

Após os testes iniciais, vários esquemas de imunossupressão foram testados com diferentes associações de MMF, com outros imunossupressores e com diminuição da dose utilizada de inibidores de calcineurina ${ }^{(25-29)}$. Outros estudos estão sendo realizados com supressão de corticoesteróides, ou $\mathrm{CNI}^{(30,31)}$ ou associação com sirolimus $^{(32)}$, buscando a diminuição do risco de rejeição aguda no póstransplante imediato e tardio.

$\mathrm{O}$ uso de MMF com doses relativamente baixas de inibidores de calcineurina é, atualmente, o protocolo mais utilizado em esquemas imunossupressores para transplantados renais, para obtenção de melhor função renal ${ }^{(1)}$.

Pacientes com nefropatia crônica do enxerto (CAN) apresentaram estabilização ou melhora da função renal com o uso da associação de MMF e 
inibidores de calcineurina com dose reduzida ${ }^{(25)}$. Em estudo com ratos que apresentavam características histopatológicas de CAN, também foi verificado o mesmo efeito e que doses terapêuticas de MMF inibem a proliferação de fibroblastos, em cultura de células ${ }^{(33)}$.

O tacrolimus e a ciclosporina afetam o metabolismo do MMF. Em estudo com pacientes transplantados renais recebendo TAC e MMF, foram encontrados níveis significativamente mais altos de ácido micofenólico, quando comparados com aqueles recebendo ciclosporina e MMF. O maior metabólito do MPA, o glucoronídeo fenólico de MPA (MPAG), tem concentração plasmática significativamente mais baixa em receptores que utilizam tacrolimus sugerindo uma inibição específica do metabolismo de MPA para $\mathrm{MPAG}^{(34)}$. Este achado foi confirmado em outro estudo, o qual demonstrou a importância do efeito inibidor de TAC sobre a enzima uridina difosfato glucoronosil transferase (UDPGT) ${ }^{(35)}$.

Em estudo recente Pereira ${ }^{(36)}$, avaliando 52 pacientes, nos seis primeiros meses após o transplante, demonstrou que, cerca de $80 \%$ dos valores de MPA-AUC estiveram abaixo do limite de $36 \mu \mathrm{g} . \mathrm{h} / \mathrm{mL} 7$ dias após o transplante e em 180 após o transplante, $35 \%$ das curvas estavam abaixo de $36 \mu \mathrm{g} . \mathrm{h} / \mathrm{mL}$, quando a dose de 1500 mg/dia de MMF foi empregada. Quando se empregou a dose de $2000 \mathrm{mg} / \mathrm{dia}$ de MMF, menos de 15\% das curvas estavam abaixo do limite inferior, em 180 dias após o transplante, tanto no grupo TAC quanto CSA. Sugerindo que a proposta de empregar doses menores de MMF quando tacrolimus é usado deve ser revista.

A ciclosporina, associada ao MMF pode diminuir os níveis plasmáticos de MPA por supressão do transporte de MPAG pela bile. A ciclosporina interfere na excreção biliar de drogas, e pode interferir na excreção de MPAG, provavelmente, por inibição da proteína dois associada à resistência a múltiplas drogas (MRP2, 
multidrug resistance-associated protein 2). Com menor quantidade de MPAG na circulação entero-hepática, os níveis de MPA, obtidos através da área sob a curva de concentração-tempo (AUC), estarão diminuídos ${ }^{(7)}$.

A utilização de várias drogas imunossupressoras, em pacientes transplantados renais, requer maior habilidade de monitorização, através de medidas farmacocinéticas que melhorem a eficácia destas drogas. A monitorização permitiu que fossem estabelecidas janelas terapêuticas para cada imunossupressor, as quais são utilizadas como indicadores para se evitar episódios de rejeição aguda e efeitos adversos como no caso da ciclosporina ${ }^{(37)}$ ou do TAC $^{(31)}$

A monitorização de TAC é feita através do nível pré-dose da droga $(\mathrm{C} 0)$. Nosso grupo, no entanto, encontrou que os níveis de TAC, medidos na segunda hora $(\mathrm{C} 2)$, tem uma melhor correlação e um menor erro de predição da AUC do que $\mathrm{C}^{(38)}$

Para o MMF, uma janela terapêutica de $30-60 \mu \mathrm{g} . \mathrm{h} / \mathrm{mL}$ para $\mathrm{AUC}_{0-12 \mathrm{~h}}$, e de 1,0 a $3,5 \mu \mathrm{g} / \mathrm{mL}$ para a pré-dose $(\mathrm{C} 0)$, foi proposta, em 2000 , por Oellerich et al., e confirmada por Mourad et al., para otimizar o acompanhamento de pacientes sob terapia com MMF/CYA/esteróide ${ }^{(6,39,40)}$.

Em pacientes pediátricos transplantados renais, no período recente póstransplante, níveis de AUC para MPA superior ou igual a $33 \mu \mathrm{g} . \mathrm{h} / \mathrm{mL}$ são necessários para prevenir episódios de rejeição aguda ${ }^{(41,42)}$. Em adultos, níveis de Cmax menor que $8 \mu \mathrm{g} / \mathrm{mL}$ podem diminuir a incidência de efeitos adversos ${ }^{(27)}$.

Em 1998, Hale et al. ${ }^{(10)}$ encontraram correlação entre níveis de MPA-AUC e rejeição aguda e também com efeitos adversos. AUC maior que $61 \mu \mathrm{g} . \mathrm{h} / \mathrm{mL}$ foi associada a efeitos adversos gastrointestinais; e AUC menor que $16 \mu \mathrm{g} . \mathrm{h} / \mathrm{mL}$ foi correlacionada com rejeição aguda. 
Em 2004, Filler ${ }^{(43)}$ sugeriu que, em crianças transplantadas renais, a melhor forma de se monitorar o MPA é através da AUC abreviada (0, 1, 2 e 4 horas).

Estas janelas terapêuticas não são facilmente alcançáveis. Muitas vezes, os níveis terapêuticos mínimos aproximam-se dos níveis tóxicos, fazendo com que a monitorização dos níveis plasmáticos destas drogas seja fundamental para o sucesso terapêutico e para se definir as janelas terapêuticas.

A necessidade de acompanhamento para se determinar a dose foi recentemente demonstrada, em 2005, por van Hest et al. ${ }^{(44)}$, em modelo de simulação computacional, tendo verificado que a exposição adequada ao MPA, é mais rapidamente obtida quando se monitora a concentração sangüínea, do que quando doses fixas de MMF são ofertadas.

Estudos multicêntricos internacionais, para verificar o impacto da monitorização de MPA sobre a evolução do transplante renal, apresentaram algumas respostas. van Gelder et al. ${ }^{(45)}$ recomendaram que, as doses devem ser ajustadas a partir da monitorização terapêutica, principalmente no período recente pós-transplante, o que pode otimizar os desfechos, especialmente em pacientes com alto risco de rejeição.

Em 2006, van Gelder et al. ${ }^{(41)}$ sugeriram que, a monitorização terapêutica é recomendável nos dias 3, 7 e uma vez entre os dias 10 e 14 após o transplante. Uma amostra deve ser analisada 3 ou 4 semanas após e que as doses ajustadas pelo método Bayesiano ${ }^{(46)}$ (que utiliza a comparação de dois ou mais tempos de coleta com a média populacional), apresentam vantagens por ser este método mais preciso, quando comparado aos modelos de regressão multilinear.

A monitorização correta exige o conhecimento da farmacocinética da droga e uma metodologia de dosagem eficaz. 
A farmacocinética do MPA difere, significativamente, nos períodos imediatamente após o transplante e tardio ${ }^{(42,47)}$. De modo geral, os dados disponíveis indicam que, no período pós-transplante recente, a concentração média de AUCMPA total é, aproximadamente, 30 a 50\% menor do que a mesma dose no período tardio ${ }^{(31,48-50)}$. Os níveis de AUC do MPA total aumentam nos três primeiros meses, e depois permanecem estáveis por doze meses ${ }^{(49)}$.

Pereira $^{(36)}$, verificou que o perfil farmacocinético de ácido micofenólico modifica-se ao longo dos seis primeiros meses após o transplante renal, e confirmouse a variabilidade, de acordo com o inibidor de calcineurina empregado.

Em 2005, David-Neto et al. ${ }^{(38)}$ observaram que o comportamento farmacocinético interindividual é bastante estável após longo período de exposição, não sendo necessária a monitorização freqüente neste período.

A necessidade de doses maiores de MMF no pós-transplante imediato, o aumento progressivo da exposição ao MPA ao longo do tempo, a diferença na evolução da farmacocinética de MPA, de acordo com o inibidor de calcineurina empregado, e a demora para se atingir a faixa terapêutica tornam o acompanhamento obrigatório.

A concentração plasmática de MPA pode ser modificada pelo tempo de transporte, fluxo de bile, condições do trato gastrointestinal, etnia, idade, perfil lipoprotéico, função hepática, medicações concomitantes, e tempo pós-transplante, fatores estes que influenciam a variação interindividual de absorção, distribuição, metabolismo e eliminação da droga ${ }^{(10,12,28,42,51-54)}$.

A determinação da concentração da droga em fluidos biológicos é o método mais adequado para a individualização da dose, buscando a melhor correlação entre concentração plasmática e o efeito farmacológico desejado. Doses individualizadas 
podem tornar a droga mais efetiva e segura. A dosagem do ácido micofenólico é o melhor parâmetro para monitorar a imunossupressão pelo $\mathrm{MMF}^{(41)}$.

Foi sugerido que, no período recente pós-transplante, a medida de exposição ao MPA, e principalmente da fração livre, pode ser um marcador melhor para efeitos hematológicos adversos do que o MPA total ${ }^{(51)}$. A MPA-AUC total aumentada, em pacientes com a função renal prejudicada, foi associada ao aumento da fração livre de $\operatorname{MPA}^{(12)}$.

A análise farmacocinética, determinada pela área sob a curva de concentração-tempo (AUC), fornece informação mais completa sobre a exposição à droga, e tem recebido atenção de vários estudos científicos, com o objetivo de se estabelecer a melhor forma de acompanhamento dos níveis terapêuticos ${ }^{(6,9,31,41,42,55-57)}$. É importante ressaltar que curvas completas demandam tempo e recursos, necessidade de maior quantidade de sangue dos pacientes, e período de permanência maior no ambulatório para as coletas de sangue.

Curvas abreviadas são mais precisas que a estimativa com um único ponto, ou com a pré-dose, e podem ser uma medida apropriada para pacientes ambulatoriais $^{(41)}$.

Para facilitar o acompahnamento terapêutico, foram sugeridas curvas farmacocinéticas abreviadas, calculadas através de equações matemáticas com uma ou mais variáveis, e concordância com a curva completa, obtida pelo método trapezoidal linear, utilizando-se a metodologia de imunoensaio enzimático (EMIT) ${ }^{(6,38,58)}$, ou $\operatorname{HPLC}^{(59)}$.

David-Neto et al. ${ }^{(60)}$, avaliando pacientes sob terapia com CellCept ${ }^{\circledR}$, nos seis primeiros meses após o transplante, encontraram boa correlação entre C2 e MPA- 
$\mathrm{AUC}_{0-12 \mathrm{~h}}$, para pacientes, em terapia com tacrolimus e ciclosporina. Em 2005, verificaram que equação que utilizou C2 apresentou boa correlação com AUC total, pelo método trapezoidal linear, em transplantados renais estáveis. Foi sugerida a equação 9,5 + (6 x C2), facilitando a monitorização de MPA, a qual pode ser realizada com uma única coleta para a monitorização de ciclosporina, tacrolimus e MPA ${ }^{(38)}$.

O conhecimento da farmacocinética do MPA é de fundamental importância para o desenvolvimento de estudos com o MMF como é o escopo deste estudo.

\subsection{Validação da metodologia de imunoensaio enzimático (EMIT)}

A capacidade de fornecer resultados analíticos confiáveis, exatos e precisos são papéis centrais da equipe de um laboratório clínico. Dados da validação analítica são úteis na introdução de um novo esquema terapêutico, no apoio aos estudos de formulações distintas, na monitorização e determinação dos níveis terapêuticos de

drogas. A validação tem impacto direto na qualidade dos tratamentos instituídos. Ela também possibilita documentação consistente para eventuais auditorias médicas ou de protocolos de pesquisa. Isto é especialmente importante nos estudos para a introdução de novas formulações genéricas.

A necessidade de acompanhamento terapêutico demanda a escolha da melhor metodologia disponível, a qual possa ser facilmente implantada no serviço de Medicina Laboratorial e que atenda às necessidades do corpo clínico em uma população específica. 
Apesar do fabricante, fornecer informações a cerca do desempenho do conjunto diagnóstico, isto não é suficiente para a sua implantação na rotina laboratorial, sem antes passar por um processo de verificação e validação.

Esta exigência se deve ao fato de que as condições na indústria podem ser diferentes daquelas presentes no laboratório que irá realizar os testes, e os resultados poderão ser diferentes das informações previamente recebidas.

A avaliação de um método requer conhecimentos e habilidades para um bom desempenho técnico, a utilização de equipamentos e materiais disponíveis no laboratório, e o uso de ferramentas estatísticas que permitam analisar os resultados obtidos, e que são importantes para o ajuste das doses ${ }^{(61)}$.

As normas internacionais, nacionais e de sistema da qualidade destacam a importância da validação de métodos analíticos nas condições de cada laboratório, garantindo a uniformidade dos resultados. A validação de um método consiste na realização de uma série de testes, com a finalidade de se documentar o desempenho do método em relação à exatidão, precisão e intervalo analítico ${ }^{(62,63)}$.

Com base nestes requisitos, o método EMIT foi avaliado nas nossas condições analíticas. Em estudos de validação, presentes na literatura, o método EMIT apresentou adequada precisão e exatidão para o acompanhamento terapêutico de $\operatorname{MPA}^{(11,64,65)}$.

Estes estudos utilizaram os seguintes parâmetros na caracterização do método: precisão intraensaio (repetibilidade do método), interensaio (reprodutibilidade do método), linearidade e sensibilidade (que permitem determinar o intervalo analítico em que os valores podem ser obtidos sem modificação da amostra), limite de detecção (capacidade do método em diferenciar resultados muito 
próximos de zero), recuperação (capacidade de um método mensurar a quantidade do analito corretamente).

A comparação com metodologia padrão é necessária para detectar erros sistemáticos relacionados à metodologia EMIT, uma vez que o método apresenta valores mais altos em relação às demais metodologias disponíveis.

A metodologia utilizada como padrão para o acompanhamento de MPA é a cromatografia líquida de alta eficiência (CLAE ou HPLC). Esta metodologia é altamente específica, e pode diferenciar os principais metabólitos do MPA: MPAG e $\mathrm{AcMPAG}^{(66)}$, mas é de difícil implantação em laboratórios clínicos de rotina.

A técnica de HPLC requer extração em fase líquida, a qual pode acarretar erros, e ainda requer equipamentos sofisticados e de custo elevado, coluna específica e detector ultravioleta (UV) ou de massa.

A espectrometria de massa acoplada à cromatografia líquida (LC-MS) é o método mais específico disponível para dosagem de MPA. Esta metodologia diferencia a relação massa/carga de átomos e moléculas ionizadas. Os íons são separados e sua quantificação é realizada com base nesta relação, gerando picos de absorção. A amostra em solução é vaporizada, isto é, quebrada em gotículas menores, as quais carregam carga assim que o solvente evapora.

A LC-MS/MS gera dois picos de relação massa/carga que são captados por dois detectores de massa, e, dessa forma é mais específica.

O método EMIT tem como princípio uma reação antígeno-anticorpo monoclonal e foi disponibilizado para facilitar a monitorização terapêutica dos níveis plasmáticos de $\mathrm{MPA}^{(11)}$. A dosagem é efetuada em equipamentos automatizados e as amostras não necessitam de preparação prévia, podendo diminuir os custos de 
monitorização. Por ser menos laborioso, é melhor adaptável à rotina de laboratórios clínicos hospitalares. Estes benefícios se estendem ao paciente, o qual receberá os resultados analíticos em menor tempo.

Esta metodologia ainda não possui registro na Agência Nacional de Vigilância Sanitária (ANVISA) do Ministério da Saúde, mas já foi parcialmente validada em estudos que podem ser complementados para uma maior confiabilidade do ensaio.

$\mathrm{Na}$ literatura, há alguns estudos com a metodologia EMIT, utilizada em estudos farmacocinéticos de MPA associado a outras drogas $(6,19,52,67-72)$, ou para estudo comparando-a com a metodologia com HPLC ${ }^{(11,42,64,65,73)}$. Nestes estudos, os autores encontraram boa correlação entre as duas metodologias, e valores, aproximadamente, $10-30 \%$ superiores, quando se emprega a metodologia EMIT, em relação ao $\operatorname{HPLC}^{(6,11,42,64,65,74)}$.

A diferença entre as metodologias é atribuída à reação cruzada do anticorpo presente no método EMIT com o metabólito AcMPAG. Como a eliminação de AcMPAG é realizada pelos rins, pacientes com função renal reduzida podem ter resultados superestimados em relação a pacientes com a função renal $\operatorname{preservada}^{(11)}$.

A eficácia dos dois métodos na prevenção de rejeição aguda, nos seis primeiros meses após o transplante renal, foi verificada por vários estudos ${ }^{(11,42,64,65,75)}$. Alguns autores acreditam que o metabólito AcMPAG pode ser responsável por efeitos adversos, podendo ser importante a sua determinação na monitorização de $\operatorname{MPA}^{(74)}$.

Em 2002, Weber et al. ${ }^{(42)}$ demonstraram que a variação interindividual foi comparável na fase inicial (21\%) pós-transplante, e na fase estável (22\%) com o uso de metodologia HPLC ou EMIT, concluindo que MPA-AUC ${ }_{0-12 \mathrm{~h}}$ e $\mathrm{C} 0$ encontraram- 
se significativamente associados ao risco de rejeição aguda, independentemente da metodologia empregada, e que os dois métodos apresentaram eficácia clínica comparável. Porém, os níveis de decisão para EMIT são um pouco mais elevados, quando comparados aos níveis para HPLC. Os resultados deste estudo foram: para HPLC $\mathrm{AUC}_{0-12 \mathrm{~h}} 30-60 \mu \mathrm{g} . \mathrm{h} / \mathrm{mL}$ e $\mathrm{C} 0$ de $1,2 \mu \mathrm{g} / \mathrm{mL}$, e para EMIT $\mathrm{AUC}_{0-12 \mathrm{~h}} 35-$ $75 \mu \mathrm{g} . \mathrm{h} / \mathrm{mL}$ e $\mathrm{C} 0$ de $1,4 \mu \mathrm{g} / \mathrm{mL}$.

Os resultados obtidos pelo método EMIT podem refletir melhor a imunossupressão, no tratamento por MMF, do que aqueles obtidos de métodos que apenas dosam MPA. A presença de MPA no plasma não atenua a reatividade do anticorpo presente no reagente EMIT com AcMPAG.

A estabilidade de AcMPAG depende do $\mathrm{pH}$ e da temperatura (sofre rápida hidrólise em $\mathrm{pH}$ fisiológico e temperatura de -20 a $4^{\circ} \mathrm{C}$ ). A estocagem, após a coleta a $-20^{\circ} \mathrm{C}$, promove a estabilização de AcMPAG por períodos de um mês ${ }^{(11)}$.

Os acil glucoronídeos são metabólitos reativos a drogas com grupo ácidocarboxílico. Sua atividade tóxica potencial resulta da ligação covalente com proteínas, lipídeos e ácidos nucléicos, levando às reações idiossincráticas e de hipersensibilidade. No entanto, o mecanismo preciso ainda não foi demonstrado ${ }^{(76)}$.

Em 2004, Prémaud et al. ${ }^{(77)}$ encontraram correlação $r^{2}=0,894$ entre a metodologia EMIT e a metodologia de cromatografia líquida de alta resolução acoplada à espectrometria de massa (LC-MS/MS), em pacientes sob terapia com MMF e CyA, e equação EMIT = 1,094 + 1,094 LC-MS/MS.

Em 2006, Prémaud et al. ${ }^{(78)}$ compararam MMF e sirolimus com a mesma metodologia, e relataram que a diferença de AUC, entre as duas metodologias, foi menor no terceiro mês após o transplante $11,7 \pm 25,6 \%$, quando comparada a 
$29,8 \pm 22 \%$ no sétimo dia após o transplante. A diferença menor no terceiro mês pode ser explicada pela melhora na função renal, a qual pode ser consistente com a diminuição dos níveis dos metabólitos de MPA, devido à melhora da excreção renal. É conhecido que a ciclosporina aumenta a exposição ao MPAG, o que pode explicar a diferença encontrada nas duas populações estudadas.

Independentemente da metodologia utilizada, a concentração de MPA total deve ser evoluída com base na função renal dos pacientes e dos níveis de albumina e bilirrubina $^{(41,42)}$.

Uma elevação da fração livre de MPA está associada a uma diminuição da ligação com proteínas, o que é observado em pacientes com baixos níveis plasmáticos de albumina, níveis elevados de bilirrubina e naqueles com insuficiência renal ${ }^{(41,42)}$.

Os testes de validação e critérios de aceitação de resultados foram efetuados segundo normas nacionais e internacionais ${ }^{(62,63,79)}$. Estudos de biodisponibilidade devem ser realizados após a validação da metodologia analítica utilizada.

\subsection{Estudo da biodisponibilidade de duas formulações de MMF.}

Medicamentos contendo o mesmo fármaco, na mesma dose molar, não produzem, necessariamente, os mesmos resultados quanto à eficácia e segurança. No começo dos anos setenta, foi constatado que diferentes formulações, administradas oralmente, apresentavam variações significativas em suas biodisponibilidades. 
O estudo de biodisponibilidade surgiu da necessidade de se entender os casos de ineficácia clínica e de intoxicação. Estudos colaborativos entre EUA e Canadá levaram à regulamentação técnica para estes estudos, em 1970, no Canadá.

Em 1977, nos Estados Unidos surgiu o Code of Federal Regulation (CRFFDA) que regulamentou os estudos de biodisponibilidade e bioequivalência, e, em 1984 The Drug Price Competition and Restoration Act e o Abbreviated NDA (ANDA), os quais regulamentaram o registro de genéricos com base nos estudos de biodisponibilidade comparada, denominada de bioequivalência.

O Federal and Drug Administration (FDA) definiu que a biodisponibilidade relaciona-se à quantidade absorvida de um fármaco, a partir de sua forma farmacêutica, e à velocidade pela qual este processo ocorre ${ }^{(80)}$.

Biodisponibilidade e bioequivalência são temas que têm gerado várias discussões, principalmente, com a introdução dos medicamentos genéricos no mundo todo. Estas discussões têm promovido a conscientização das agências reguladoras sobre os problemas clínicos relacionados à bioequivalência, bem como a busca do aprimoramento destes estudos.

Atualmente os testes de bioequivalência são realizados in vivo, comparando a nova formulação com a droga de referência, em voluntários sadios, usando uma única dose da droga ${ }^{(80,81)}$.

A definição de biodisponibilidade inclui os parâmetros de velocidade e extensão, através dos quais, a substância ativa de um fármaco é absorvida (atinge a circulação sistêmica), a partir de uma forma farmacêutica, e se torna disponível no sítio de ação ${ }^{(80,81)}$. 
Os fatores que afetam a biodisponibilidade são: fármaco, formulação, processo de fabricação, forma farmacêutica e a via de administração ${ }^{(81)}$.

Os parâmetros farmacocinéticos que expressam a biodisponibilidade são: área sob a curva $\left(\mathrm{AUC}_{0}-\mathrm{t}\right)$, concentração máxima $(\mathrm{Cmax})$ e tempo necessário para atingir a concentração máxima (Tmax). $\mathrm{AUC}_{0} \mathrm{t}_{\mathrm{t}}$ expressa a quantidade absorvida (extensão de absorção) e Cmax, relacionado à Tmax, reflete a velocidade de absorção ${ }^{(80)}$.

No contexto do medicamento genérico, um produto farmacêutico deve ser terapeuticamente equivalente ao produto inovador, o qual teve sua eficácia e segurança comprovada através de estudos clínicos.

O medicamento genérico deve ser uma cópia de qualidade garantida (equivalente farmacêutico) do fármaco de referência, administrado na mesma dose e via de administração extravascular ${ }^{(80)}$.

A comprovação da equivalência terapêutica, base para a intercambialidade, é a demonstração de que o medicamento genérico possuirá o mesmo perfil de eficácia e segurança que o medicamento inovador, sem a necessidade dos estudos clínicos.

A bioequivalência substitui a comparação direta (ensaios clínicos) pela indireta (das farmacocinéticas), baseando-se no princípio de que a similaridade dos perfis de concentração-tempo no sangue (soro ou plasma) proporciona semelhantes resultados quanto à eficácia e segurança ${ }^{(82)}$.

A bioequivalência é o estudo comparativo das biodisponibilidades entre duas formulações da mesma droga ${ }^{(82)}$.

Alguns estudos de bioequivalência já estão relatados na literatura para drogas imunossupressoras em transplantados renais; a droga mais estudada quanto à 
bioequivalência nesta população, foi a ciclosporina ${ }^{(83-85)}$. Nestes artigos, foi levantada a necessidade de que a bioequivalência deve ser realizada em populações específicas, e não apenas em voluntários sadios. Esta opinião é compartilhada por outros autores, no que diz respeito às drogas imunossupressoras ${ }^{(84,86,87)}$.

Testes de bioequivalência com duas formulações idênticas de MMF, em transplantados renais, ainda não estão descritos na literatura.

Há estudos comparando a bioequivalência entre micofenolato mofetil formulação clássica e micofenolato sódico ${ }^{(88,89)}$.

Tendo em vista a importância do estudo de biodisponibilidade para se comprovar a eficácia clínica de duas formulações de MMF, disponíveis para a terapia imunossupressora de pacientes transplantados renais, analisamos a possibilidade de troca entre as duas formulações, quando utilizadas nas mesmas doses. Para atender a necessidade de monitorização dos níveis plasmáticos de MPA, nestes pacientes, de maneira segura, rápida e precisa, validamos a metodologia EMIT através da precisão intraensaio e interensaio, linearidade, sensibilidade, recuperação e correlação com metodologia padrão LC-MS/MS. 
2. OBJETIVOS 


\subsection{Objetivo primário}

Verificar se a formulação de micofenolato mofetil MMF-SA apresenta a mesma biodisponibilidade que a formulação de referência, em pacientes transplantados renais estáveis.

\subsection{Objetivo secundário}

Avaliar o método de imunoensaio enzimático (EMIT) para monitorização dos níveis plasmáticos de ácido micofenólico, em pacientes transplantados renais estáveis. 
3. MÉTODOS 


\subsection{Metodologia da validação do imunoensaio enzimático}

\subsubsection{Reagente}

Neste estudo, foi utilizado o reagente comercial da marca EMIT $^{\circledR}$ 2000Mycophenolic Acid Test (Dade Behring Marburg Gmbh, Marburg-Germany), os lotes utilizados para a validação da metodologia na Divisão de Laboratório Central da Faculdade de Medicina da Universidade de São Paulo (DLC-HCFMUSP) foram: reativo 6R919U/L-R2, controle 6R69UL e calibrador 6R929U/L.

O conjunto reagente contém: anticorpo monoclonal de ratos, para ácido micofenólico em matriz aquosa de albumina sérica bovina (BSA), dinucleotídeo de nicotinamida e adenina, agentes conservantes (azida sódica em concentração menor que $0,1 \%$ ) e enzima: ácido micofenólico ligado à glicose-6-fosfatodesidrogenase.

\subsubsection{Princípio do método}

O ensaio emprega uma técnica de imunoensaio enzimático homogênea, para análise do MPA total no plasma. Esta técnica baseia-se na competição pelo sítio de ligação do anticorpo anti-MPA. O MPA da amostra compete com o MPA marcado com a enzima glicose-6-fosfato desidrogenase (G6P-DH) do conjunto reagente. A enzima ativa não ligada converte o dinucleotideo de nicotinamida e adenina (NAD) 
para a sua forma reduzida (NADH), resultando numa alteração da cinética de absorção, a qual pode ser medida, espectrofotometricamente, no comprimento de onda de 340 ๆm. A atividade da enzima diminui após a ligação ao anticorpo, permitindo a medida da concentração de MPA na amostra. A concentração endógena de G6P-DH não interfere neste ensaio, pois a coenzima NAD funciona somente com a enzima bacteriana Leucomostoc mesenteroides empregada.

De acordo com o fabricante, o ensaio EMIT $^{\circledR} 2000$ permite determinar concentrações entre 0,5 e $15,0 \mu \mathrm{g} / \mathrm{mL}$ de MPA. O volume mínimo de plasma necessário para as dosagens é de $50 \mu \mathrm{L}$, requisito do equipamento para volume morto. Porém, são utilizados, na reação, $3 \mu \mathrm{L}$ da amostra e $155 \mu \mathrm{L}$ do reativo.

Este estudo não incluiu testes com interferentes, devido à ausência de padrões contendo estas substâncias endógenas ou drogas disponíveis, para a realização dos mesmos.

O ensaio foi realizado no analisador bioquímico automatizado Cobas Miraplus ${ }^{\circledR}$ da Roche Diagnostics System (Hoffmann La Roche Ltd, Basiléia, Suíça), com tempo previsto para início das dosagens de, aproximadamente, 15 minutos, e com a capacidade de dosar de 60-80 amostras por hora. A programação do equipamento foi realizada segundo as orientações do fabricante.

Os reativos, controles e calibradores ficaram armazenados em temperatura de $2^{\circ} \mathrm{C}$ a $8^{\circ} \mathrm{C}$, segundo as orientações do fabricante. 


\subsubsection{Calibração}

Na calibração, foram utilizados seis níveis de calibradores da marca EMIT $^{\circledR}$ 2000 (Dade Behring Marburg Gmbh, Marburg-Germany) para dosagem de ácido micofenólico com concentrações conhecidas (zero; 0,5;2,0;5,0;10,0 e 15,0 $\mu \mathrm{g} / \mathrm{mL}$ ) de ácido micofenólico em matriz BSA, agentes conservantes e azida sódica em concentração menor que $0,01 \%$.

\subsubsection{Validação do Ensaio EMIT® 2000-Mycophenolic Acid Test}

A calibração do equipamento foi realizada com os seis calibradores do conjunto reagente. Os calibradores foram colocados em ordem crescente na bandeja de calibradores, definida para o analito. A seguir, foram verificadas as leituras dos calibradores que deviam estar dentro dos limites de calibração. Quando algum calibrador não é aceito, o equipamento mostra uma mensagem de erro: out of range, sendo necessária a repetição da curva de calibração.

A calibração foi realizada antes das dosagens. A calibração é definida como o processo para testar um método analítico, com a finalidade de estabelecer uma relação entre a concentração conhecida de um analito (calibrador) e o valor medido na amostra. A calibração relaciona-se com a exatidão do método ${ }^{(63)}$.

A calibração foi realizada a cada mês e repetida quando os controles não responderam dentro da faixa de referência aceitável (média estipulada mais ou menos dois desvios-padrão), ou quando ocorreu a mudança de lote do conjunto reagente.

Os controles de ácido micofenólico com três concentrações conhecidas em matriz BSA foram dosados a cada corrida das dosagens, e os resultados avaliados em 
termos da média $\pm 2 \mathrm{DP}$. Foram adotados, para análise dos resultados do controle, as regras múltiplas de Westgard ${ }^{(90)}$.

$\mathrm{Na}$ dosagem foram pipetados $100-200 \mu \mathrm{L}$ da amostra em cubetas do equipamento. Os resultados em concentração são obtidos por comparação da leitura da absorbância da amostra com a leitura dos calibradores, na curva de calibração.

A validação do método seguiu os critérios estabelecidos pelo Clinical Laboratory Improvement Act (CLIA) ${ }^{(63)}$ e National Commitee on Cinical Laboratory Standard (NCCLS) ${ }^{(62)}$, atual Clinical Laboratory Standard Institute $(\mathrm{CLSI})^{(91)}$. Estes critérios são os mesmos adotados pela $\operatorname{ANVISA}^{(79)}$.

A precisão de um método é definida como a concordância entre resultados de replicatas das dosagens.

A precisão foi estudada utilizando-se os controles de qualidade presentes no conjunto reagente com concentrações de: $1,0 \mu \mathrm{g} / \mathrm{mL}$ (nível baixo), 7,5 $\mu \mathrm{g} / \mathrm{mL}$ (nível médio) e $12 \mu \mathrm{g} / \mathrm{mL}$ (nível alto). Estes controles são preparados em matriz sintética (BSA). Para evitar efeito de matriz diferente do plasma nos resultados, usamos, também, amostras de pacientes transplantados renais estáveis, para o estudo da precisão intraensaio e interensaio.

Em todos os testes de validação, foram calculadas: as médias, desvio-padrão e coeficiente de variação dos valores obtidos. A média e o desvio-padrão foram calculados com a ajuda de programa Excell versão 5.0 (Microsoft ${ }^{\circledR}$, Windows XP). O coeficiente de variação é obtido através da razão do desvio-padrão/média multiplicado por 100 .

Estudou-se a precisão intraensaio através da análise, no mesmo dia, de 30 replicatas dos três níveis de controle e 10 replicatas de uma amostra contendo 
concentração conhecida de MPA coletada de paciente transplantado renal estável. Foram realizadas duas corridas no mesmo dia, para minimizar erros devido à presença de interferentes (corrente elétrica e variação de temperatura).

A precisão interensaio foi determinada em 30 dias, sendo realizada a análise dos três níveis de controle em replicata, em duas corridas, a cada dia. Uma amostra contendo concentração conhecida de MPA foi dosada durante 10 dias consecutivos em duas corridas ao dia.

Os coeficientes de variação para os testes intra e interensaio foram considerados adequados quando resultou valor menor do que $15 \%{ }^{(79)}$ e quando o desvio-padrão (DP) de um par de resultados em duplicata, na mesma corrida analítica, não foi maior que $5,5 \%{ }^{(92,93)}$.

O limite de detecção foi determinado após a dosagem do branco do reativo em 20 replicatas. O coeficiente de variação adequado é de $20 \%$ entre as leituras, realizadas em replicata ${ }^{(79)}$.

A sensibilidade analítica foi avaliada através de diluições seriadas de uma mesma amostra (calibrador $0,5 \mu \mathrm{g} / \mathrm{mL}$ ) até a verificação do menor valor detectável pelo método, com coeficiente de variação entre as dosagens inferior a $15 \%{ }^{(79)}$.

A linearidade foi determinada através de diluição de amostra com valor conhecido de MPA $(30 \mu \mathrm{g} / \mathrm{mL})$, e as dosagens foram realizadas em dupicata. A linearidade do método, definida pelo fabricante, é de $15 \mu \mathrm{g} / \mathrm{mL}$. A diluição foi realizada com calibrador de valor zero até a verificação do maior valor detectável pelo método. O resultado obtido foi considerado adequado quando apresentou reprodutibilidade sem a necessidade de diluição, e o coeficiente de variação entre as leituras em duplicata foi inferior a $15 \%^{(79)}$. 
Um método é linear quando a recuperação de diluições seriadas é linearmente proporcional à concentração real da $\operatorname{amostra}^{(92)}$.

O intervalo analítico foi definido através do menor valor detectável (sensibilidade do método) e do valor máximo detectável (linearidade).

A estabilidade da amostra foi verificada em três amostras previamente dosadas e com valores conhecidos, estocadas em câmara-fria a $-20^{\circ} \mathrm{C}$. Foram realizadas as dosagens em 7, 30, 60 e 90 dias, e os resultados analisados em termos percentuais de perda em relação à concentração obtida no tempo zero. Este teste foi considerado aceitável quando a perda foi inferior a $10 \%$ do valor inicial.

Estudou-se a recuperação do método, adicionando um calibrador de valor conhecido a uma amostra sem MPA. Foram considerados valores de recuperação aceitáveis níveis de 80 a $120 \%$ de recuperação, em relação ao valor esperado ${ }^{(79)}$. Neste teste empregamos calibradores com concentrações de: 2,0; 5,0 e 10,0 $\mu \mathrm{g} / \mathrm{mL}$, os quais foram adicionados à amostra sem MPA.

Comparamos os dados de variância obtidos no estudo da precisão interensaio com os dados de variância interensaio descritos pelo fabricante e testamos a hipótese de que as duas variâncias são estatisticamente iguais. Comparamos a variância dos dois conjuntos de dados através do teste F, em que:

Teste $\mathrm{F}=(\text { maior desvio-padrão })^{2} /(\text { menor desvio-padrão })^{2}$

Quando as duas variâncias são iguais, o valor de F é igual a um. À medida que o resultado se torna maior que um, existe a possibilidade de que a diferença seja significativa. Para verificar qual valor de F pode ser aceito com a confiança de que a diferença não é significativa, utilizamos os valores críticos de $\mathrm{F}$, nível de significância de $5 \%$, ou seja, com $95 \%$ de certeza ${ }^{(62)}$. Para obter o valor crítico de F, consultamos a tabela para valores de $\mathrm{F}$ a $5 \%$. 
Foram, ainda, avaliadas vinte e nove amostras de plasma de voluntários sadios que participaram de um estudo de bioequivalência de micofenolato mofetil. Estas amostras foram utilizadas para comparação entre as metodologias LCMS/MS e EMIT. O estudo comparativo entre os resultados obtidos foi realizado através da correlação de Pearson, e pelo Erro de concordância avaliado pelo método de Bland-Altman, o qual correlaciona a média de dois métodos com a diferença entre eles ${ }^{(94)}$.

O equipamento utilizado para as dosagens por LC-MS/MS pela empresa Cromoanalysis Ltda. foi o API-2000, com turbo íon spray da marca Perkin-ElmerSciex ${ }^{\circledR}$, Concord, Canadá. A extração de MPA, nas amostras, foi realizada em meio ácido com hexano-éter. Neste equipamento, a ionização é realizada no modo negativo, para a fragmentação e a colisão utilizando-se nitrogênio puro e, ao final, encontram-se dois detectores de massa: massa/carga (m/z) 319,0 e m/z 191,1, gerando dois espectrocromatogramas. Os padrões foram preparados com MPA e metanol.

\subsubsection{Controle da Qualidade}

O controle da qualidade foi realizado em cada lote de dosagens das amostras, com os controles de qualidade do conjunto reagente. Estes controles contemplam três faixas analíticas: baixa, média e alta. Os resultados obtidos, necessariamente, deveriam estar no intervalo da média \pm 2 desvios-padrão estabelecidos pelo fabricante ${ }^{(90)}$. O controle da qualidade garantiu a precisão do processo durante todo o estudo. 
Ao final do experimento, foi calculado o coeficiente de variação entre todas as dosagens de controles.

Foi calculado o erro total (erro aleatório obtido através do $\mathrm{CV}(\%)+$ erro sistemático obtido através da diferença entre o valor esperado e o valor obtido em porcentagem). O erro máximo permitido para drogas ainda em estudo é de $\pm 25 \%{ }^{(63)}$.

Após a validação do método, efetuamos as dosagens das amostras de pacientes.

\subsection{Metodologia do estudo de bioequivalência entre duas formulações de MMF}

\subsubsection{Amostras de Pacientes}

Entre maio de 2003 e janeiro de 2005, foram coletadas as farmacocinéticas de 24 pacientes ambulatoriais transplantados renais adultos, os quais assinaram o termo de consentimento livre e esclarecido.

\section{Critérios de Inclusão}

- Receptor de primeiro transplante ou de retransplante, de doadores falecidos ou vivos, aparentado ou não, com idade entre 18 e 60 anos.

- Paciente recebendo a principal formulação de MMF, com dosagens estáveis nos últimos três meses, no decorrer dos quais, a dose não tenha sido modificada por no mínimo 30 dias. 
- Função renal estável nestes últimos três meses (creatinina sérica inferior a $2,0 \mathrm{mg} / \mathrm{dL})$

- Autorização para a participação no estudo através de assinatura do termo de consentimento livre e esclarecido.

- Teste de gravidez negativo para mulheres em idade fértil. As mulheres férteis utilizaram um método contraceptivo eficaz durante o estudo e durante as 6 semanas posteriores à descontinuação da medicação do estudo, mesmo quando existia antecedente pessoal de infertilidade.

\section{Critérios de Exclusão}

- Pacientes com transplante múltiplo de órgãos, ou transplante prévio de qualquer outro órgão diferente de rim.

- Pacientes com qualquer tipo de hipersensibilidade conhecida ao micofenolato mofetil ou componentes da fórmula farmacêutica.

- Pacientes HIV positivos.

- Pacientes com antecedentes de neoplasia nos últimos cinco anos.

- Pacientes com infecção clinicamente significativa.

- Pacientes com teste de gravidez positivo.

- Pacientes com hepatopatia caracterizada por elevação, de duas ou mais vezes, da atividade das enzimas hepáticas Aspartato transaminase (AST ou TGO) e Alanina transaminase (ALT ou TGP).

- Pacientes com trombocitopenia, contagem de plaquetas inferior a $75.000 / \mathrm{mm}^{3}$. 
- Pacientes com neutropenia (inferior a $1.500 / \mathrm{mm}^{3}$ ) e hemoglobina inferior a $6,0 \mathrm{~g} / \mathrm{dL}$ antes do recrutamento.

- Pacientes recebendo alguma outra droga em investigação.

- Evidência de uso contínuo de drogas ilegais ou alcoolismo.

\subsubsection{Drogas}

Utilizaram-se neste estudo: MMF-SA (Strides Arcolab Ltd, Bangalore, Índia), distribuído no Brasil pela Celofarm Ltd (Espirito Santo, Brasil), registrada como droga genérica de MMF sob licença número \#1.3764.0083.001-3, lotes TWI 3024 com validade até novembro de 2006, e TWI 2001 com validade até março de 2005; e CellCept ${ }^{\circledR}$ (Hoffman la Roche, Basiléia, Suíça) lote B 1100 com validade até setembro de 2005 .

Todos os pacientes envolvidos no estudo estavam em terapia com MMF CellCept ${ }^{\circledR}$ em uma mediana de 19 meses.

\subsubsection{Análise de amostras de pacientes transplantados renais estáveis}

As amostras com 2,0 mL de sangue dos pacientes foram obtidas através de uma veia do antebraço, a qual permaneceu puncionada durante todo o tempo da coleta. As amostras foram coletadas em frasco contendo anticoagulante As amostras foram coletadas em frasco contendo anticoagulante ácido etilenodiamino tetraacético (EDTA) da marca BD ${ }^{\circledR}$. 
Após a coleta de sangue, a amostra foi encaminhada à área analítica e centrifugada a $1258 \mathrm{~g}$ que corresponde 2500 rotações por minuto (rpm). O plasma foi separado das hemácias e transferido para um frasco de plástico previamente identificado com nome e tempo de coleta da curva farmacocinética. Estas amostras foram conservadas em temperatura de $-20^{\circ} \mathrm{C}$ até o momento da análise, por um período não superior a 15 dias.

\subsubsection{Comparação de Bioequivalência entre duas formulações de MMF}

Estudou-se a biodisponibilidade de uma nova formulação genérica de MMF (MMF-SA), comparada com formulção de referência CellCept ${ }^{\circledR}$.

O desenho de estudo foi do tipo cruzado, dose única, duas formulações, dois períodos e duas seqüências.

Neste estudo, os pacientes foram randomizados em dois grupos, os quais receberam uma ou outra droga $\left(\mathrm{MMF}-\mathrm{SA}\right.$ ou CellCept $\left.{ }^{\circledR}\right)$ para a primeira coleta de farmacocinética (PK1). Depois, houve a troca dos medicamentos para a segunda coleta de farmacocinética (PK2), com um período de descanso de uma semana entre as duas farmacocinéticas, em que os pacientes continuaram recebendo a medicação CellCept ${ }^{\circledR}$.

Os números para a randomização foram gerados por um programa estatístico (Sigma Stat, versão 2.0, Jandel Scientific, San Rafael, CA, USA), e envelopes fechados contendo o nome da formulação para a primeira farmacocinética (PK1) ou para a segunda farmacocinética (PK2) foram sendo gerados aleatoriamente. 
Depois de assinar o termo de consentimento livre e esclarecido e da evolução das linhas de base, os pacientes receberam o primeiro envelope da seqüência disponível.

Uma amostra de cada formulação foi armazenada na Clínica de Transplante Renal, para futura análise, se requerida.

A dose que o paciente vinha recebendo foi mantida para as farmacocinéticas com ambas as formulações de MMF.

No dia prévio à farmacocinética, os pacientes foram orientados a tomar sua dose noturna exatamente às 20 horas. No dia seguinte, foram admitidos no hospital para a coleta da farmacocinética. Às 8 horas, os pacientes receberam a dose da formulação para a qual foram aleatorizados para a primeira farmacocinética PK1, juntamente com leite. Um desjejum foi oferecido 2 horas após a primeira coleta, de cada farmacocinética.

O sangue foi coletado nos intervalos de tempo $0,1,2,3,4,6,8,10$ e 12 horas, após a dose oral matinal, designadas de $\mathrm{C} 0, \mathrm{C} 1, \mathrm{C} 2, \mathrm{C} 3, \mathrm{C} 4, \mathrm{C} 6, \mathrm{C} 8, \mathrm{C} 10$ e $\mathrm{C} 12$, respectivamente. Concentração mínima (Cmin) e concentração máxima (Cmax) foram definidas como os níveis plasmáticos: máximo e mínimo (C12 para este estudo) de MPA. O tempo para atingir a máxima concentração foi definido como Tmax.

Os comprimidos de Cellcept ${ }^{\circledR}$ foram obtidos através da farmácia do hospital. MMF-SA (Strides-Arcolab) foi entregue aos investigadores pela distribuidora no Brasil.

\subsubsection{Análise dos resultados Farmacocinéticos}

Foram determinados: tempo para obtenção da concentração máxima (Tmax), a concentração máxima (Cmax), a concentração mínima (Cmin ou C12). A área sob 
a curva concentração-tempo foi calculada pelo método trapezoidal. Os cálculos da $\mathrm{AUC}_{0-12 \mathrm{~h}}$ foram realizados com a ajuda do programa estatístico Sigma STAT 2.03 (Jandel Scientific, San Rafael, CA, USA).

Os parâmetros farmacocinéticos que caracterizam a velocidade e extensão da absorção da droga foram analisados estatisticamente. Os parâmetros farmacocinéticos de interesse são: $\mathrm{AUC}_{0-12 \mathrm{~h}}$ e Cmax.

O teste Anderson-Darling foi aplicado para verificar se os dados tinham uma distribuição normal. Como este critério foi preenchido, seguiu-se para a próxima etapa estatística, em que os dados obtidos para as duas formulações foram comparados, usando-se a análise de variância (ANOVA). Foram calculadas e comparadas as médias \pm erro-padrão (SE), para cada momento de aferição das duas farmacocinéticas.

Para todas as análises, foram considerados os efeitos de interação, para avaliar o esquema cruzado (período, seqüência de administração das drogas), para Cmax, Tmax e $\mathrm{AUC}_{0-12 \mathrm{~h}}$

O intervalo de confiança de $90 \%$ da razão entre as médias da droga teste/referência deve encontrar-se inteiramente dentro do intervalo de bioequivalência para os parâmetros $\left(\mathrm{Cmax}\right.$ e $\left.\mathrm{AUC}_{0-12 \mathrm{~h}}\right)$, para que duas formulações possam ser consideradas como bioequivalentes ${ }^{(80)}$. A diferença entre as duas formulações deve ser inferior a $20 \%$, ou seja, $80 \%<$ IC $90 \%\left(\mu_{\mathrm{t}} / \mu_{\mathrm{r}}\right)<125 \%$ este intervalo é conhecido como intervalo de bioequivalência; em que $\mu_{\mathrm{r}}$ é a média populacional da droga de referência e $\mu_{\mathrm{t}}$ é a média populacional da droga em teste.

O intervalo de confiança $90 \%$ para $\mathrm{AUC}_{0-12 \mathrm{~h}}$ e Cmax foi calculado através do teste $t$ de Student bicaudal, para a razão entre as médias geométricas das duas formulações, utilizando-se os resultados transformados em logarítimos ${ }^{(95)}$. 
Foram ainda realizados testes $t$ de Student ${ }^{(96)}$, para verificar se AUC, entre quem recebeu ciclosporina ou tacrolimus, variava de acordo com a formulação de MMF administrada. E para verificar se a meia-vida e a constante de eliminação eram variáveis de acordo com a formulação administrada.

Os testes foram realizados ao nível de 5\%. O pacote estatístico utilizado foi o SAS 8.0 (Statistical Analytical System - SAS Institute Inc, Cary, NC).

\subsection{Aspectos éticos e análise de riscos}

Este estudo foi aprovado pela CAP/PESQ número 157/04. Os dados obtidos para o estudo clínico randomizado cruzado fazem parte de um projeto previamente aprovado pela CAP/PESQ com número 933/02. Anexos A e B.

A administração de ácido micofenólico via oral e as coleta de sangue foram realizadas na Unidade de Transplante Renal do HCFMUSP pela equipe de pesquisa clínica.

As amostras coletadas foram enviadas à Divisão de Laboratório Central do Hospital das Clínicas da Universidade de São Paulo (DLC-HCFMUSP), Serviço de Bioquímica Clínica, onde foram realizadas as análises dos níveis plasmáticos de MPA.

Os dados das análises foram gerados com os recursos e com a infra-estrutura já existente na DLC e na Unidade de Transplante Renal do HCFMUSP.

Os dados obtidos estão arquivados na Unidade de Transplante Renal, no setor de pesquisa clínica do HCFMUSP. O material biológico permanece armazenado no Serviço de Bioquímica da DLC-HCFMUSP, a temperatura de $-20^{\circ} \mathrm{C}$. 
4. RESULTADOS 


\subsection{Calibração}

A calibração foi realizada antes dos testes de validação e dos estudos de farmacocinética. A sua validade foi avaliada de acordo com a resposta dos controles, inclinação da curva, e desvios obtidos em relação às curvas anteriores. As calibrações durante todo o estudo, apresentaram as mesmas características em termos de inclinação.

A curva de calibração é traçada entre as leituras do menor e maior calibrador, em termos de concentração (Figura 1).

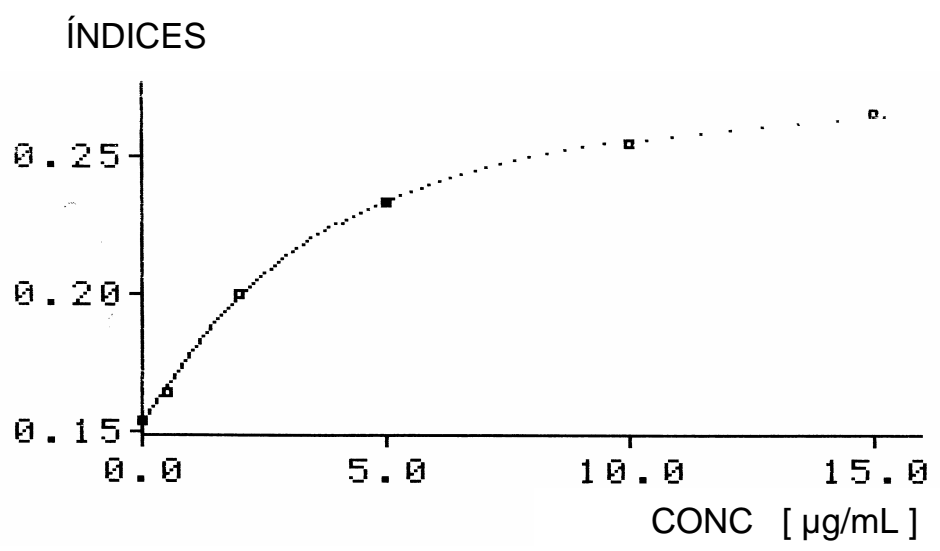

Figura 1 - Representação Gráfica da curva de calibração.

Os desvios obtidos entre as leituras dos calibradores e o valor esperado foram menores que $5 \%(0,2 \%-3,45 \%)$. 


\subsection{Validação do método EMIT}

\subsubsection{Precisão intraensaio e interensaio}

A tabela 1 descreve a precisão intra e interensaio do método EMIT. O coeficiente de variação intraensaio variou de $2,14 \%$ a $5,09 \%$, e o interensaio de $4,18 \%$ a $5,02 \%$.

Tabela 1. Resultados obtidos para precisão intraensaio e interensaio (CV\%)

\begin{tabular}{|c|c|c|c|c|c|c|c|}
\hline \multirow[b]{2}{*}{$\begin{array}{l}\text { Controles } \\
(\mathbf{n}=\mathbf{3 0})\end{array}$} & \multirow[b]{2}{*}{$\begin{array}{c}\text { Concentração } \\
(\mu \mathrm{g} / \mathrm{mL})\end{array}$} & \multicolumn{3}{|c|}{ Intraensaio } & \multicolumn{3}{|c|}{ Interensaio } \\
\hline & & $\begin{array}{c}\text { Média } \\
(\mu \mathrm{g} / \mathrm{mL})\end{array}$ & DP & $\begin{array}{l}\text { CV } \\
(\%)\end{array}$ & $\begin{array}{c}\text { Média } \\
(\mu \mathrm{g} / \mathrm{mL})\end{array}$ & DP & $\begin{array}{l}\text { CV } \\
(\%)\end{array}$ \\
\hline Controle baixo & 1,0 & 1,06 & 0,08 & 4,19 & 1,12 & 0,11 & 5,00 \\
\hline Controle médio & 7,5 & 8,05 & 0,72 & 3,62 & 8,11 & 0,85 & 4,64 \\
\hline Controle alto & 12,0 & 13,75 & 0,92 & 2,14 & 12,99 & 1,40 & 5,02 \\
\hline Plasma $(n=10)$ & 3,15 & 3,05 & 0,15 & 5,09 & 2,99 & 0,22 & 4,18 \\
\hline
\end{tabular}

$\mathrm{DP}=$ desvio-padrão; $\mathrm{CV}(\%)$ = coeficiente de variação para três níveis diferentes de controle e para plasma contendo ácido micofenólico (MPA).

O método apresenta boa precisão intra e interensaio, com CV abaixo de $15 \%$ para todos os níveis de controles e para a amostra de plasma. 


\subsubsection{Linearidade, Limite de deteç̧ão e Sensibilidade analítica}

A tabela 2 apresenta os dados dos testes de linearidade, sensibilidade analítica e limite de detecção.

O método EMIT apresentou-se como linear até o valor de $14,575 \mu \mathrm{g} / \mathrm{mL}$, próximo ao valor mais alto da curva de calibração $(15 \mu \mathrm{g} / \mathrm{mL})$. Do mesmo modo, mostrou ser sensível para valores iguais ou superiores a $0,02 \mu \mathrm{g} / \mathrm{mL}$. O limite de detecção foi de 0,01 para leitura do branco do reagente.

Tabela 2. Limite de detecção, sensibilidade analítica e linearidade

\begin{tabular}{lccc}
\hline $\mathbf{( n = 2 0 )}$ & Média $(\boldsymbol{\mu g} / \mathbf{m L})$ & DP & CV (\%) \\
\hline Limite de detecção & 0,01 & 0,0015 & 15,00 \\
Sensibilidade Analítica & 0,02 & 0,0016 & 7,90 \\
Linearidade & 14,58 & 0,3300 & 2,24 \\
\hline
\end{tabular}

DP = Devio-padrão da média, $\mathrm{CV}(\%)=$ coeficiente de variação

\subsubsection{Estabilidade do analito MPA na amostra matriz}

Os resultados de estabilidade de três amostras aleatórias com concentração de $3,2 \mu \mathrm{g} / \mathrm{mL}, 8,5 \mu \mathrm{g} / \mathrm{mL}$, e $13,3 \mu \mathrm{g} / \mathrm{mL}$, testadas após conservação em câmara-fria $\left(-20^{\circ} \mathrm{C}\right)$, sem nenhum tipo de conservante, estão descritos na tabela 3. Observou-se que a perda foi maior em amostras com valores mais baixos, e que a menor porcentagem de perda ocorre em até 30 dias. Após este prazo, as perdas em amostras de baixa concentração podem estar próximas de $10 \%$. 
Tabela 3. Estabilidade da amostra (porcentagem de perda ao longo do tempo)

\begin{tabular}{ccccc}
\hline $\begin{array}{c}\text { Valor esperado } \\
(\boldsymbol{\mu g} / \mathbf{m L})\end{array}$ & $\mathbf{7}$ dias & $\mathbf{3 0}$ dias & $\mathbf{6 0}$ dias & $\mathbf{9 0}$ dias \\
\hline 3,2 & $6,2 \%$ & $6,2 \%$ & $9,4 \%$ & $9,8 \%$ \\
8,5 & $1,0 \%$ & $2,2 \%$ & $5,9 \%$ & $9,3 \%$ \\
13,3 & $1,6 \%$ & $1,1 \%$ & $1,5 \%$ & $7,8 \%$ \\
\hline
\end{tabular}

As análises foram efetuadas em duplicata e o desvio-padrão entre as duplicatas foi inferior a 5,0\%.

\subsubsection{Recuperação}

A tabela 4 mostra os valores esperados, obtidos, e a porcentagem de recuperação para três níveis de controles, quando adicionados a uma amostra de plasma sem MPA. Todos os valores estão compreendidos entre $80 \%$ e $120 \%$.

Tabela 4. Teste de recuperação por adição de concentração conhecida de padrão em amostra de plasma sem MPA

\begin{tabular}{cccc}
\hline $\begin{array}{c}\text { Adição de MPA } \\
(\mu \mathrm{g} / \mathrm{mL})\end{array}$ & $\begin{array}{c}\text { MPA obtido } \\
(\mu \mathrm{g} / \mathrm{mL})\end{array}$ & Recuperação & $\begin{array}{c}\text { CV } \\
(\mathbf{n}=\mathbf{1 0})\end{array}$ \\
\hline 10.0 & 9,78 & $97,8 \%$ & $4,5 \%$ \\
5.0 & 5,18 & $103,6 \%$ & $8,63 \%$ \\
2,0 & 2,24 & $111,3 \%$ & $5,72 \%$ \\
\hline
\end{tabular}


A tabela 5 compara os valores das variâncias obtidos em nosso estudo com os obtidos pelo fabricante

Tabela 5. Comparação entre as variâncias obtidas nos testes de interensaio realizados na DLC, quando comparados aos do fabricante.

\begin{tabular}{lcccc}
\hline & $\begin{array}{c}\text { Valores Obtidos } \\
\mathbf{n = 6 0}\end{array}$ & $\begin{array}{c}\text { Valores do Fabricante } \\
\mathbf{n = 2 4 0}\end{array}$ & F calculado & F crítico \\
\hline Controle baixo & 0,0030 & 0,0031 & 1,01 & 1,32 \\
Controle médio & 0,1410 & 0,1230 & 1,15 & 1,32 \\
Controle alto & 0,4260 & 0,4190 & 1,01 & 1,32 \\
\hline
\end{tabular}

$\mathrm{O}$ valor calculado para $\mathrm{F}$ não é maior que o valor crítico, para todos os níveis de controle, indicando que os resultados não são estatisticamente diferentes, e que a diferença entre as duas variâncias ocorreu apenas por variação aleatória devido ao erro amostral.

\subsubsection{Comparação de metodologia EMIT com LC-MS/MS}

As Figuras 2 e 3 mostram a comparação das metodologias EMIT e a cromatografia líquida acoplada à espectrofotometria de massa (LC-MS/MS), para a dosagem de MPA plasmático em 29 amostras.

As médias $\pm \mathrm{SD}$ não foram estatisticamente diferentes $(6,09 \pm 7,766 \mu \mathrm{g} / \mathrm{mL}$ vs $6,31 \pm 7,771 \mu \mathrm{g} / \mathrm{mL}, \mathrm{p}=\mathrm{NS})$, respectivamente, para LC-MS/MS e EMIT. Houve uma forte correlação entre as metodologias $\left(r^{2}=0.961\right)$, onde LC-MS/MS $=-0,0984+(0,981$ x EMIT). Os dados são apresentados no anexo C.

A metodologia LC-MS/MS tem precisão intraensaio de $4,96 \%-8,38 \%$ e precisão interensaio de $1,17 \%-6,89 \%$, caracterizadas pelo coeficiente de variação. Estes dados foram fornecidos pela empresa que realizou as análises por LC-MS/MS. 


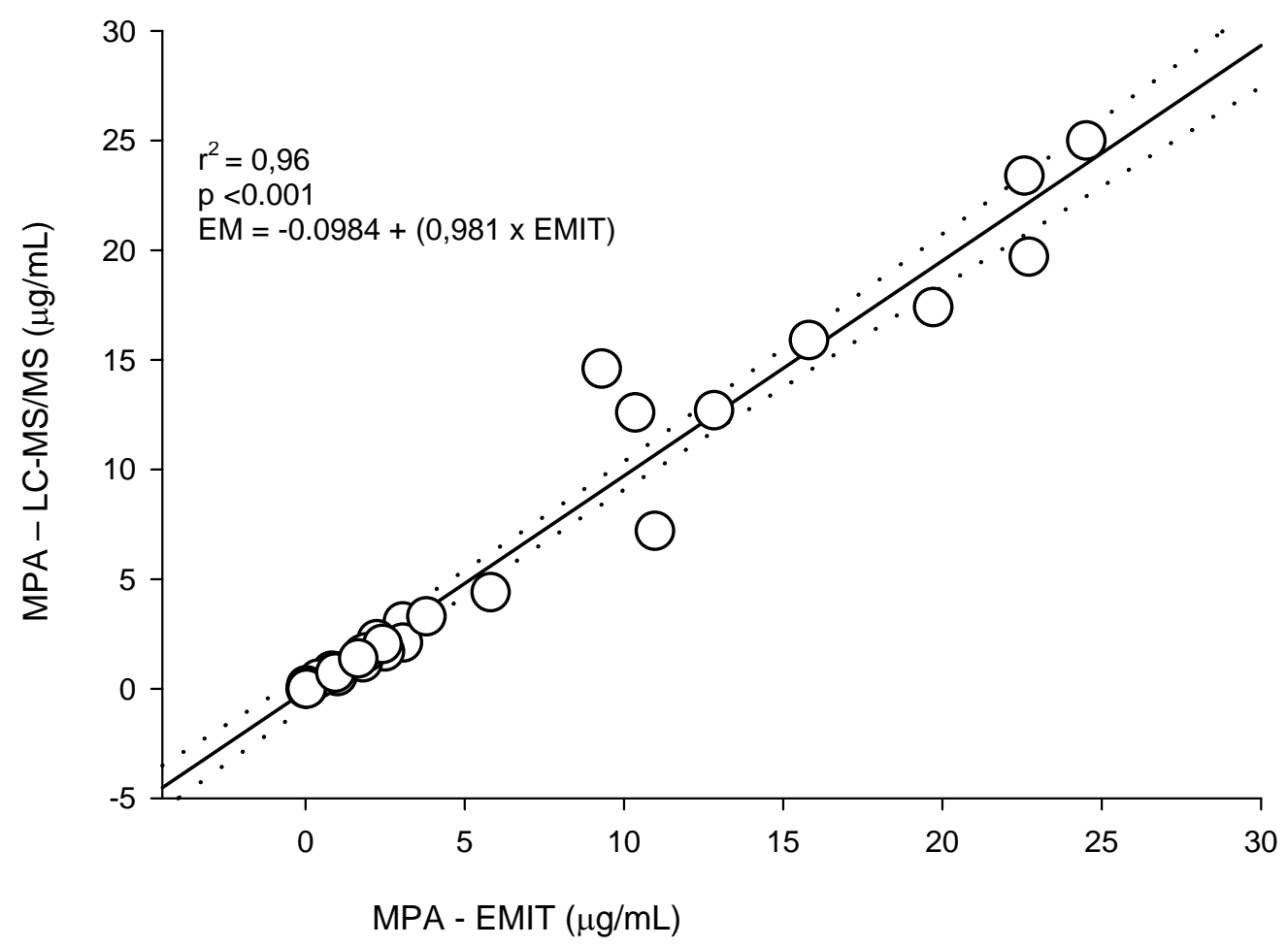

Figura 2. Correlação entre dosagens de MPA pelo método EMIT e LC-MS/MS. Linhas pontilhadas representam o intervalo de confiança $95 \%$.

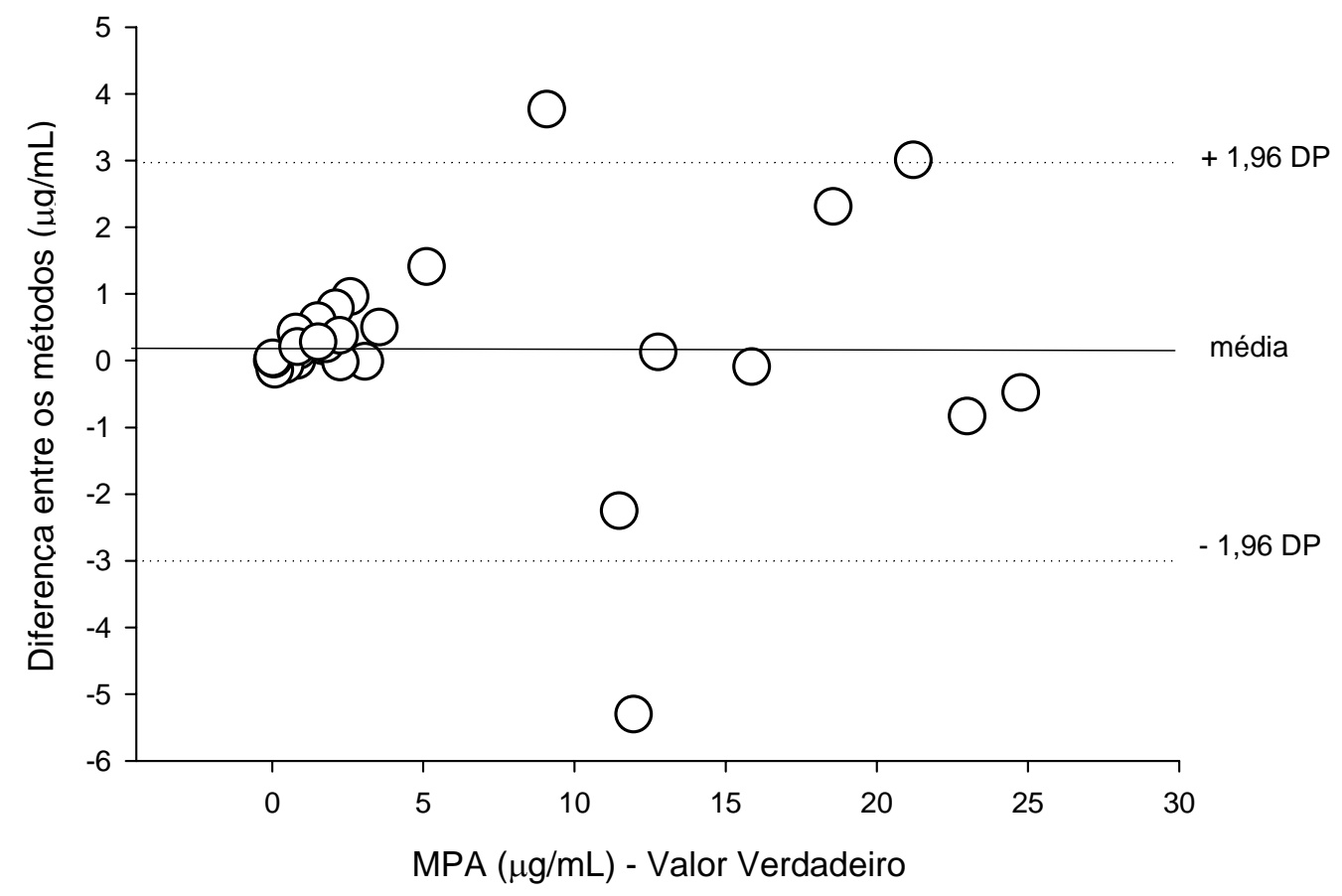

Figura 3. Erro de concordância estimado por Bland-Altman ${ }^{(94)}$ 


\subsubsection{Controle da Qualidade}

Em cada corrida para dosagem de MPA, foram dosados os controles de qualidade, presentes no conjunto reagente. Estes dados estão resumidos na tabela 6 e nas figuras 4a, 4b e 4c, as quais representam a dispersão em torno da média para os três níveis de controle. Os resultados demonstraram que os valores obtidos encontram-se dentro do intervalo da média \pm 2DP.

Tabela 6. Dados de controle de qualidade obtidos durante o período das dosagens

\begin{tabular}{lcccc}
\hline & $\begin{array}{c}\text { Valor esperado } \\
(\boldsymbol{\mu g} / \mathbf{m L})\end{array}$ & $\begin{array}{c}\text { Média } \\
(\boldsymbol{\mu g} / \mathbf{m L})\end{array}$ & DP & CV (\%) \\
\hline Controle baixo & 1,0 & 1,02 & 0,06 & 5,39 \\
Controle médio & 7,5 & 7,85 & 0,41 & 5,22 \\
Controle alto & 12,0 & 12,6 & 0,59 & 4,84 \\
\hline
\end{tabular}

$\mathrm{DP}=$ desvio padrão $\mathrm{CV}=$ Coeficiente de variação em $\%$

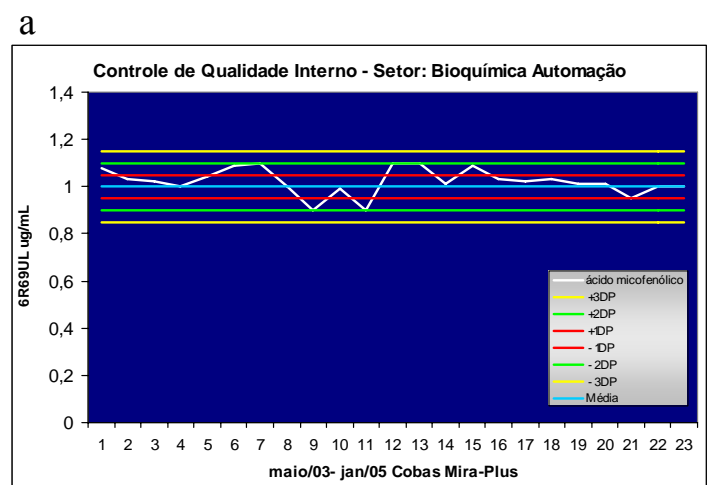

$\mathrm{b}$

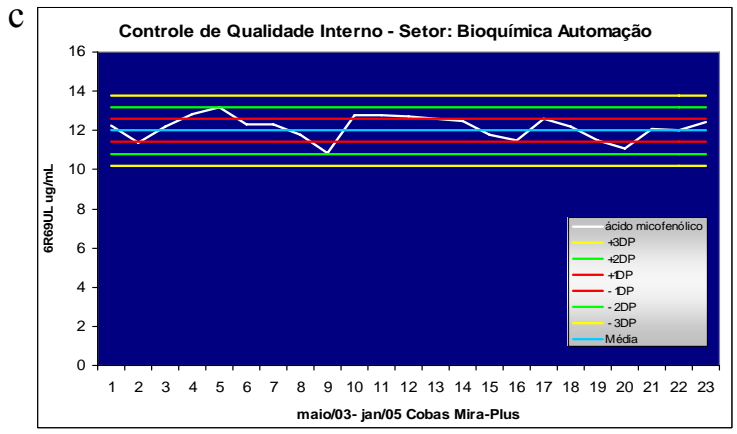

Figuras 4a, 4b e 4c. Representação gráfica da dispersão dos valores do Controle de Qualidade. 
A tabela 7 descreve o erro total obtido para cada nível de controle ao longo do período de estudo.

Tabela 7. Erro total, em porcentagem, para o teste EMIT durante o período das dosagens

\begin{tabular}{lcccc}
\hline & $\begin{array}{c}\text { Valor esperado } \\
(\boldsymbol{\mu} \mathbf{g} / \mathbf{m L})\end{array}$ & $\begin{array}{c}\text { Média } \\
(\boldsymbol{\mu g} / \mathbf{m L})\end{array}$ & $\begin{array}{c}\text { Erro sistemático } \\
\mathbf{( \% )}\end{array}$ & $\begin{array}{c}\text { Erro total } \\
(\mathbf{\%})\end{array}$ \\
\hline Controle baixo & 1,0 & 1,02 & 2 & 10,89 \\
Controle médio & 7,5 & 7,85 & 5 & 13,61 \\
Controle alto & 12,0 & 12,6 & 5 & 12,99 \\
\hline
\end{tabular}

\subsection{Análise da Biodisponibilidade de duas formulações diferentes de MMF}

\subsubsection{Dados Demográficos}

A população de 24 pacientes era composta por 15 homens e 9 mulheres, com idade média de $42 \pm 14$ anos (19-67 anos), peso corporal de 64,1 $\pm 11,8 \mathrm{~kg}$; dezesseis pacientes eram brancos e oito não-brancos; 20 pacientes receberam o primeiro transplante e 4 haviam recebido o segundo transplante. Em relação aos órgãos doados, estes eram provenientes de 17 indivíduos falecidos e de sete doadores vivos (um vivo não relacionado). $\mathrm{Na}$ ocasião da realização da primeira coleta de farmacocinética, a mediana do intervalo de tempo, após o transplante foi de 19 meses (6- 291 meses). 


\subsubsection{Drogas}

Os 24 pacientes envolvidos no estudo utilizavam MMF (CellCept $\left.{ }^{\circledR}\right)$, via oral, a cada 12 horas, com dose de 25,13 $\pm 5,84 \mathrm{mg} / \mathrm{k} /$ dia. Sete pacientes recebiam ciclosporina (Neoral ${ }^{\circledR}-$ Novartis Pharmaceutical, Basiléia, Suíça) 2,85 \pm 0,68mg/k/dia; 14 recebiam tacrolimus (Prograf ${ }^{\circledR}-$ Fujisawa, Japão) 0,09 \pm $0,05 \mathrm{mg} / \mathrm{Kg} /$ dia e 24 recebiam prednisona $0,12 \pm 0.05 \mathrm{mg} / \mathrm{Kg} /$ dia. Três pacientes não recebiam inibidores de calcineurina.

A função renal era estável, com creatinina sérica de $1,5 \pm 0,4 \mathrm{mg} / \mathrm{dL}$ e depuração de creatinina, avaliado pela equação de Cockcroft-Gault, de $54 \pm$ $17 \mathrm{~mL} / \mathrm{min} / 1,73 \mathrm{~m}^{2}$.

Os dados da linha de base dos pacientes no início dos estudos estão descritos na tabela 8 e no anexo D. 
Tabela 8. Dados demográficos e clínicos dos pacientes que se submeteram ao estudo farmacocinético com as duas formulações de MMF

\begin{tabular}{lcc}
\hline Dados demográficos e outras características & & \\
\hline Homens & 15 & - \\
Mulheres & 9 & \pm 14 \\
*Idade (anos) & 42 & $6-291$ \\
Tempo pós-transplante mediana (em meses) & 19 & $\pm 11,8$ \\
*Peso (kg) & 64,1 & \\
Etnia & & - \\
$\quad$ Brancos & 16 & - \\
$\quad$ Não brancos & 7 & $\pm 0,4$ \\
*Creatinina Sérica (mg/dL) & 1,5 & \pm 17 \\
*Depuração de Creatinina (mL/min/1,73m ${ }^{2}$ ** & 54 & $\pm 5,84$ \\
*MMF (mg/k/dia) & 25,13 & $\pm 0,68$ \\
*Ciclosporina/ co-administração (n=7) mg/k/dia & 2,85 & $\pm 0,05$ \\
*Tacrolimus/ co-administração $(\mathrm{n}=14) \mathrm{mg} / \mathrm{k} / \mathrm{dia}$ & 0,09 & $\pm 0,05$ \\
*Prednisona/ co-administração $(\mathrm{n}=24) \mathrm{mg} / \mathrm{k} / \mathrm{dia}$ & 0,12 & \\
\hline
\end{tabular}

*Dados representam média \pm desvio-padrão

**estimado pela equação de Cockcroft e Gault

\subsubsection{Análise farmacocinética das duas formulações}

A tabela 9 e a Figura 5 mostram as concentrações plasmáticas (médias $\pm \mathrm{SE}$ ) dos parâmetros farmacocinéticos para as duas formulações em estudo, assim como a razão entre as médias das concentrações obtidas. Não houve diferença estatisticamente significativa entre os valores de C0, C1, C2, C3, C4, C6, C8 e C12. A maior diferença encontrada foi na concentração da $10^{\mathrm{a}}$ hora $(p=0,234$ e razão das médias MMF$\mathrm{SA} /$ CellCept $\left.^{\circledR}=0,74\right)$, não sendo estatisticamente significativa. A Figura 5 mostra que os valores médios obtidos, para as duas formulações, sobrepõem-se uns aos outros. 
Tabela 9. Média, erro padrão e razão das concentrações plasmáticas e parâmetros farmacocinéticos para as duas formulações em estudo

\begin{tabular}{|c|c|c|c|c|c|}
\hline \multirow{2}{*}{$\begin{array}{c}\text { Tempo (horas) } \\
\text { C0 }\end{array}$} & \multicolumn{2}{|c|}{$\begin{array}{c}\text { CellCept }^{\circledR} \\
\text { Média SE }(\mu \mathrm{g} / \mathrm{mL})\end{array}$} & \multicolumn{2}{|c|}{$\begin{array}{c}\text { MMF-SA } \\
\text { Média SE }(\mu \mathrm{g} / \mathrm{mL})\end{array}$} & \multirow{2}{*}{$\begin{array}{c}\begin{array}{c}\text { Médias MMF- } \\
\text { SA/CellCept }\end{array}{ }^{\circledR} \\
1,17\end{array}$} \\
\hline & 2,59 & 0,32 & 3,04 & 0,37 & \\
\hline $\mathrm{C} 1$ & 11,17 & 1,37 & 10,40 & 1,17 & 0,93 \\
\hline $\mathrm{C} 2$ & 6,04 & 0,79 & 6,80 & 0,81 & 1,12 \\
\hline $\mathrm{C} 3$ & 4,29 & 0,54 & 4,97 & 0,63 & 1,15 \\
\hline $\mathrm{C} 4$ & 3,41 & 0,31 & 3,60 & 0,51 & 1,06 \\
\hline C6 & 3,07 & 0,38 & 2,74 & 0,27 & 0,89 \\
\hline $\mathrm{C} 8$ & 2,61 & 0,27 & 2,57 & 0,37 & 0,98 \\
\hline $\mathrm{C} 10$ & 3,58 & 0,59 & 2,65 & 0,37 & 0,74 \\
\hline $\mathrm{C} 12$ & 2,67 & 0,35 & 2,60 & 0,37 & 0,97 \\
\hline Tmax (horas) & 1,42 & 0,21 & 1,29 & 0,17 & 0,91 \\
\hline $\mathrm{Cmax}(\mu \mathrm{g} / \mathrm{mL})$ & 11,29 & 1,35 & 11,05 & 1,08 & 0,98 \\
\hline $\operatorname{AUC}_{0-12 \mathrm{~h}}(\mu \mathrm{g} \cdot \mathrm{h} / \mathrm{mL})$ & 49,11 & 5,15 & 47,59 & 3,99 & 0,97 \\
\hline
\end{tabular}

$\mathrm{C} 0, \mathrm{C} 1, \mathrm{C} 2, \mathrm{C} 3, \mathrm{C} 4, \mathrm{C} 6, \mathrm{C} 8, \mathrm{C} 10, \mathrm{C} 12$ representam as concentrações médias obtidas para as duas formulações de MMF e o erro-padrão, para cada momento da coleta nos intervalos de tempo $0,1,2,3,4,6,8,10$ e 12 horas. Cmax é a média da concentração máxima obtida, e $\mathrm{AUC}_{0-12 \mathrm{~h}}$ é a média da área total sob a curva de concentração-tempo para cada uma das formulações de MMF.

As diferenças entre as médias das duas formulações, para $\mathrm{Cmax}$ e $\mathrm{AUC}_{0-12 \mathrm{~h}}$ não foram estatisticamente significativas, $\operatorname{Cmax}(p=0,74)$ e $\operatorname{AUC}_{0-12 \mathrm{~h}}(p=0,54)$. 


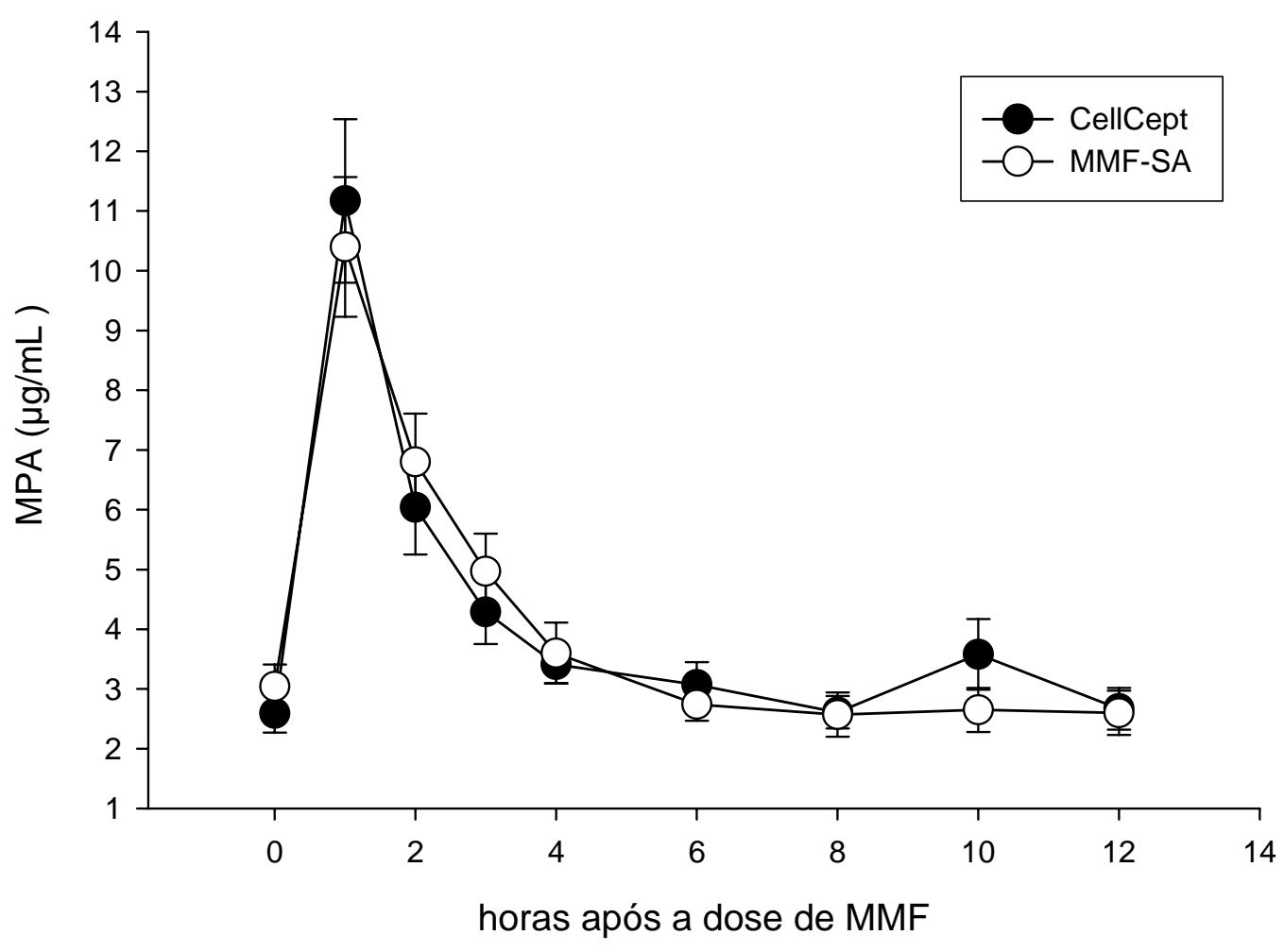

Figura 5- Médias \pm SE de todos os pacientes que participaram do estudo $(n=24)$, obtidas para as duas formulações em estudo de MMF

As figuras 6 e 7 demonstram o perfil farmacocinético dos 24 pacientes do estudo, representados através das curvas concentração-tempo, para as duas formulações de MMF. 


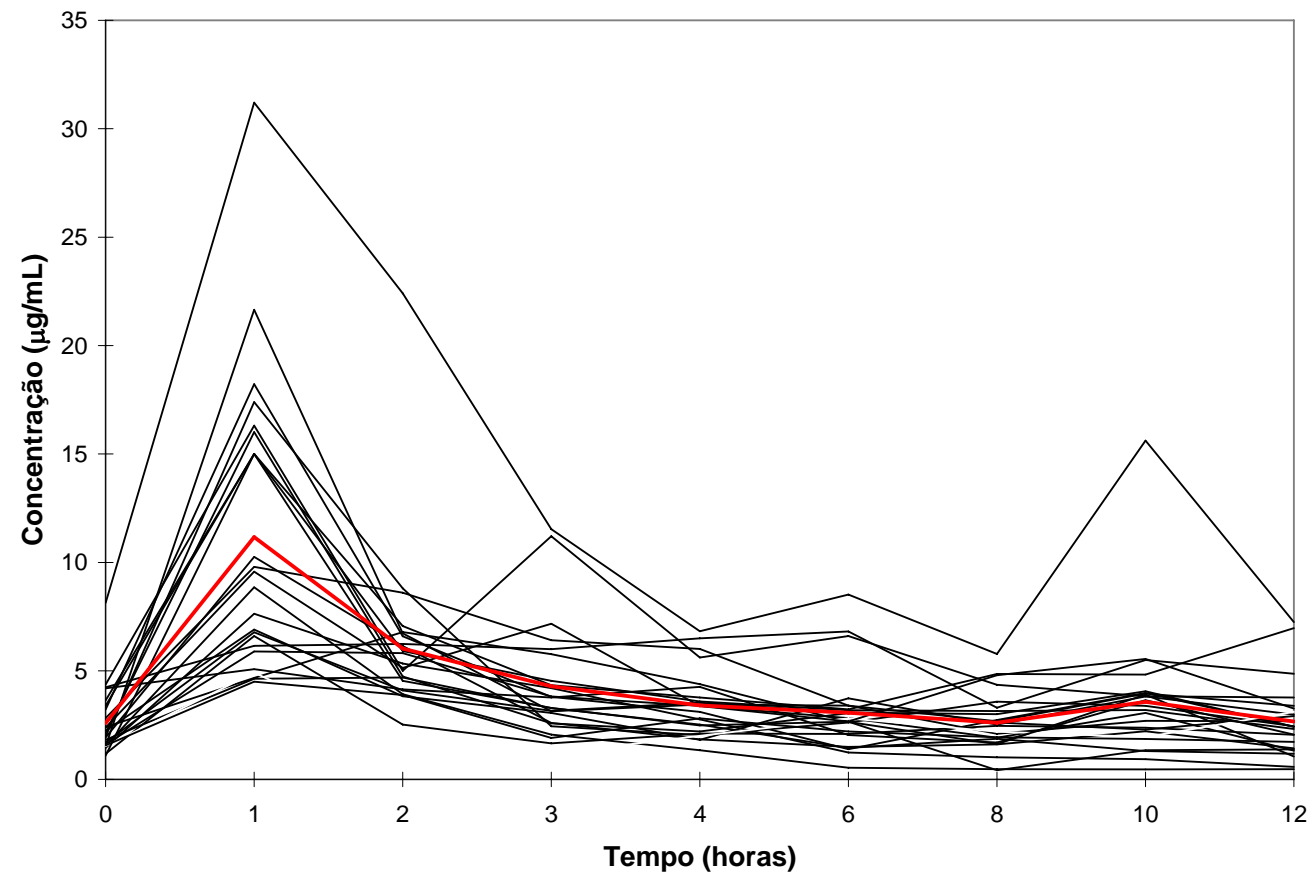

Figura 6 - Representação gráfica do perfil farmacocinético CellCept ${ }^{\circledR}(n=24)$

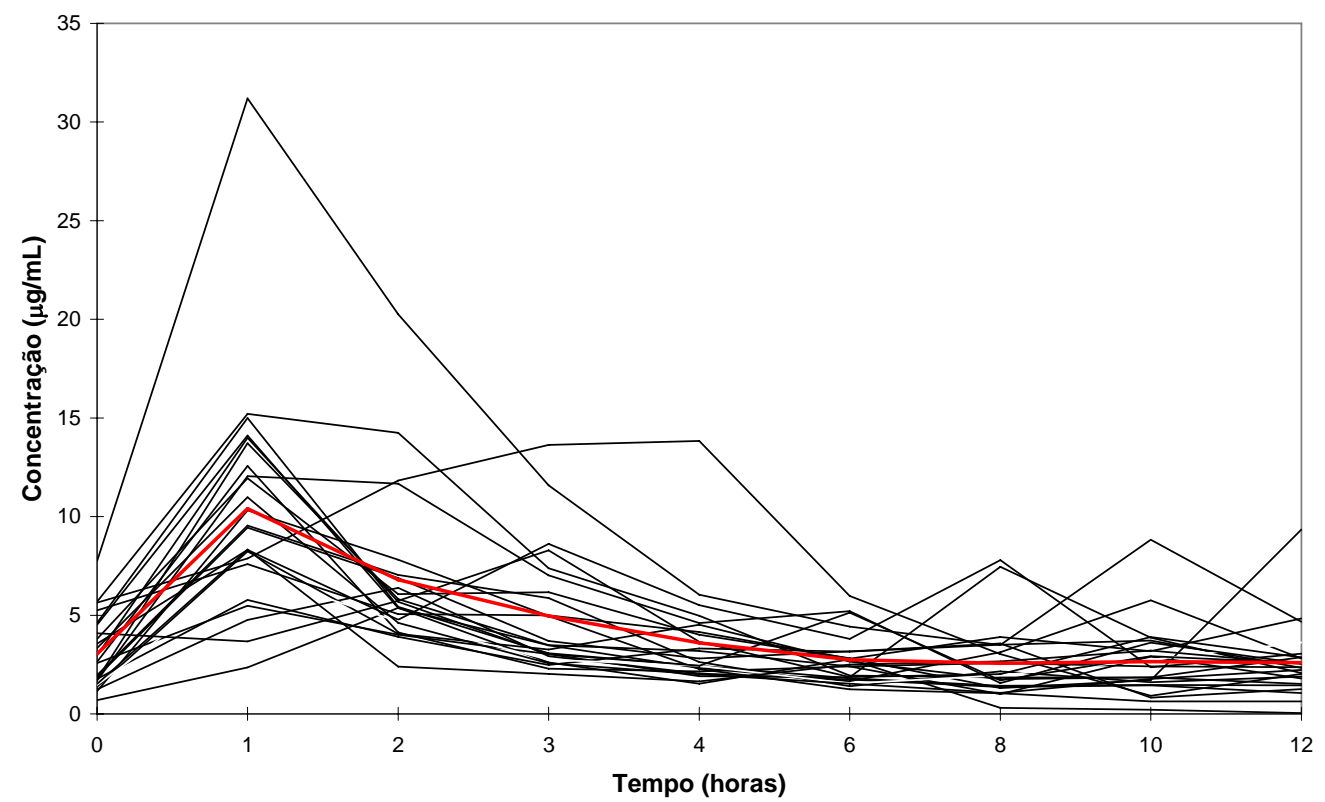

Figura7 - Representação gráfica do perfil farmacocinético de MMF-SA (n=24)

Observamos que um paciente apresentou um segundo pico mais intenso, com CellCept ${ }^{\circledR}$ na décima hora após a dose. 
Sete pacientes $(29,2 \%)$ apresentaram MPA-AUC abaixo da janela terapêutica com a formulação de referência e sete com a formulação genérica. Enquanto três pacientes apresentaram resultados de MPA-AUC acima desta faixa com a formulação referência $(12,5 \%)$ e cinco com a formulação genérica $(20,8 \%)$. Dois pacientes $(8,3 \%)$ apresentaram Cmax, com a formulação genérica, aproximadamente 50\% acima do valor obtido com a formulação de referência, mas a diferença entre as AUC foi de 11,5\% .

Definimos, para segundo pico, qualquer elevação acima de 1,96 vezes a variação interensaio, que foi 5\%. Em 2005, Cattaneo et al. ${ }^{(30)}$ sugeriram, para segundo pico, a MPA-AUC ${ }_{4-12 \mathrm{~h}}$. Vinte e um pacientes apresentaram um segundo pico durante a farmacocinética do CellCept ${ }^{(\mathbb{R}}$ e outros vinte e um durante a farmacocinética com MMF-SA. Três pacientes tiveram um segundo pico durante a administração do CellCept $^{\circledR}$, mas não com MMF-SA. Três outros tiveram um segundo pico com MMF-SA, mas não com CellCept ${ }^{\circledR}$. O tempo médio para o segundo pico foi comparável para as duas formulações $8,4 \pm 2,9$ horas (MMF-SA), e 6,8 $\pm 2,8$ horas $\left(\right.$ CellCept $\left.^{\circledR}\right) p=$ NS. A média da concentração de MPA plasmático, para o segundo pico, foi de 4,73 \pm $3,4 \mu \mathrm{g} / \mathrm{mL}$ (MMF-SA), e de 4,43 $\pm 2,34 \mu \mathrm{g} / \mathrm{mL}\left(\right.$ CellCept $\left.^{\circledR}\right), \mathrm{p}=\mathrm{NS}$.

A tabela 10 apresenta os resultados das análises de variância ANOVA para Cmax, $\mathrm{AUC}_{0-12 \mathrm{~h}}$ e Tmax.

Tabela 10. Resultado da análise de variâncias com medidas repetidas para a concentração máxima (Cmax) e AUC0-12h e tempo máximo para atingir Cmax (Tmax)

\begin{tabular}{lccc}
\hline Efeito & $\begin{array}{c}\text { Cmax } \\
\text { Valor de }\end{array}$ & $\begin{array}{c}\text { AUC }_{\mathbf{0 - 1 2 h}} \\
\text { Valor de }\end{array}$ & $\begin{array}{c}\text { T max } \\
\text { Valor de p }\end{array}$ \\
\hline Período & 0,5802 & 0,4530 & 0,2092 \\
Droga & 0,7735 & 0,5566 & 0,6102 \\
Período *droga & 0,2663 & 0,4228 & 0,5082 \\
\hline
\end{tabular}


O comportamento das duas drogas quanto a: Cmax, AUC e Tmax, não foram estatisticamente diferentes com a ordem de administração da droga. Não houve diferença estatisticamente significativa da média de Cmax, de AUC e de Tmax, de um período para o outro e de uma droga para a outra.

A tabela 11 mostra o intervalo de confiança 90\% (IC 90\%) dos valores obtidos para Cmax e AUC, para a razão da formulação teste/referência. Os resultados estão contidos dentro do intervalo de bioequivalência (80\% -125\%).

Tabela 11. Análise de bioequivalência: IC $(90 \%)$ da razão entre as médias geométricas entre as duas formulações MMF-SA e CellCept ${ }^{\circledR}$ com resultados transformados em logaritmos para Cmax e $\mathrm{AUC}_{0-12 \mathrm{~h}}$

\begin{tabular}{lccc}
\hline $\begin{array}{l}\text { Parâmetros } \\
\text { farmacocinéticos }\end{array}$ & Razão & IC 90\% & Poder (\%) \\
\hline Cmax & 1,067 & $0,936-1,217$ & 61,68 \\
& & $(93,57 \%-121,73 \%)$ & \\
AUC $_{0-12 \mathrm{~h}}$ & 1,010 & $0,938-1,089$ & 99,85 \\
& & $(93,75 \%-108,90 \%)$ & \\
\hline
\end{tabular}

Não foi observada diferença estatisticamente significativa para a meia-vida de eliminação da droga $\left(T_{1 / 2}\right)$ entre as duas formulações $p=0,23$, ou para a constante de eliminação (Kel) $p=0,33$, na população estudada.

Os resultados dos testes, entre quem fez uso de Ciclosporina e quem fez uso de tacrolimus associado ao $\mathrm{MMF}$, para a medida de $\mathrm{AUC}_{0-12 \mathrm{~h}}$ demonstraram que não há diferença estatisticamente significativa quando se utiliza uma ou outra formulação associada a ciclosporina $p=0,3086$ ou tacrolimus $p=0,2220$. 
5. DISCUSSÃO 
O Ministério da Saúde regula e controla a doação de órgãos e fornece drogas imunosupressoras para pacientes transplantados. Em 2004, o sistema público de saúde gastou 168 milhões de dólares no programa de transplante renal e 58,7 milhões foram utilizados na aquisição de drogas imunossupressoras. Segundo MedinaPestana $^{(97)}$, em 2004, 58.000 pacientes estavam sob diálise no Brasil e todos estes pacientes eram possíveis candidatos ao transplante renal.

A administração criteriosa de drogas imunossupressoras é desejável e qualquer medida que diminua estes gastos, sem diminuir a eficácia destas drogas, merece ser estudada.

Há alguns anos atrás, a imunossupressão após o transplante de órgãos estava restrita à administração empírica e não monitorada de azatioprina e prednisona. Com a evolução dos métodos diagnósticos, a monitorização auxiliou no sucesso alcançado no transplante de órgãos sólidos, incluindo crianças e idosos.

A monitorização terapêutica dos níveis plasmáticos de MPA é sugerida pela literatura, principalmente no período recente pós-transplante ${ }^{(41)}$.

A introdução de um ensaio automatizado facilita a monitorização terapêutica de drogas (TDM), uma vez que técnicas como HPLC e LC-MS/MS são mais trabalhosas. O desenvolvimento da metodologia EMIT facilitou esta monitorização, embora apresente erro sistemático que superestima estes resultados, devido à reação cruzada do metabólito AcMPAG com os anticorpos presentes no reagente ${ }^{(11)}$. 
Para alguns autores, a dosagem de MPA total e AcMPAG seria uma vantagem desta metodologia ${ }^{(11,64,65)}$, enquanto para outros, seria importante diferenciar as frações de $\mathrm{MPA}^{(6)}$. A diferenciação só é possível através de metodologias como o HPLC e LC-MS/MS.

A execução de uma validação metodológica é um processo árduo, mas a qualidade dos dados produzidos está diretamente ligada à qualidade do parâmetro estudado em sua rotina laboratorial. As restrições de tempo e recursos, geralmente não permitem as validações para todos os métodos. E isto resulta em ineficiência, dispêndio de recursos, desgaste da imagem do laboratório clínico, resultados pouco confiáveis, inexatidão e por fim prejuízos ao tratamento do paciente.

Os parâmetros estudados na validação, bem como a realização em laboratório certificado NBR ISO 9001:2000, asseguraram a qualidade das análises e dos resultados obtidos no estudo da farmacocinética de MPA. Os dados obtidos são compatíveis com os de outros autores, nas mesmas condições do nosso estudo.

A faixa analítica definida em nosso estudo de validação para a metodologia EMIT $(0,02-14,575 \mu \mathrm{g} / \mathrm{mL})$ abrangeu os valores mínimo (C0) e máximo (Cmax), sugeridos na literatura, afim de se evitar episódios de rejeição aguda ${ }^{(27,40)}$. O método conseguiu, ainda, detectar valores muito próximos de zero, e permitiu boa reprodutibilidade de resultados mesmo para valores baixos.

Em nosso estudo, comparando as metodologias EMIT e LC-MS/MS em amostras de voluntários sadios, não encontramos diferenças estatisticamente significativas entre as duas metodologias. Com o método analítico, empregado neste estudo, os resultados tendem a ser ligeiramente superiores aos obtidos por HPLC ${ }^{(42)}$ em pacientes transplantados renais. 
Hosotsubo et al. ${ }^{(64)}$ encontraram coeficiente de correlação $\left(r^{2}\right)$ de 0,990 entre a metodologia EMIT e HPLC e Vogl et al. ${ }^{(65)}$, obtiveram correlação $\mathrm{r}=0,970$.

Em 1998, Beal et al. ${ }^{(11)}$ observaram que a diferença entre as metodologias é maior no intervalo médio da curva, sugerindo que o metabólito AcMPAG deve ser o responsável pela superestimativa (Cmax para AcMPAG ocorre entre 4-8 horas). O CV intraensaio, neste estudo, foi de $3,6 \%-8,9 \%$, a porcentagem de recuperação de MPA foi de $95,6 \%-100,1 \%$, compatíveis com os nossos resultados.

Em contraste com nossos resultados, Prémaud et al. ${ }^{(77)}$, comparando pacientes transplantados renais que estavam sob terapia com ciclosporina e corticoesteróide associada ao MMF, encontraram uma diferença significativa entre as duas metodologias, quando comparadas a $\mathrm{AUC}_{0-9 \mathrm{~h}}(61,4 \%$ de superestinativa com EMIT).

Os mesmos autores, em estudo com MMF associado ao sirolimus e corticoesteróides, encontraram uma superestimativa de $18,7 \%$ para EMIT e observaram que esta diferença era reduzida com o tempo pós-transplante. Os autores não encontraram diferença no resultado de amostras controle que não continham metabólitos, confirmando que a diferença deve-se à reação cruzada entre o metabólito AcMPAG com o anticorpo anti-MPA, presente no reagente EMIT. As concentrações de AcMPAG são maiores no primeiro mês, após o transplante em pacientes que receberam ciclosporina, do que naqueles que receberam Sirolimus. Os autores enfatizaram que a diminuição da diferença associada ao tempo póstransplante deve-se a melhora dos níveis de creatinina e da função renal ${ }^{(78)}$.

Os estudos de Prémaud et al. confirmaram que a superestimativa relacionada ao método EMIT está relacionada às drogas associadas ao MMF, as quais alteram seu metabolismo no período pós-transplante ou com a preservação da função renal. 
Estes fatores devem ser levados em conta quando analisamos os resultados da monitorização terapêutica de MPA, independentemente da metodologia utilizada.

Em 2006, Van Gelder et al. ${ }^{(41)}$ observaram que, apesar da técnica por HPLC ser mais específica e de ser utilizada como padrão para a validação de outras metodologias, para se discriminar pacientes que têm rejeição aguda ou não, os dois métodos apresentaram curvas de características operacionais (sensibilidade e especificidade) comparáveis. As diferenças encontradas entre as duas metodologias $(10 \%-30 \%)$ foram menores para AUC do que para $\mathrm{C} 0$, e que o erro sistemático foi relativamente maior em pacientes com a função renal prejudicada, confirmando que não importa qual método seja utilizado, desde que o MPA total seja analisado no contexto da função renal e dos níveis de albumina e bilirrubina. A diminuição da ligação protéica encontrou-se associada ao aumento da fração livre de MPA, presente em pacientes com baixos níveis de albumina e altos níveis de bilirrubina séricas, e naqueles com insuficiência renal.

Novas técnicas estão sendo desenvolvidas para sistemas automatizados com capacidade de discriminar MPA total da fração livre com excelente correlação com HPLC e LC-MS/MS ${ }^{(98)}$.

A metodologia EMIT para a monitorização terapêutica de MPA, validada por nós, demonstrou-se adequada para a população estudada. Os dados obtidos em estudos farmacocinéticos por nosso grupo ${ }^{(36,38,60,70)}$, consolidam na prática da clínica nefrológica a importância desta validação, assegurando qualidade e confiabilidade a estes resultados laboratoriais. A metodologia é de fácil aplicação na rotina laboratorial e apresentou exatidão e precisão para aplicabilidade na monitorização terapêutica de MPA em transplantados renais. 
O estudo da farmacocinética foi conduzido através de desenho para estudo clínico randomizado, do tipo cruzado, padrão neste tipo de análise ${ }^{(95)}$.

As farmacocinéticas foram coletadas após a dose matutina de MMF. O ciclo circadiano pode afetar os níveis plasmáticos de MPA. Satoh et al. ${ }^{(99)}$, descreveram que AUC e Cmax estão mais elevadas na dose matinal, em relação à dose noturna, em pacientes transplantados hepáticos.

A farmacocinética de pacientes transplantados renais foi escolhida, pois esta é a população que usa o micofenolato mofetil no nosso meio. Este é o primeiro estudo de biodisponibidade de uma formulação genérica de MMF em transplantados renais da literatura.

Pacientes transplantados renais têm características diferentes da população normal, que podem interferir na absorção, transporte e metabolismo do MPA, podem apresentar níveis de hemoglobina e de proteínas plasmáticas abaixo do valor normal, utilização de outras drogas associadas ao MMF, variações no tempo pós-transplante, outras comorbidades associadas (diabéticos) e infecções virais.

O teste com uma nova droga genérica, nesta população, é uma demonstração mais realista do uso das mesmas, com segurança e eficácia clínica, permitindo a intercambialidade entre as formulações no dia-a-dia. Com base na literatura, acreditamos ser mais adequado o uso do teste de bioequivalência em populações que normalmente fazem uso destas drogas ${ }^{(84-86,89)}$.

Este estudo refere-se ao uso de um grupo específico de pacientes, não podendo ser extrapolado para a população transplantada de outros órgãos sólidos. $\mathrm{O}$ uso de voluntários normais também apresentaria o mesmo viés ${ }^{(83)}$. 
Conforme descrito, na tabela 8 , os dados demográficos deste estudo representam uma amostra da nossa população de transplantados renais em termos de: raça, sexo, idade, número de transplantes, entre outros.

É bem conhecida a interferência, no metabolismo de MPA, da raça e tipo de $\mathrm{CNI}^{(7,58)}$, e testar uma droga genérica em condições similares as da prática clínica parece ser adequado. Destaque-se que foi mantida a mesma proporção de pacientes que usam inibidores de calcineurina no serviço de transplantes renais do HCFMUSP na população estudada.

As figuras 6 e 7 representam a variação interindividual dos 24 pacientes para cada formulação. Pela observação das farmacocinéticas individuais, nota-se que um paciente apresentou o segundo pico mais intenso, na décima hora após a dose para a formulação de referência. Fato sugestivo de que a recirculação entero-hepática foi mais intensa com esta formulação neste paciente. Este caso justifica a maior variabilidade de absorção na décima hora, entre as duas formulações, que pode ser observada na figura 5. O coeficiente de variação interindividual para a formulação referência foi de $52 \%$ e da formulação genérica foi de $41,2 \%$.

Os dados demonstraram que a formulação MMF-SA é bioequivalente à formulação CellCept ${ }^{\circledR}$, uma vez que os IC $90 \%$, para a área sob a curva e para a Cmax, estão contidos entre $80 \%-125 \%$, conforme a definição para bioequivalência ${ }^{(100)}$.

A análise das duas curvas farmacocinéticas, na Figura 5, demonstra que elas estão sobrepostas. Média $\pm \mathrm{SE}$ da concentração máxima (Cmax) e área sob a curva (AUC) não apresentaram médias estatisticamente diferentes para CellCept ${ }^{\circledR} \mathrm{e}^{\mathrm{MMF}-}$ SA. Os intervalos de confiança 90\% MMF-SA para Cmax $(93,57 \%-121,73 \%)$ e $\mathrm{AUC}_{0-12 \mathrm{~h}}(93,75 \%$ - 108.90\%) estão dentro do intervalo de bioequivalência. 
O conceito de bioequivalência sugere que algumas drogas podem ser substituídas por outras que apresentem as mesmas características, sem que haja a necessidade de ajustes nas doses ou monitorização terapêutica adicional. A droga genérica é idêntica ou bioequivalente à droga comercial de referência na dosagem, via de administração, características de desempenho, qualidade e intenção de uso ${ }^{(101)}$.

O MMF-SA pode ser considerado bioequivalente ao CellCept ${ }^{\circledR}$, para a população estudada de transplantados renais estáveis, podendo haver intercambialidade entre as duas formulações. Com a segurança de que a extensão e a velocidade de absorção serão as mesmas, ou seja, os perfis de concentração-tempo plasmáticos, entre as duas formulações, proporcionam semelhantes resultados quanto à eficácia e segurança ${ }^{(82)}$.

No Brasil, de acordo com a lei número 9787/99 do Ministério da Saúde que definiu medicamento genérico como sendo droga bioequivalente ao produto de referência. Novas formulações podem ser produzidas após a expiração, a renúncia, da proteção de patente ou de outros direitos de exclusividade, desde que tenham sua eficácia e qualidades comprovadas em estudos de bioequivalência relativa ${ }^{(95)}$.

Em setembro de 2006 foi aberta para consulta pública, a resolução 156 de 11/08/2006, publicada no Diário Oficial da União, para críticas e sugestões, quanto ao regulamento técnico para medicamentos genéricos, contraceptivos orais e hormônios endógenos de uso oral. Este documento incluiu a necessidade do protocolo de biodisponibilidade relativa para micofenolato mofetil, realizado em centro certificado pela ANVISA, com estudos in vitro e in vivo para cada local onde a nova formulação é fabricada ${ }^{(101)}$. 
O poder do teste $t$ bi-caudal de $61,68 \%$ para Cmax explica-se, devido ao maior coeficiente de variação intraindividual para Cmax $(25,42 \%)$, justificando-se pelo número de participantes no estudo. Para alguns autores, a média e o intervalo de confiança devem ser complementados com os estudos de variabilidade intraindividual $^{(102)}$, desde que seus níveis sejam superiores a 30\%. Em nosso estudo, o desenho proposto foi adequado para concluir a bioequivalência do MMF-SA.

O nosso desenho de estudo foi diferente do usual, uma vez que os pacientes continuaram recebendo CellCept ${ }^{\circledR}$ no período de descanso (washout). Isto fez com que a concentração C12 constituisse o nível mínimo que deve ser comparado antes da administração de MMF-AS. Em consequência, a pré-dose $(\mathrm{C} 0)$ refere-se à concentração de CellCept ${ }^{\circledR}$ advinda da dose anterior.

Após a absorção, MPA é principalmente metabolizado em seu metabólito MPAG, este é filtrado pelos rins e excretado na bile, alcançando o intestino delgado, onde, por ação das bactérias intestinais, é novamente transformado em MPA e reabsorvido, gerando um segundo pico ${ }^{(8)}$, o qual, raramente é analisado nas publicações. Foi observado um segundo pico em $87 \%$ dos pacientes que receberam MPA, nas duas formulações, na mesma freqüência e intensidade. Sendo este, também, um reflexo de que as taxas de absorção, metabolismo e excreção foram similares para as duas formulações, quando administradas nas mesmas doses equimolares.

Durante o estudo da farmacocinética de MPA, um segundo pico é usualmente detectado entre 6 e 12 horas . O tempo médio para o segundo pico foi comparável para as duas formulações, dentro do intervalo de 6 e12 horas, sugerido na literatura .

É desejável na aquisição de medicamentos, que estes tenham, antes de tudo, qualidade, em termos de eficácia, efetividade e adequação ao perfil da população que 
se pretende atender. Na viabilização econômica das unidades de saúde, em especial nos serviços públicos, a oferta de produtos de qualidade, em quantidades adequadas, com aquisição por preço justo, são aspectos fundamentais. Principalmente, na terapia com drogas imunossupressoras, cujos preços são elevados em relação a outros medicamentos de uso crônico.

O MMF vem sendo oferecido gratuitamente aos pacientes transplantados renais, através de programas públicos de saúde. Estudos como este, aplicam-se e justificam-se para complementar os preconizados para o registro de genéricos. Diferenças nas formulações oferecidas poderiam comprometer o tratamento destes pacientes. A farmacoeconomia deste tipo de imunossupressor é pouco estudada em nosso meio, sendo um desafio futuro a ser enfrentado por centros universitários como o nosso.

Como uma perspectiva futura, este estudo poderá ser estendido a outras populações, que apresentem características de alteração do metabolismo da droga, como é o caso de pacientes diabéticos e transplantados no período recente após o transplante.

O desenvolvimento de estudos farmacogenéticos pode ser útil, no tratamento individualizado de pacientes transplantados renais sob terapia imunossupressora. É bem conhecida a ação da subfamília de enzimas CyP3A do citocromo P450 sobre o metabolismo de ciclosporina, tacrolimus e rapamicina e da ação da enzima tiopurina metil transferase sobre o metabolismo de azatioprina ${ }^{(103)}$

Dentre as novas perspectivas para a Medicina Laboratorial do século XXI encontram-se os estudos farmacogenéticos e farmacodinâmicos. Nesta linha de investigação inserem-se a farmacogenética e a farmacodinâmica do MPA, com a medida da atividade da IMPDH ${ }^{(45)}$. 
A capacidade da formulação genérica em evitar rejeição aguda no longo prazo, não é conhecida, mas está implícita no estudo de bioequivalência. O que vem sendo discutido, amplamente, é a necessidade de avaliações repetidas dos estudos de bioequivalência, em acompanhamento de pacientes no longo prazo ${ }^{(87)}$ a denominada fármaco-vigilância.

A validação metodológica do MPA em população de transplantados renais estáveis, seguida da avaliação da biodisponibilidade de duas formulações disponíveis, comprovando-se a sua intercambialidade, traz propostas desafiadoras para a continuidade desta linha de investigação na monitorização terapêutica de drogas em transplantados renais, integrando equipes multidisciplinares. 
6. CONCLUSÕES 
Através dos estudos de bioequivalência utilizando os parâmetros $\mathrm{AUC}_{0-12 \mathrm{~h}} \mathrm{e}$ Cmax concluímos que a formulação MMF-SA tem biodisponibilidade similar à da droga de referência, em pacientes transplantados renais estáveis, sendo as duas formulações intercambiáveis na população estudada, sem prejuízo da eficácia terapêutica.

A metodologia EMIT validada para monitorização terapêutica dos níveis plasmáticos de MPA, apresentou precisão, exatidão e intervalo analítico adequados para aplicabilidade na população estudada e resultados comparáveis aos obtidos com a metodologia padrão na população do estudo, com função renal estável. 
7. ANEXOS 
Anexo A. Protocolo de pesquisa $n^{0}$ 157/04
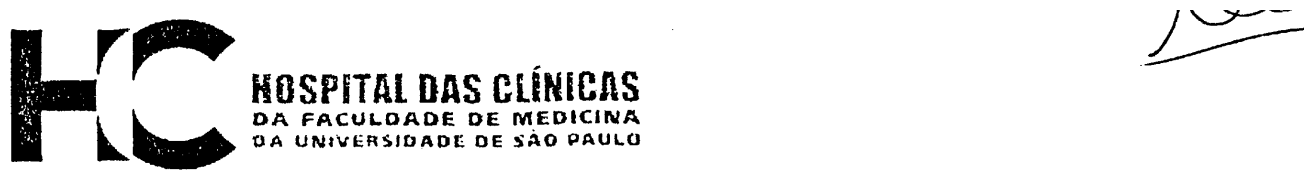

\section{DIRETORIA CLÍNICA}

\section{Comissão de Ética para Análise de Projetos de Pesquisa}

\section{APROVAÇÃO}

A Comissão de Ética para Análise de Projetos de Pesquisa - CAPPesq da Diretoria Clínica do Hospital das Clínicas e da Faculdade de Medicina da Universidade de São Paulo, em sessão de 29.04.04, APROVOU o Protocolo de Pesquisa $n^{\circ}$ 157/04, intitulado: "Avaliação do método de imunoensaio enzimático (EMIT) na monitoração da concentração plasmática de Ácido Micofenólico em pacientes transplantados renais estáveis. Uma experiência brasileira inédita" apresentado pela ÁREA DE FISIOPATOLOGIA EXPERIMENTAL, inclusive 0 Termo de Consentimento Livre $e$ Esclarecido.

Pesquisador(a) Responsável: Prof. Dr. Elias DAvid-Neto

Pesquisador(a) Executante: Sra. Paschoalina Romano

CAPPesq, 29 de Abril de 2004.

Encaminhe-se à CPG-FMUSP para as devidas providéncias. S.P., 07105,04

C.cupinentor.

Prof. D Dra Mana Mitzı Brentanı

Coordenadora do Curso de

Pos-Graduaçāo do programa

de Fisiopatologia Experimental

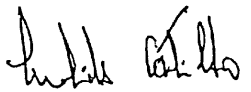

PROF. DR. EUCLIDES AYRES DE CASTILHO Presidente da Comissão de Ética para Análise de Projetos de Pesquisa

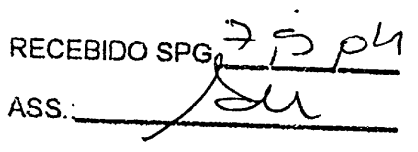

OBSERVAÇÃO: Cabe aO pesquisador elaborar e apresentar à CAPPesq, os relatórios parciais e final sobre a pesquisa (Resolução do Conselho Nacional de Saúde $n^{\circ} 196$, de 10.10.1996, inciso IX.2, letra "c") 
Anexo B. Protocolo de pesquisa $n^{0}$ 933/02

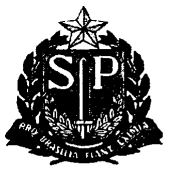

HOSPITAL DAS CLÍNICAS

DA FACULDADE DE MEDICINA DA UNIVERSIDADE DE SÃO PAULO

CAIXA POSTAL, 8091 - SÃO PAULO - BRASIL

\section{DIRETORIA CLÍNICA}

\section{Comissão de Ética para Análise de Projetos de Pesquisa}

\section{APROVACÃO}

A Comissão de Ética para Análise de Projetos de Pesquisa - CAPPesq da Diretoria Clínica do Hospital das Clínicas e da Faculdade de Medicina da Universidade de São Paulo, em sessão de 20.11.02, APROVOU o Protocolo de Pesquisa $n^{\circ}$ 933/02, intitulado: "Estudo de bioequivalência do micofenolato mofetil da formulação de Refrat(B) com a formulação de Cellcept", apresentado pelo Departamento de CLÍNICA MÉDICA, bem como o Termo de Consentimento Livre e Esclarecido.

Pesquisador(a) Responsável: PROF. DR. ELIAS DAVID-NETO

CAPPesq, 20 de Novembro de 2002.

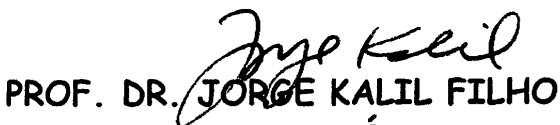
Presidente da Comissão de Ética para Análise de Projetos de Pesquisa

OBSERVAÇÃO: Cabe ao pesquisador elaborar e apresentar à CAPPesq, os relatórios parciais e final sobre a pesquisa (Resolução do Conselho Nacional de Saúde $n^{\circ} 196$, de 10.10.1996, inciso IX.2, letra "c"). 
Anexo C. Valores obtidos na dosagem de ácido micofenólico pelos métodos LCMS/MS e EMIT

\begin{tabular}{|c|c|c|c|}
\hline $\mathbf{n}=\mathbf{2 9}$ & $\begin{array}{c}\text { LC-MS/MS } \\
\mu \mathrm{g} / \mathrm{mL}\end{array}$ & $\begin{array}{l}\text { EMIT } \\
\mu \mathrm{g} / \mathrm{mL}\end{array}$ & media \\
\hline 1 & 0,00 & 0,00 & 0,00 \\
\hline 2 & 0,82 & 0,82 & 0,82 \\
\hline 3 & 14,60 & 9,30 & 12,0 \\
\hline 4 & 25,00 & 24,52 & 24,8 \\
\hline 5 & 23,40 & 22,57 & 23,0 \\
\hline 6 & 19,70 & 22,71 & 21,2 \\
\hline 7 & 17,40 & 19,71 & 18,6 \\
\hline 8 & 12,60 & 10,35 & 11,5 \\
\hline 9 & 7,20 & 10,97 & 9,1 \\
\hline 10 & 4,40 & 5,81 & 5,1 \\
\hline 11 & 3,07 & 3,06 & 3,1 \\
\hline 12 & 2,10 & 3,06 & 2,6 \\
\hline 13 & 1,70 & 2,49 & 2,1 \\
\hline 14 & 1,20 & 1,80 & 1,5 \\
\hline 15 & 0,57 & 1,00 & 0,8 \\
\hline 16 & 1,57 & 1,79 & 1,7 \\
\hline 17 & 2,26 & 2,24 & 2,3 \\
\hline 18 & 0,79 & 0,94 & 0,9 \\
\hline 19 & 0,46 & 0,40 & 0,4 \\
\hline 20 & 0,15 & 0,02 & 0,1 \\
\hline 21 & 0,05 & 0,07 & 0,1 \\
\hline 22 & 0,00 & 0,04 & 0,0 \\
\hline 23 & 15,90 & 15,81 & 15,9 \\
\hline 24 & 12,70 & 12,83 & 12,8 \\
\hline 25 & 3,30 & 3,80 & 3,6 \\
\hline 26 & 1,66 & 1,91 & 1,8 \\
\hline 27 & 2,04 & 2,42 & 2,2 \\
\hline 28 & 0,73 & 0,94 & 0,8 \\
\hline \multirow[t]{2}{*}{29} & 1,38 & 1,66 & 1,5 \\
\hline & 6,09 & 6,31 & \\
\hline Média & 6,20 & & \\
\hline Correlação (r) & 0,980 & & \\
\hline C.V $(\%$ & 57,13 & & \\
\hline D.P & 7,70 & & \\
\hline
\end{tabular}

Fonte: Resultados por LC-MS/MS foram disponibilizados pela empresa Cromoanalysis Ltda. 


\section{Anexo D. Banco de dados}

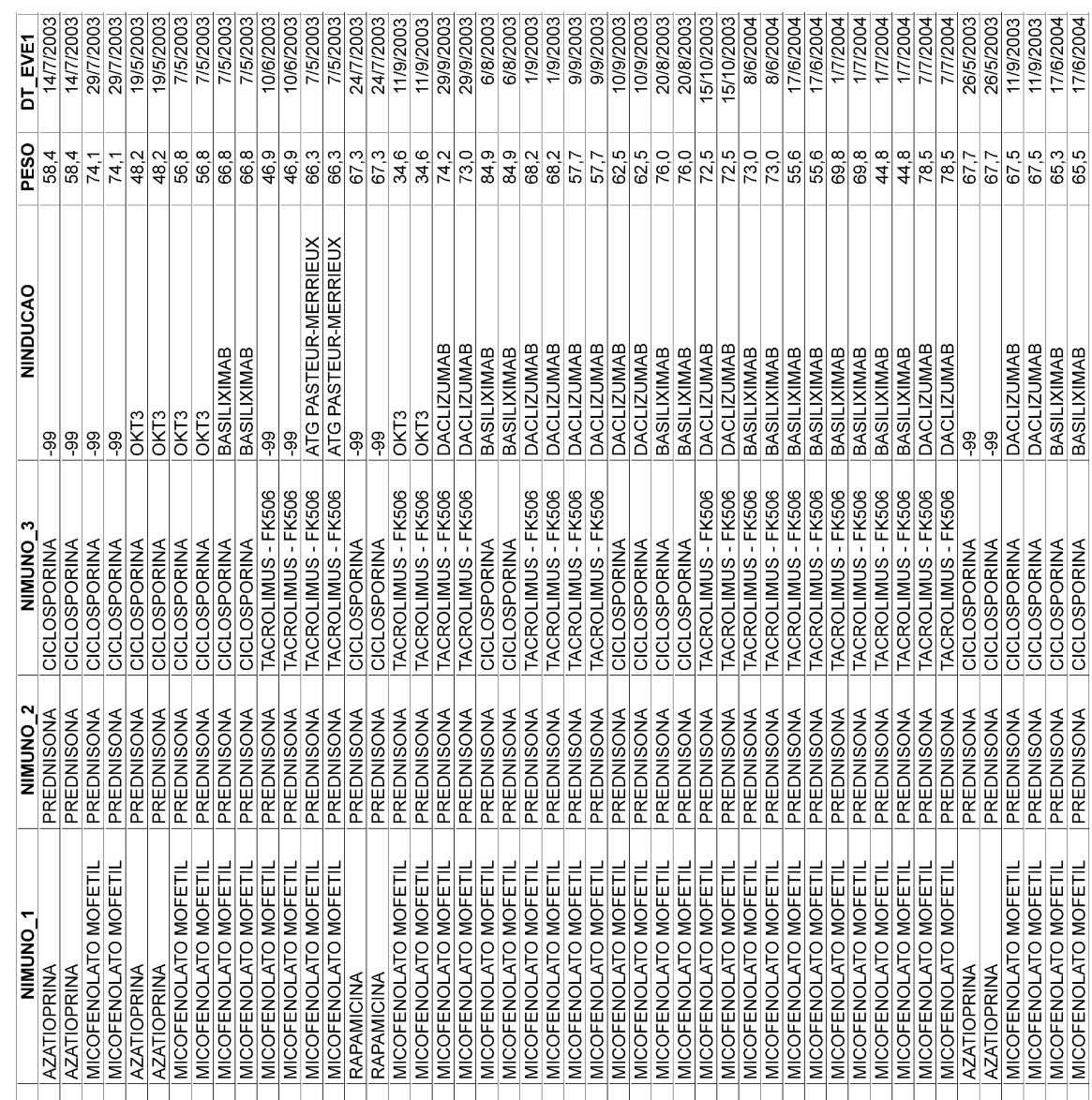

$\stackrel{0}{\circ}$

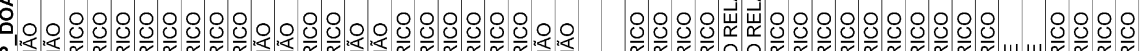
$\mathrm{s}$

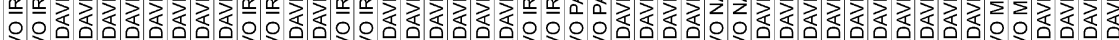

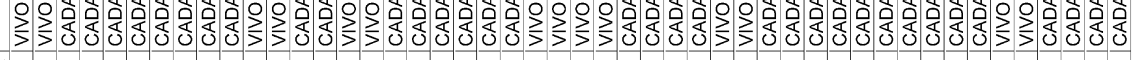

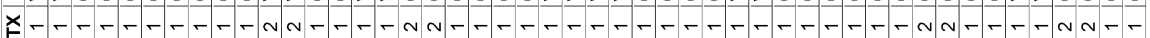

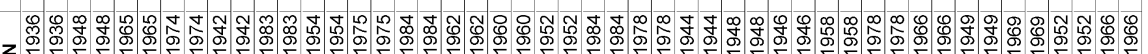

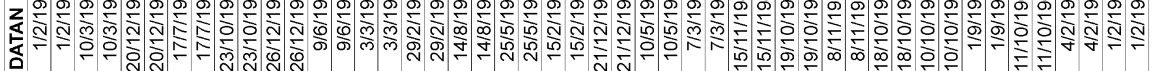

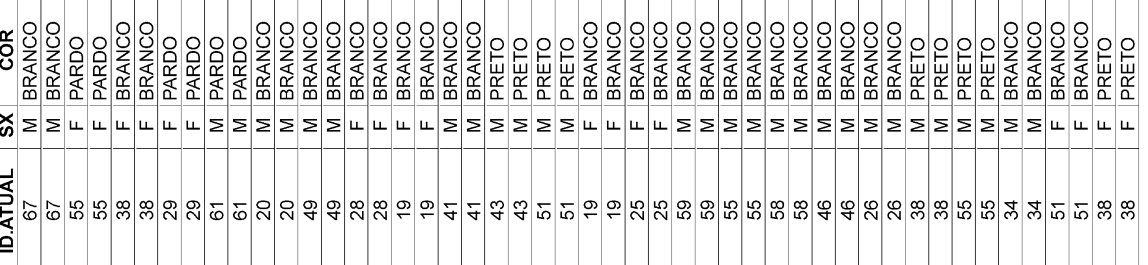

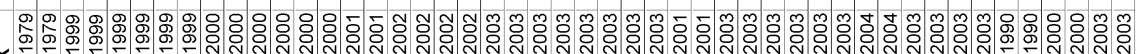

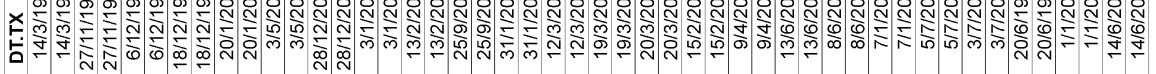

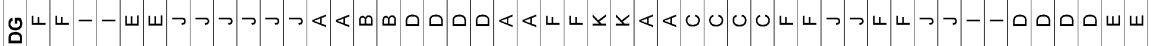

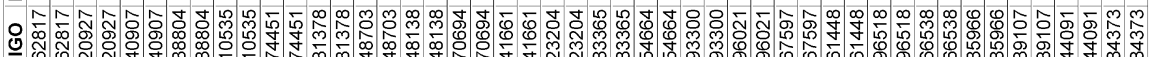

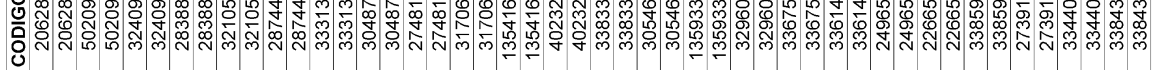



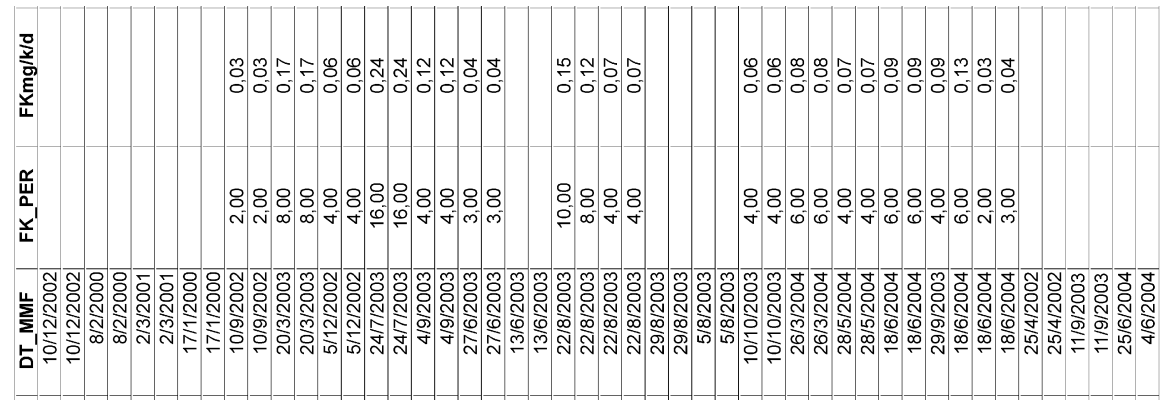

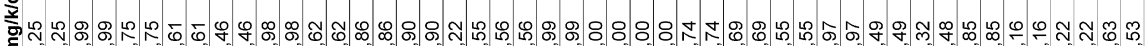

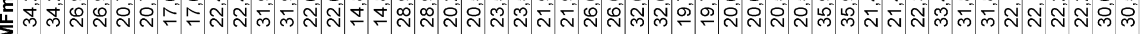

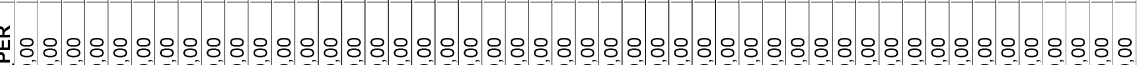

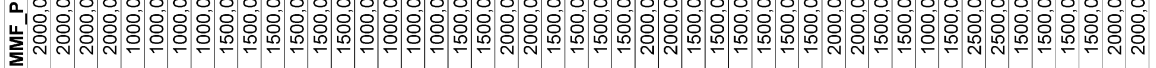

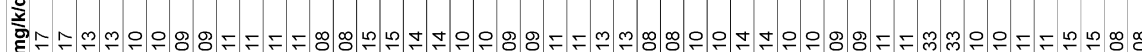

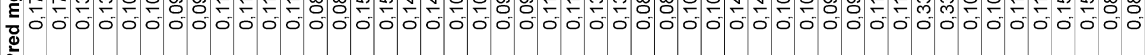

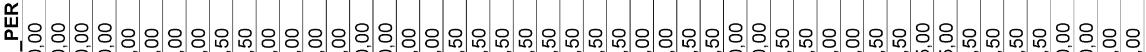

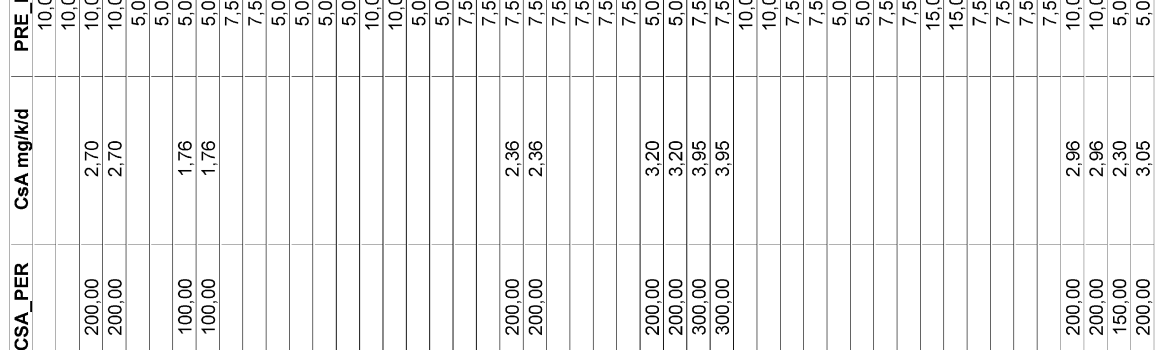

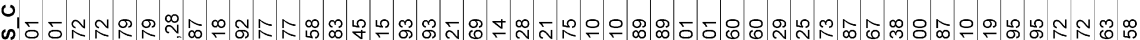

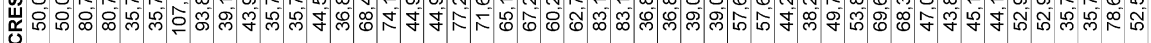

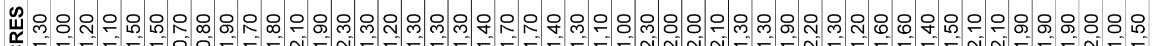

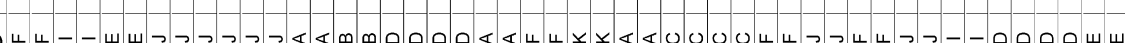

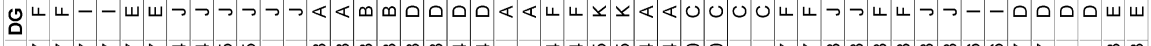

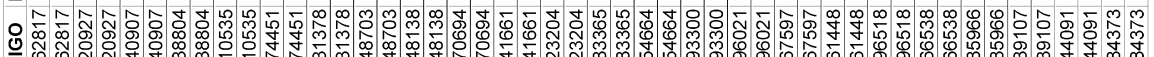

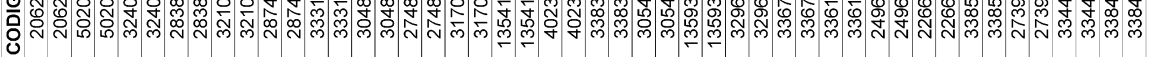




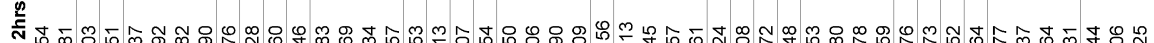

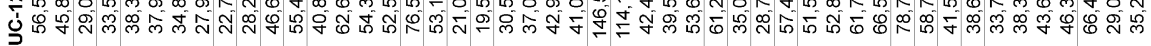

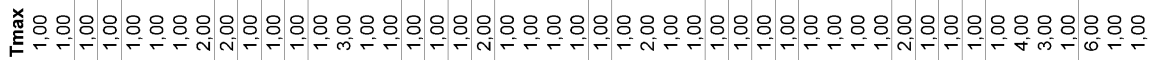

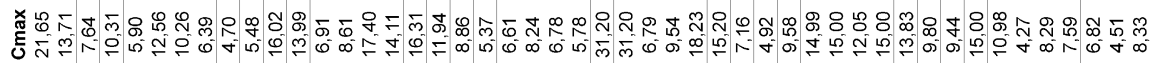

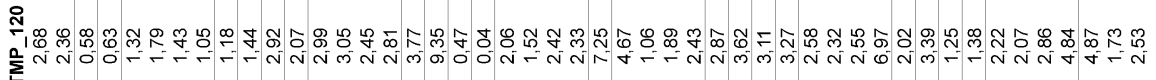

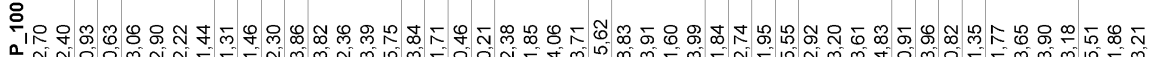

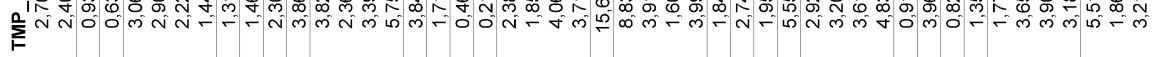

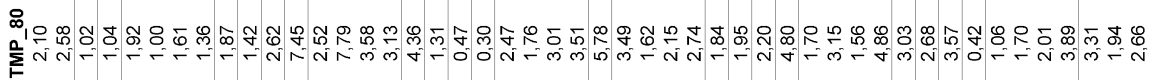

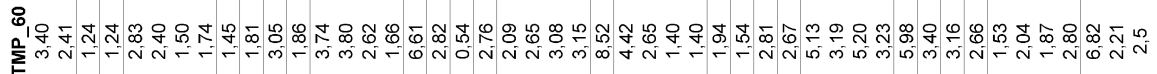

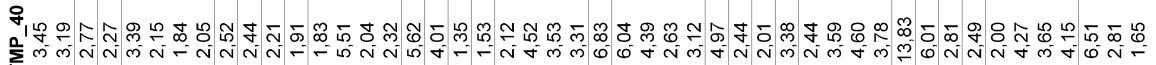

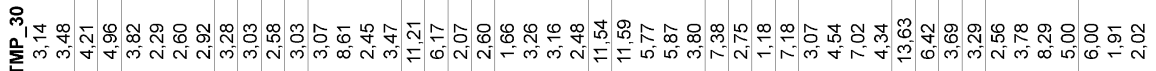

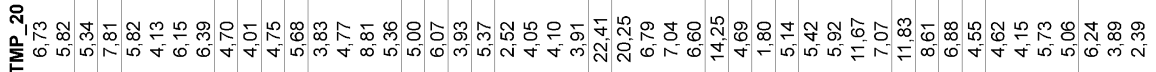

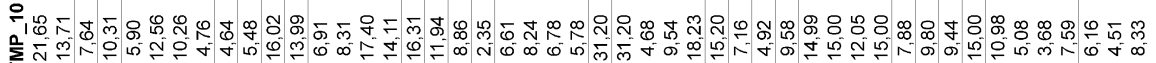

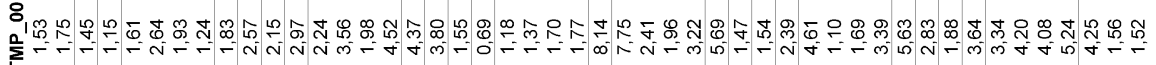

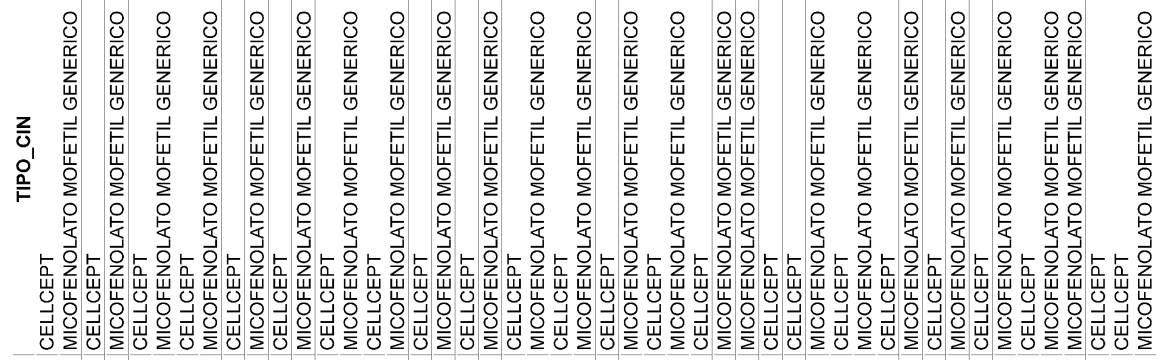
ż

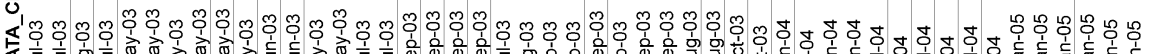

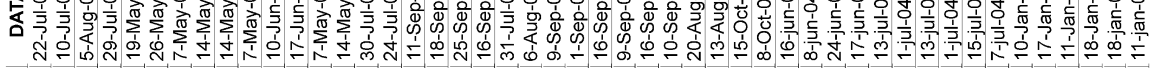

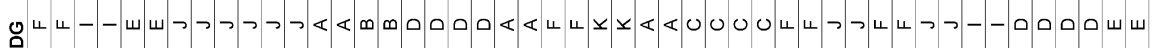

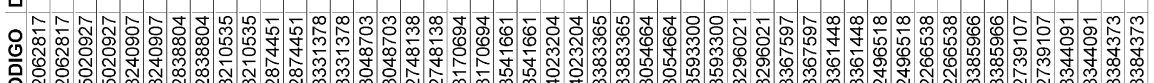

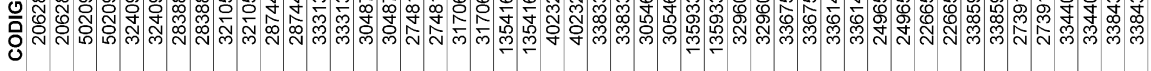


8. REFERÊNCIAS 
1. Halloran PF. Immunosuppressive drugs for kidney transplantation. $N$ Engl $J$ Med. 2004;351(26):2715-29.

2. Hariharan S, Johnson CP, Bresnahan BA, Taranto SE, McIntosh MJ, Stablein D. Improved graft survival after renal transplantation in the United States, 1988 to 1996. $N$ Engl J Med. 2002;342(9):605-12.

3. Pirsch J, Bekersky I, Vincenti F, Boswell G, Woodle ES, Alak A, Kruelle, M, Fass N, Facklam D, Mekki Q. Coadministration of tacrolimus and mycophenolate mofetil in stable kidney transplant patients: pharmacokinetics and tolerability. J Clin Pharmacol. 2000;40(5):527-32.

4. Kramer BK, Montagnino G, Del Castillo D, Margreiter R, Sperschneider H, Olbricht CJ, Kruger B, Ortuno J, Kohler H, Kunzendorf U, Stummvoll HK, Tabernero J M, Muhlbacher F, RiveroM, Arias M. Efficacy and safety of tacrolimus compared with cyclosporin A microemulsion in renal transplantation: 2 year follow-up results. Nephrol Dial Transplant. 2005;20(5):968-73.

5. Bullingham R, Monroe S, Nicholls A, Hale M. Pharmacokinetics and bioavailability of mycophenolate mofetil in healthy subjects after single-dose oral and intravenous administration. J Clin Pharmacol. 1996;36(4):315-24.

6. Oellerich M, Shipkova M, Schutz E, Wieland E, Weber L, Tonshoff B, Armstrong VW. Pharmacokinetic and metabolic investigations of mycophenolic acid in pediatric patients after renal transplantation: implications for therapeutic drug monitoring. German Study Group on Mycophenolate Mofetil Therapy in Pediatric Renal Transplant Recipients. Ther Drug Monit. 2000;22(1):20-6.

7. van Gelder T, Klupp J, Barten MJ, Christians U, Morris RE. Comparison of the effects of tacrolimus and cyclosporine on the pharmacokinetics of mycophenolic acid. Ther Drug Monit. 2001;23(2):119-28.

8. Bullingham RE, Nicholls A, Hale M. Pharmacokinetics of mycophenolate mofetil (RS61443): a short review. Transplant Proc. 1996;28(2):925-9.

9. Parker G, Bullingham R, Kamm B, Hale M. Pharmacokinetics of oral mycophenolate mofetil in volunteer subjects with varying degrees of hepatic oxidative impairment. J Clin Pharmacol. 1996;36(4):332-44.

10. Hale MD, Nicholls AJ, Bullingham RE, Hene R, Hoitsma A, Squifflet JP, Weimar W, Vanrenterghem Y, Van de Woude FJ, Verpooten GA. The pharmacokinetic-pharmacodynamic relationship for mycophenolate mofetil in renal transplantation. Clin Pharmacol Ther. 1998;64(6):672-83. 
11. Beal JL, Jones CE, Taylor PJ, Tett SE. Evaluation of an immunoassay (EMIT) for mycophenolic acid in plasma from renal transplant recipients compared with a high-performance liquid chromatography assay. Ther Drug Monit. 1998;20(6):685-90.

12. Weber LT, Shipkova M, Lamersdorf T, Niedmann PD, Wiesel M, Mandelbaum A, Zimmerhackl LB, Schutz E, Mehls O, Oellerich M, Armstrong V, Tonshoff B. Pharmacokinetics of mycophenolic acid (MPA) and determinants of MPA free fraction in pediatric and adult renal transplant recipients. German Study group on Mycophenolate Mofetil Therapy in Pediatric Renal Transplant Recipients. J Am Soc Nephrol. 1998;9(8):1511-20.

13. Allison AC, Hovi T, Watts RW, Webster AD. Immunological observations on patients with Lesch-Nyhan syndrome, and on the role of de-novo purine synthesis in lymphocyte transformation. Lancet. 1975;2(7946):1179-83.

14. Allison AC, Eugui EM. Immunosuppressive and other effects of mycophenolic acid and an ester prodrug, mycophenolate mofetil. Immunol Rev. 1993;136:5-28.

15. Allison AC, Eugui EM. Preferential suppression of lymphocyte proliferation by mycophenolic acid and predicted long-term effects of mycophenolate mofetil in transplantation. Transplant Proc. 1994;26(6):3205-10.

16. Allison AC, Eugui EM. Immunosuppressive and long-acting anti-inflammatory activity of mycophenolic acid and derivative, RS-61443. $\mathrm{Br} J$ Rheumatol. 1991;30(Suppl 2):57-61.

17. Eugui EM, Mirkovich A, Allison AC. Lymphocyte-selective antiproliferative and immunosuppressive activity of mycophenolic acid and its morpholinoethyl ester (RS-61443) in rodents. Transplant Proc. 1991;23(2 Suppl 2):15-8.

18. Jonsson CA, Carlsten H. Mycophenolic acid inhibits inosine 5'-monophosphate dehydrogenase and suppresses immunoglobulin and cytokine production of B cells. Int Immunopharmacol. 2003;3(1):31-7.

19. Sanquer S, Breil M, Baron C, Dhamane D, Astier A, Lang P. Induction of inosine monophosphate dehydrogenase activity after long-term treatment with mycophenolate mofetil. Clin Pharmacol Ther. 1999;65(6):640-8.

20. van Besouw NM, van der Mast BJ, Smak Gregoor PJ, Hesse CJ, Jzermans JN, van Gelder T, Weimar W. Effect of mycophenolate mofetil on erythropoiesis in stable renal transplant patients is correlated with mycophenolic acid trough levels. Nephrol Dial Transplant. 1999;14(11):2710-3.

21. Sollinger HW. Mycophenolate mofetil for the prevention of acute rejection in primary cadaveric renal allograft recipients. U.S. Renal Transplant Mycophenolate Mofetil Study Group. Transplantation. 1995;60(3):225-32.

22. Sollinger HW. From mice to man: the preclinical history of mycophenolate mofetil. Clin Transplant. 1996;10(1 Pt 2):85-92. 
23. Placebo-controlled study of mycophenolate mofetil combined with cyclosporin and corticosteroids for prevention of acute rejection. European Mycophenolate Mofetil Cooperative Study Group. Lancet. 1995;345(8961):1321-5.

24. A blinded, randomized clinical trial of mycophenolate mofetil for the prevention of acute rejection in cadaveric renal transplantation. The Tricontinental Mycophenolate Mofetil Renal Transplantation Study Group. Transplantation. 1996;61(7):1029-37.

25. Weir MR, Anderson L, Fink JC, Gabregiorgish K, Schweitzer EJ, Hoehn-Saric E, Klassen DK, Cangro CB, Johnson LB, Kuo PC, Lim JY, Bartlett ST. A novel approach to the treatment of chronic allograft nephropathy. Transplantation. 1997;64(12):1706-10.

26. Dudley C, Pohanka E, Riad H, Dedochova J, Wijngaard P, Sutter C, Silva HT Jr. Mycophenolate mofetil substitution for cyclosporine a in renal transplant recipients with chronic progressive allograft dysfunction: the "creeping creatinine" study. Transplantation. 2005;79(4):466-75.

27. Mourad M, Malaise J, Chaib Eddour D, De Meyer M, Konig J, Schepers R, Squifflet JP, Wallemacq P. Pharmacokinetic basis for the efficient and safe use of low-dose mycophenolate mofetil in combination with tacrolimus in kidney transplantation. Clin Chem. 2001;47(7):1241-8.

28. Kuypers DR, Vanrenterghem Y, Squifflet JP, Mourad M, Abramowicz D, Oellerich M, Armstrong V, Shipkova M, Daems J. Twelve-month evaluation of the clinical pharmacokinetics of total and free mycophenolic acid and its glucuronide metabolites in renal allograft recipients on low dose tacrolimus in combination with mycophenolate mofetil. Ther Drug Monit. 2003 Oct;25(5):609-22.

29. Suwelack B, Gerhardt U, Hohage H. Withdrawal of cyclosporine or tacrolimus after addition of mycophenolate mofetil in patients with chronic allograft nephropathy. Am J Transplant. 2004;4(4):655-62.

30. Cattaneo D, Merlini S, Zenoni S, Baldelli S, Gotti E, Remuzzi G, Perico N. Influence of co-medication with sirolimus or cyclosporine on mycophenolic acid pharmacokinetics in kidney transplantation. Am J Transplant. 2005;5(12):2937-44.

31. Kuypers DR, Claes K, Evenepoel P, Maes B, Coosemans W, Pirenne J, Vanrenterghem Y. Long-term changes in mycophenolic acid exposure in combination with tacrolimus and corticosteroids are dose dependent and not reflected by trough plasma concentration: a prospective study in 100 de novo renal allograft recipients. J Clin Pharmacol. 2003;43(8):866-80.

32. Ciancio G, Burke GW, Gaynor JJ, Mattiazzi A, Roth D, Kupin W, Nicolas M,Ruiz P, Rosen A, Miller J. A randomized long-term trial of tacrolimus and sirolimus versus tacrolimus and mycophenolate mofetil versus cyclosporine (NEORAL) and sirolimus in renal transplantation. I. Drug interactions and rejection at one year. Transplantation. 2004;77(2):244-51. 
33. Stoves J, Newstead CG, Baczkowski AJ, Owens G, Paraoan M, Hammad AQ. A randomized controlled trial of immunosuppression conversion for the treatment of chronic allograft nephropathy. Nephrol Dial Transplant. 2004;19(8):2113-20.

34. Zucker K, Rosen A, Tsaroucha A, de Faria L, Roth D, Ciancio G, Esquenazi V, Burke G, Tzakis A, Miller J. Unexpected augmentation of mycophenolic acid pharmacokinetics in renal transplant patients receiving tacrolimus and mycophenolate mofetil in combination therapy, and analogous in vitro findings. Transpl Immunol. 1997;5(3):225-32.

35. Hubner GI, Eismann R, Sziegoleit W. Drug interaction between mycophenolate mofetil and tacrolimus detectable within therapeutic mycophenolic acid monitoring in renal transplant patients. Ther Drug Monit. 1999;21(5):536-9.

36. Pereira LM. Co-interferências da farmacocinética dos inibidores de calcineurina em associação com micofenolato mofetil em pacientes transplantados renais (tese). São Paulo: Universidade de São Paulo; 90p. Defesa em 5 de julho de 2006.

37. Mahalati K, Belitsky P, West K, Kiberd B, Fraser A, Sketris I, Panek R. Approaching the therapeutic window for cyclosporine in kidney transplantation: a prospective study. J Am Soc Nephrol. 2001;12(4):828-33.

38. David-Neto E, Pereira LM, Kakehashi E, Sumita NM, Mendes ME, Castro MC, Romano P, Mattos RM, Batista VR, Nahas WC, Ianhez LE. The need of mycophenolic acid monitoring in long-term renal transplants. Clin Transplant. 2005;19(1):19-25.

39. Mourad M, Wallemacq P, Konig J, de Frahan EH, Eddour DC, De Meyer M, Malaise J, Squifflet JP. Therapeutic monitoring of mycophenolate mofetil in organ transplant recipients: is it necessary? Clin Pharmacokinet. 2002;41(5):319-27.

40. Mourad M, Malaise J, Chaib Eddour D, De Meyer M, Konig J, Schepers R, Squifflet JP, Wallemacq P. Correlation of mycophenolic acid pharmacokinetic parameters with side effects in kidney transplant patients treated with mycophenolate mofetil. Clin Chem. 2001;47(1):88-94.

41. van Gelder T, Meur YL, Shaw LM, Oellerich M, DeNofrio D, Holt C, Kaplan B, Kuypers D, Meiser B, Toenshoff B, Mamelok RD. Therapeutic drug monitoring of mycophenolate mofetil in transplantation. Ther Drug Monit. 2006; 28(2):145-54.

42. Weber LT, Shipkova M, Armstrong VW, Wagner N, Schutz E, Mehls O, Zimmerhackl LB, Oellerich M, Tonshoff B. Comparison of the Emit immunoassay with HPLC for therapeutic drug monitoring of mycophenolic acid in pediatric renal-transplant recipients on mycophenolate mofetil therapy. Clin Chem. 2002;48(3):517-25. 
43. Filler G. Abbreviated mycophenolic acid AUC from $\mathrm{C} 0, \mathrm{C} 1, \mathrm{C} 2$ and $\mathrm{C} 4$ is preferable in children after renal transplantation on mycophenolate mofetil and tacrolimus therapy. Transpl int. 2004; 17(3):120-5

44. van Hest R, Mathot R, Vulto A, Weimar W, van Gelder T. Predicting the usefulness of therapeutic drug monitoring of mycophenolic acid: a computer simulation. Ther Drug Monit. 2005;27(2):163-7.

45. van Gelder T. Mycophenolate mofetil: how to further improve using an already successful drug? Am J Transplant. 2005;5(2):199-200.

46. Le Guellec C, Bourgoin H, Buchler M, Le Meur Y, Lebranchu Y, Marquet P, Paintaud G. Population pharmacokinetics and Bayesian estimation of mycophenolic acid concentrations in stable renal transplant patients. Clin Pharmacokinet. 2004;43(4):253-66.

47. Johnson AG, Rigby RJ, Taylor PJ, Jones CE, Allen J, Franzen K, Falk MC, Nicol D. The kinetics of mycophenolic acid and its glucuronide metabolite in adult kidney transplant recipients. Clin Pharmacol Ther. 1999;66(5):492-500.

48. Meier-Kriesche HU, Steffen BJ, Hochberg AM, Gordon RD, Liebman MN, Morris JA, Kaplan B. Long-term use of mycophenolate mofetil is associated with a reduction in the incidence and risk of late rejection. Am J Transplant. 2003;3(1):68-73.

49. Borrows R, Chusney G, James A, Stichbury J, Van Tromp J, Cairns T, Griffith M, Hakim N, McLean A, Palmer A, Papalois V, Taube D. Determinants of mycophenolic acid levels after renal transplantation. Ther Drug Monit. 2005;27(4):442-50.

50. Weber LT, Lamersdorf T, Shipkova M, Niedmann PD, Wiesel M, Zimmerhackl LB Staskewitz A, Schutz E, Mehls O, Oellerich M, Armstrong VW, Tonshoff B. Area under the plasma concentration-time curve for total, but not for free, mycophenolic acid increases in the stable phase after renal transplantation: a longitudinal study in pediatric patients. German Study Group on Mycophenolate Mofetil Therapy in Pediatric Renal Transplant Recipients. Ther Drug Monit. 1999;21(5):498-506.

51. Le Guellec C, Buchler M, Giraudeau B, Le Meur Y, Gakoue JE, Lebranchu Y, Marquet P, Paintaud G. Simultaneous estimation of cyclosporin and mycophenolic acid areas under the curve in stable transplant patients using a limited sampling strategy. Eur J Clin Pharmacol. 2002;57(11):805-11.

52. Filler G, Lepage N, Delisle B, Mai I. Effect of cyclosporine on mycophenolic acid area under the concentration-time curve in pediatric kidney transplant recipients. Ther Drug Monit. 2001;23(5):514-9. 
53. Morissette P, Albert C, Busque S, St-Louis G, Vinet B. In vivo higher glucuronidation of mycophenolic acid in male than in female recipients of a cadaveric kidney allograft and under immunosuppressive therapy with mycophenolate mofetil. Ther Drug Monit. 2001;23(5):520-5.

54. Bullingham R, Shah J, Goldblum R, Schiff M. Effects of food and antacid on the pharmacokinetics of single doses of mycophenolate mofetil in rheumatoid arthritis patients. Br J Clin Pharmacol. 1996;41(6):513-6.

55. Shum B, Duffull SB, Taylor PJ, Tett SE. Population pharmacokinetic analysis of mycophenolic acid in renal transplant recipients following oral administration of mycophenolate mofetil. Br J Clin Pharmacol. 2003;56(2):188-97.

56. Mudge DW, Atcheson B, Taylor PJ, Sturtevant JM, Hawley CM, Campbell SB, Isbel NM, Nicol DL, Pillans PI, Johnson DW. The effect of oral iron admiinistration on mycophenolate mofetil absorption in renal transplant recipients: a randomized, controlled trial. Transplantation. 2004 Jan 27;77(2):206-9.

57. Shaw LM, Korecka M, Venkataramanan R, Goldberg L, Bloom R, Brayman KL. Mycophenolic acid pharmacodynamics, pharmacokinetics provide a basis for rational monitoring strategies. Am J Transplant. 2003;3(5):534-42.

58. Buchler M, Lebranchu Y, Beneton M, Le Meur Y, Heng AE, Westeel PF, Le Guellec C, Libert F, Hary L, Marquet P, Paintaud G. Higher exposure to mycophenolic acid with sirolimus than with cyclosporine cotreatment. Clin Pharmacol Ther. 2005;78(1):34-42.

59. Pawinski T, Hale M, Korecka M, Fitzsimmons WE, Shaw LM. Limited sampling strategy for the estimation of mycophenolic acid area under the curve in adult renal transplant patients treated with concomitant tacrolimus. Clin Chem. 2002;48(9):1497-504.

60. David-Neto E, Pereira MP, Ribeiro Castro MC, Ventura CG, de Mattos RM, Sumita NM, Mendes ME, Romano P, Nahas WC, Ianhez LE. C2 for tacrolimus, MPA and CyA. A single approach for therapeutic drug monitoring. Transplantation. 2004;78(2)suuppl1:279.

61. Técnicas ABNT. NBR-ISO 9001: Sistema de gestão da qualidade, requisitos. Rio de Janeiro; 2000. 12p.

62. National Committee on Clinical Laboratory Standard (NCCLS). Evaluation of precision performance of clinical chemistry devices; aprroved guideline - EP5 T2. Wayne; 1999,43p.

63. Clinical Laboratory Improvement Act program fee collection - HCFA. Final rule with comment. Fed Regist. 1992;57(40):7188-218. 
64. Hosotsubo H, Takahara S, Imamura R, Kyakuno M, Tanaka T, Yazawa K, Hanafusa T, Matsumiya K, Nonomura N, Okuyama A, Sugimoto H. Analytic validation of the enzyme multiplied immunoassay technique for the determination of mycophenolic acid in plasma from renal transplant recipients compared with a high-performance liquid chromatographic assay. Ther Drug Monit. 2001;23(6):669-74.

65. Vogl M, Weigel G, Seebacher G, Griesmacher A, Laufer G, Muller MM. Evaluation of the EMIT Mycophenolic Acid Assay from Dade Behring. Ther Drug Monit. 1999;21(6):638-43.

66. Holt DW, Armstrong VW, Griesmacher A, Morris RG, Napoli KL, Shaw LM. International Federation of Clinical Chemistry/International Association of Therapeutic Drug Monitoring and Clinical Toxicology working group on immunosuppressive drug monitoring. Ther Drug Monit. 2002;24(1):59-67.

67. Barten MJ, Rahmel A, Garbade J, Bold A, Bittner HB, Dhein S, Mohr FW, Gummert JF. Pharmacodynamic monitoring of the conversion of cyclosporine to tacrolimus in heart and lung transplant recipients. Transplant Proc. 2005;37(10):4532-4.

68. Barten MJ, Rahmel A, Garbade J, Richter M, Bittner HB, Dhein S, Mohr FW, Gummert JF. C0h/C2h monitoring of the pharmacodynamics of cyclosporin plus mycophenolate mofetil in human heart transplant recipients. Transplant Proc. 2005;37(2):1360-1

69. Cox VC, Ensom MH. Mycophenolate mofetil for solid organ transplantation: does the evidence support the need for clinical pharmacokinetic monitoring? Ther Drug Monit. 2003;25(2):137-57.

70. David-Neto E, Pereira Araujo LM, Sumita NM, Mendes ME, Ribeiro Castro MC, Alves CF, Kakehashi E, Romano P, Yagyu EM, Queiroga M, Nahas WC, Ianhez LE. Mycophenolic acid pharmacokinetics in stable pediatric renal transplantation. Pediatr Nephrol. 2003;18(3):266-72.

71. Shipkova M, Schutz E, Armstrong VW, Niedmann PD, Wieland E, Oellerich M. Overestimation of mycophenolic acid by EMIT correlates with MPA metabolite. Transplant Proc. 1999;31(1-2):1135-7.

72. Filler G, Gellermann J, Zimmering M, Mai I. Effect of adding Mycophenolate mofetil in pediatric renal transplant recipients with chronical cyclosporine nephrotoxicity. Transpl Int. 2000;13(3):201-6.

73. Westley IS, Sallustio BC, Morris RG. Validation of a high-performance liquid chromatography method for the measurement of mycophenolic acid and its glucuronide metabolites in plasma. Clin Biochem. 2005;38(9):824-9. 
74. Shipkova M, Niedmann PD, Armstrong VW, Schutz E, Wieland E, Shaw LM, Oellerich M. Simultaneous determination of mycophenolic acid and its glucuronide in human plasma using a simple high-performance liquid chromatography procedure. Clin Chem. 1998;44(7):1481-8.

75. Schutz E, Shipkova M, Armstrong VW, Niedmann PD, Weber L, Tonshoff B, Pethig K, Wahlers T, Braun F, Ringe B, Oellerich M. Therapeutic drug monitoring of mycophenolic acid: comparison of HPLC and immunoassay reveals new MPA metabolites. Transplant Proc. 1998 Jun;30(4):1185-7.

76. Shipkova M, Schutz E, Armstrong VW, Niedmann PD, Oellerich M, Wieland E. Determination of the acyl glucuronide metabolite of mycophenolic acid in human plasma by HPLC and Emit. Clin Chem. 2000;46(3):365-72.

77. Premaud A, Rousseau A, Le Meur Y, Lachatre G, Marquet P. Comparison of liquid chromatography-tandem mass spectrometry with a commercial enzymemultiplied immunoassay for the determination of plasma MPA in renal transplant recipients and consequences for therapeutic drug monitoring. Ther Drug Monit. 2004;26(6):609-19.

78. Premaud A, Rousseau A, Picard N, Marquet P. Determination of mycophenolic acid plasma levels in renal transplant recipients co-administered sirolimus: comparison of an enzyme multiplied immunoassay technique (EMIT) and liquid chromatography-tandem mass spectrometry. Ther Drug Monit. 2006; 28(2):274-7.

79. Brasil. Ministério da Saúde. Agência Nacional de Vigilância Sanitária. Medicamentos ICdBL. "Resolução n.899, 29 de maio de 2003", determina a publicação do Guia para a validação de métodos analíticos e bioanalíticos [acesso em 23 jun. 2003]. Disponível em: www.anvisa.gov.br

80. United States. Department of Health and Human Services. Food and Drug Administration. Fed Reg. Bioequivalence requirements and in vivo bioavailability procedures.1977;42:1624-53. [acesso em 22 jul. 2003] Disponível em: http://www. accessdata. fda.gov/scriptsterm/Bioavilability.

81. Salmonson T, Rane A. Clinical pharmacokinetics in the drug regulatory process. Clin Pharmacokinet. 1990;18(3):177-83.

82. Gleiter CH, Klotz U, Kuhlmann J, Blume H, Stanislaus F, Harder S, Paulus H, Poethko-Muller C, Holz-Slomczyk M. When are bioavailability studies required? A German proposal. J Clin Pharmacol. 1998;38(10):904-11.

83. David-Neto E, Kakehashi E, Alves CF, Pereira LM, de Castro MC, de Mattos RM, Sumita N M, Romano P, Mendes ME, Nahas WC, Ianhez LE. Bioequivalence of a new cyclosporine a formulation to Neoral. Ther Drug Monit. 2004;26(1):53-7. 
84. Hibberd AD, Trevillian PR, Roger SD, Wlodarczyk JH, Stein AM, Bohringer EG, Milson-Hawke SM. Assessment of the bioequivalence of a generic cyclosporine A by a randomized controlled trial in stable renal recipients. Transplantation. 2006;81(5):711-7.

85. Pollard S, Nashan B, Johnston A, Hoyer P, Belitsky P, Keown P, Helderman H. A pharmacokinetic and clinical review of the potential clinical impact of using different formulations of cyclosporin A. Clin Ther. 2003;25(6):1654-69.

86. Alloway RR, Isaacs R, Lake K, Hoyer P, First R, Helderman H, Bunnapradist S, Leichtman A, Bennett MN, Tejani A, Takemoto SK. Report of the American Society of Transplantation conference on immunosuppressive drugs and the use of generic immunosuppressants. Am J Transplant. 2003;3(10):1211-5.

87. Taber DJ, Baillie GM, Ashcraft EE, Rogers J, Lin A, Afzal F, Baliga P, Rajagopalan PR, Chavin KD. Does bioequivalence between modified cyclosporine formulations translate into equal outcomes? Transplantation. 2005;80(11):1633-5.

88. Salvadori M, Holzer H, de Mattos A, Sollinger H, Arns W, Oppenheimer F, Maca J, Hall M. Enteric-coated mycophenolate sodium is therapeutically equivalent to mycophenolate mofetil in de novo renal transplant patients. Am J Transplant. 2004;4(2):231-6.

89. Arns W, Breuer S, Choudhury S, Taccard G, Lee J, Binder V, Roettele J, Schmouder R. Enteric-coated mycophenolate sodium delivers bioequivalent MPA exposure compared with mycophenolate mofetil. Clin Transplant. 2005;19(2):199-206.

90. Westgard JO BP, Hunt MR. A multiple-rule shewhart chart for quality control Clin Chem. 1981;27:493-501.

91. Clinical and Laboratory Standards Institute (CLSI). Evaluation of Precision Performance of Clinical Chemistry Devices; Approved Guideline- EP-5 A2, $2^{\mathrm{a}}$.ed.Wayne;2006, 48p.

92. Painter P. Clinical chemistry. Laboratory managment \& clinical correlations: Philadelphia: Lippincott Willians \& Wilkings; 2002. 1ª.ed., cap 10, p.122-51.

93. Brasil. Ministério da Saúde. Agência Nacional de Vigilância Sanitária. Medicamentos ICdBL. "Resolução n.391/1999". Determina a publicação das Bases Legais para a instituição do medicamento genérico no Brasil. [acesso em 22 jan. 2004]. Disponível em: http://www.anvisa.gov.br.

94. Bland JM AD. Statistical methods for assessing agreement between two methods of clinical measurement. Lancet. 1986;1:307-10. 
95. Brasil. Ministério da Saúde. Agência Nacional de Vigilância Sanitária.Legislação.VisaLegis. "Resolução n.397, de 12 de novembro de 2004". Guia para provas de biodisponibilidade relativa/bioequivalência. [acesso em 22 de jan. 2005].Disponível em: http://www.anvisa.gov.br.

96. Bussab WO MP. Estatística básica. São Paulo: Atual Editora; 1987, 4ª .ed.,321p.

97. Medina-Pestana JO. Organization of a high-volume kidney transplant program the "assembly line" approach. Transplantation. 2006;81(11):1510-20.

98. DomKe I EJ, Langmann T. Measurement of total and free mycophenolic acid with new enzyme receptor methods on Cobas Integra systems. Clin Chem. 2005;51:C148.

99. Satoh S, Tada H, Murakami M, Tsuchiya N, Li Z, Numakura K, Saito M.Inoue T, Miura M, Hayase Y, Suzuki T, Habuchi T. Circadian pharmacokinetics of mycophenolic acid and implication of genetic polymorphisms for early clinical events in renal transplant recipients. Transplantation. 2006;82(4):486-93.

100. United States. Department of Healthy and Human Services. Food and Drug Administration. Center for Drug Evaluation and Research. Approved drug products with therapeutic equivalence evaluations. Rockville,2005. [acesso em 28 jul. 2006] Disponível em: http:// www.fda.gov/cder/orange/default.htm.

101. Brasil. Ministério da Saúde. Agência Nacional de Vigilância Sanitária. Legislação. VisaLegis. "Resolução RDC n.156, de 13 de setembro de 2006". Guia para provas de biodisponibilidade relativa/bioequivalência. Inclusão do protocolo de biodisponibilidade relativa para contraceptivos orais, hormônios endógenos, ciclosporina e micofenolato de mofetila. [acesso em 22 nov. 2006] Disponível em: http://e-legis.bvs.br/leisref/public/showAct.php.

102. Levy G. The clay feet of bioequivalence testing. J Pharm Pharmacol. 1995;47(12A):975-7

103. Dirks NL, Huth B, Yates CR, Meibohm B. Pharmacokinetics of immunosuppressants: a perspective on ethnic differences. Int J Clin Pharmacol Ther. 2004;42(12):701-18. 
APÊNDICE 


\section{Artigo publicado como suplemento do IFCC - AACC/ 2005}

Romano P, Sumita NM, Mendes ME, Batista VR, Ebner PAR, Burattini MN, Araujo LMP, Castro MCR, David-Neto E. The EMIT (®) 2000 Dade Behring Myophenolic Acid Assay: An Application Protocol for the Cobas Mira-Plus Chemistry System. Clinical Chemistry 2005, 51(6) (suppl): A 147. (Presented at XIX International Congress of Clinical Chemistry, IFCC -AACC; 2005 jul 24-28; Orlando, Florida, USA, Abstracts). 


\title{
Wednesday, July 27, 10:00 am - 12:30 pm \\ TDM/Toxicology/DAU
}

\author{
C-145
}

The EMIT ${ }^{\circledR} 2000$ Dade Behring Mycophenolic Acid Assay: An Application Protocol for the Cobas Mira Plus Chemistry System

P. Romano ${ }^{1}$, N.M. Sumita ${ }^{1}$, M. E. Mendes', V. R. Morsoleto Batista ${ }^{1}$, P. A. Rezende Ebner', M. N. Burattini', L. M. Pereira Araujo², M. C. R. Castro², E. David Neto ${ }^{2}$. 'Central Laboratory Division \& Laboratories of Medical Investigation (LIM-03) of Hospital das Clínicas da Faculdade de Medicina da Universidade de São Paulo (HCFMUSP), São Paulo, Brazil, 'Renal Transplantatioñ Unit of Hospital das Clinicas da Faculdade de Medicina da Universidade de São Paulo (HCFMUSP), São Paulo, Brazil,

Background and Objective: Mycophenolic acid (MPA) is a potent immunosuppressive drug used for the prophylaxis of organ rejection in transplantation. Some studies in renal transplantation suggest that blood concentration of MPA should be monitored to maximize efficacy. A fixed daily dose is usually used without monitoring of blood levels. Frequently, doses are adjusted according to gastrointestinal side effects and blood counts. The aim of this study was evaluating the performance of EMIT 2000 Dade Behring Mycophenolic Acid Assay (Dade Behring Marburg GmbH, Marburg, Germany).

Materials and Methods: This enzymatic immunoassay measures the values of total MPA in plasma, collected with anticoagulant EDTA. The reagent contains mouse monoclonal antibody that is reactive to MPA in an aqueous / bovine serum albumin (BSA) matrix. MPA in the sample competes with MPA labed with the enzyme glucose-6-phosphate dehydrogenate (G6P-DH). Active (unbound) enzyme converts $\mathrm{NAD}$ to $\mathrm{NADH}$, resulting in a kinetic absorbance change that can be measured spectrophotometrically. The MPA concentration is inversely proportional to the rate of $\mathrm{NADH}$ formation at wavelength of $340 \mathrm{\eta m}$. The assay has been optimized to measure total MPA from 0.1 to $15.0 \mu \mathrm{g} / \mathrm{mL}$. The reaction was performed on the COBAS MIRA Plus chemistry system (Roche Diagnostics); using three control samples (low, medium and high): The detection limit was obtained analyzing 28 times a sample of plasma without MPA. The recovery test was assessed using plasma without MPA, and control sample containing the drug was added resulting three different final concentrations: $1.0 \mu \mathrm{g} / \mathrm{mL} ; 2.0 \mu \mathrm{g} / \mathrm{mL}$ and $10.0 \mu \mathrm{g} / \mathrm{mL}$.

Results: The assay was found to be linear up to $14.57 \mu \mathrm{g} / \mathrm{mL}$. The detection limit was $0.01 \mu \mathrm{g} / \mathrm{mL}$, in 28 dosages. Functional sensitivity was $0.02 \pm 0.01 \mu \mathrm{g} / \mathrm{mL}$. The CV of within-run precision ranged from $4.19 \pm 0.08 \%$ to control sample with a concentration of $1.0 \mu \mathrm{g} / \mathrm{mL}$ of MPA, $3.62 \pm 0.72 \%$ for concentration of $7.5 \mu \mathrm{g} / \mathrm{mL}$ and $2.14 \pm 0.92 \%$ for concentration of $12.0 \mu \mathrm{g} / \mathrm{mL}$. The $\mathrm{CV}$ of between-run precision ranged from $5.0 \pm 0.11 \%$ to control sample with $1.0 \mu \mathrm{g} / \mathrm{mL}, 4.64 \pm 0.85 \%$ for concentration of 7.5 $\mu \mathrm{g} / \mathrm{mL}$ and $5.02 \pm 1.4 \%$ for concentration of $12.0 \mu \mathrm{g} / \mathrm{mL}$. The recovery test ranged from 0.9 to $1.1 \mu \mathrm{g} / \mathrm{mL}, 1.8$ to $2.0 \mu \mathrm{g} / \mathrm{mL}$ and 9.2 to $10.8 \mu \mathrm{g} / \mathrm{mL}$, respectively to concentrations of $1.0 \mu \mathrm{g} / \mathrm{mL}, 2.0 \mu \mathrm{g} / \mathrm{mL}$ and $10.0 \mu \mathrm{g} / \mathrm{mL}$.

Conclusion: The EMIT 2000 Dade Bebring Mycophenolic Acid Assay is a simple fast, and convenient alternative to evaluate MPA in blood plasma sample. 